\title{
The relationship between youth crime and education
}

Citation for published version (APA):

Rud, I. (2015). The relationship between youth crime and education. [Doctoral Thesis, Maastricht University]. Maastricht University. https://doi.org/10.26481/dis.20150623ir

Document status and date:

Published: 01/01/2015

DOI:

10.26481/dis.20150623ir

Document Version:

Publisher's PDF, also known as Version of record

\section{Please check the document version of this publication:}

- A submitted manuscript is the version of the article upon submission and before peer-review. There can be important differences between the submitted version and the official published version of record.

People interested in the research are advised to contact the author for the final version of the publication, or visit the DOI to the publisher's website.

- The final author version and the galley proof are versions of the publication after peer review.

- The final published version features the final layout of the paper including the volume, issue and page numbers.

Link to publication

\footnotetext{
General rights rights.

- You may freely distribute the URL identifying the publication in the public portal. please follow below link for the End User Agreement:

www.umlib.nl/taverne-license

Take down policy

If you believe that this document breaches copyright please contact us at:

repository@maastrichtuniversity.nl

providing details and we will investigate your claim.
}

Copyright and moral rights for the publications made accessible in the public portal are retained by the authors and/or other copyright owners and it is a condition of accessing publications that users recognise and abide by the legal requirements associated with these

- Users may download and print one copy of any publication from the public portal for the purpose of private study or research.

- You may not further distribute the material or use it for any profit-making activity or commercial gain

If the publication is distributed under the terms of Article $25 \mathrm{fa}$ of the Dutch Copyright Act, indicated by the "Taverne" license above, 
The Relationship between Youth Crime and

Education 
(C) Iryna Rud, Maastricht 2015

All rights reserved. No part of this publication may be reproduced, stored in a retrieval system or transmitted in any form, or by any means, electronic, mechanical, photocopying, recording, or otherwise, without the prior permission in writing, from the author.

ISBN 978-94-003-0101-6

Cover design and print production: Raadhuis voor creatieve communicatie, Alkmaar

This book is no. VIII of the TIER Research Series, a PhD thesis series published by TIER. 


\title{
THE RELATIONSHIP BETWEEN YOUTH CRIME AND EDUCATION
}

\author{
Proefschrift \\ ter verkrijging van de graad van doctor \\ aan de Universiteit Maastricht, \\ op gezag van de Rector Magnificus \\ Prof.dr. L.L.G. Soete \\ volgens het besluit van het College van Decanen, \\ in het openbaar te verdedigen \\ op dinsdag 23 juni 2015 om 16.00 uur \\ door
}

Iryna Vladimirovna Rud 


\section{Promotors:}

Prof. dr. W.N.J. Groot

Prof. dr. H. Maassen van den Brink

\section{Copromotor:}

Dr. C.P.B.J. van Klaveren

\section{Beoordelingscommissie:}

Prof. dr. G.P.M.F. Mols (voorzitter)

Prof. dr. J.A.M. Heijke

Prof. dr. F.L. Leeuw

Prof. dr. H.D. Webbink (Erasmus Universiteit Rotterdam)

Prof. dr. B.J. ter Weel 
To my parents and Ron 



\section{Acknowledgements}

Life constantly brings new challenges. Looking back over the last few years, I realize that being a PhD candidate and writing a dissertation has been an important and challenging period of my life, which has not only taught me valuable research skills but also boosted my personal development. The completion of this dissertation could not have been possible without the support and encouragement from different people to whom I am greatly indebted.

First of all, I would like to thank Wim Groot and Henriëtte Maassen van den Brink for recognizing my potential as a researcher and providing me with this wonderful opportunity to join the TIER team. Your thorough guidance as my PhD supervisors and your continued faith in my abilities are very much appreciated. I have learned from you how to become an independent and confident thinker.

My sincere gratitude also goes to my co-supervisor, Chris van Klaveren, for his enthusiasm in guiding me through my PhD dissertation and keeping me on the right track. Chris, your critical approach in conducting research and your 'out-of-thebox' thinking have helped me in shaping my analyzing abilities and argumentation skills. I value your constructive feedback on my drafts and prompt replies to my emails even during non-official working hours. 
Dear professors Hans Heijke, Frans Leeuw, Gerard Mols, Dinand Webbink and Bas ter Weel, thank you very much for being part of the assessment committee, and for your time and thoughtful suggestions. Prof. Heijke, special thanks to you for introducing me to the world of research through your dedicated guidance of my master thesis back in 2009.

Furthermore, I would like to thank several people who were supportive during my PhD. Olivier Marie, I appreciate your advices on data, providing me with fruitful comments on my last paper and keeping me updated on all major events related to economics of education and crime. Martin Broxterman, your constant online help whenever I had questions about the CBS data was very important to me. Marjo van Ophoven-Gommans, thank you for introducing me to many of your colleagues from the CBS Heerlen and for encouraging me to speak Dutch during lunch breaks.

Next, I would like to express my sincere gratitude to my former colleagues from TIER Maastricht. Sofie Cabus, our discussions were very useful to me in developing new research ideas. Carla Haelermans, I have learned from you how to manage my time more efficiently. The dinners that you have been initiating in Maastricht and The Hague were always a good way to relax. Dimona Bartelet, thanks for keeping my work lively with all your nice stories. Sabrina Wollmann, I enjoyed a lot our fun chats and reenergizing coffee breaks. Eline Sneyers, I admire your positive and joyful attitude even during the busiest times. Johan Coenen, thank you for your kindness and willingness to help me whenever it was needed. Erik Meyer, your ability to stay calm no matter the circumstances often positively affected me. Ferdi Widiputera, your supportive words and smiles kept me motivated during long working hours. Further, I am grateful to senior researchers Joris Ghysels and Kristof de Witte for their valuable research advices and feedback. Carla Lenssen, thanks a lot for answering my countless questions related to administrative issues. Roel Ariës, Emily Brounts, Hans Duyx, Mieke Goos, Marleen Gulikers, Astrid Lamers, Erik Pompen, Frans Ronteltap, Nyasha Tirivayi, Inne Vandyck and Eline Verweij, thank you all for creating a pleasant working environment and for being great colleagues. 
I would also like to thank my current colleagues at the CPB. From the first working day I have felt myself very welcome there. The nice atmosphere and encouraging people at the CPB have helped me in staying motivated to finish my dissertation during late evenings after work and weekends.

My PhD life would be less exciting without the company of awesome people whom I know from my study trips, different social events in Maastricht and PhD Academy, including Burcu, Cheng, Iman, Inge, Jessie, Julia, Hendrik, Howard, Lisa, Malou, Mariëtte, Narendra, Nevena, Paula, Rina and Tia. Furthermore, I am thankful to current and former PhD students from the economic faculty, Aleksandar, Bart, Benedikt, Christine, Elnaz, Eva, Jan, Nadine, Paul, Roxanne, Simone, Thomas, Tyas, Ulf and Vera, for the great time together while sharing work-related stories during coffee breaks or just enjoying life at different PhD parties.

I feel lucky to have made friends also during conference visits. Lara and Yu, since I have met you in Catanzaro and Perth, respectively, we have stayed closely in touch and you have provided me with a rich source of inspiration. I am also thankful to people whom I know from different AEGEE events across Europe, and especially to Anita, Ania, Elena, Henk, Jonas, Klaudia, Masha, Samet, Slava and Svetlana, for their great spirit which has helped me to look at many things from a different perspective.

I further would like to acknowledge my Eastern European friends whom I met in Maastricht. Oksana, our chats on the way to the CBS and back were always very insightful. Katiusha and Taniusha, the time I spent with you in Maastricht and Krakow is unforgettable. I wish we could see each other more often. Yanitsa, your optimistic energy is simply contagious. Eszter, thank you for your great support and for many positive vibes you always send to me in your emails. Tanya, I am happy that we have found each other after all those stories I have heard about you. It feels now like I have known you forever. Anya, I am thankful for your kind hospitality in Strasburg, Bruges and Kyiv and for all your encouragements. Dorina and Alex, our quality times and numerous dinners together with that delicious food are priceless. I really appreciate those cozy moments in your company. Olka, I admire your 
enthusiasm and persistence in everything what you are doing, which provide me with a great example to follow. Thanks a lot for all our relaxing evenings, with pleasant talks and a good glass of wine.

I would also like to express my gratitude to my school time friends. Irynko, thank you for being my very good friend. I am happy to always receive a very warm welcome in Kyiv from you and Sasha. Vika and Olya, I love catching up with you when I am travelling back to Ukraine.

Diana and Marieke, my two paranymphs, I am grateful for your continued friendship and amazing support. Marieke, we have not only shared our office together, but also many wonderful experiences, including partying in Maastricht and Cologne as well as travelling to Ukraine, Italy and Portugal. You are truly 'mestnaia i krutaia'! Dianka, I feel blessed that our roads have crossed in Maastricht in 2008. Your sharp mind, abilities to inspire and to comfort are incredible. Thank you, Dianka, and Niels for making me feel always so much at home when I visit you.

Мама и папа, огромное спасибо за ваш нескончаемый позитив, юмор, и способность поддержать и направить в трудные моменты. Я вас очень люблю! Я также благодарна Диане и Оле, моим старшим сестрам, за их любовь и терпение.

Beste Marianne, Henk, Bart en Suzan, bedankt voor jullie steun en oprechte interesse in mijn werk. Onze tijd samen is altijd gezellig. Ik ben echt blij met mijn Nederlandse familie.

Ten slotte wil ik mijn vriend bedanken voor zijn liefde, steun en veel geduld tijdens de afgelopen periode. Ron, ik heb enorm veel gehad aan je hulp, positieve energie, bemoedigende woorden en je geloof in mij. Zonder jou aan mijn zij zou ik niet zijn wie ik nu ben. Heel erg bedankt daarvoor!

Iryna Rud

May 2015 


\section{Contents}

1 Introduction 1

1.1 Motivation 1

1.2 Previous studies and identified research gaps 5

$\begin{array}{lll}1.3 & \text { Research objectives }\end{array}$

$1.4 \quad$ Contributions of this dissertation 8

$\begin{array}{lll}1.5 & \text { Thesis outline } & 10\end{array}$

2 The relationship between youth crime and education: an $\begin{array}{ll}\text { empirical literature review } & 15\end{array}$

$\begin{array}{lll}2.1 & 15\end{array}$

2.2 The nature of youth crime in comparison to adult crime 16

$\begin{array}{lll}2.3 & \text { Literature search strategy and selection criteria }\end{array}$

$\begin{array}{lll}2.4 & \text { Childhood and adolescent interventions } & 20\end{array}$

2.4.1 Early childhood interventions $\quad 21$

2.4.2 Early school-age interventions 24

2.4.3 Adolescent interventions 26

$2.5 \quad$ Empirical studies on the relationship between youth crime and education $\quad 30$

2.5.1 The effects of education on youth crime 30

2.5.2 The effects of criminal behavior on educational outcomes 36

$\begin{array}{lll}2.6 & \text { Discussion } & 38\end{array}$

3 What drives the relationship between criminal involvement and early school leaving? 
$3.1 \quad$ Introduction 51

3.2 Data 54

$\begin{array}{lll}3.3 & 60\end{array}$

$3.4 \quad$ Results 63

3.5 Heterogeneity in the relationship between early criminal $\begin{array}{ll}\text { involvement and early school leaving } & 68\end{array}$

$\begin{array}{lll}3.6 & \text { First criminal involvement } & 71\end{array}$

$\begin{array}{lll}3.7 & \text { Sensitivity analysis } & 73\end{array}$

$\begin{array}{lll}3.8 & \text { Discussion } & 73\end{array}$

4 The effect of restorative juvenile justice on future $\begin{array}{ll}\text { educational outcomes } & 77\end{array}$

$\begin{array}{lll}4.1 & 77 \text { Introduction } & 77\end{array}$

4.2 Restorative juvenile justice intervention Halt 80

$\begin{array}{lll}4.3 & \text { Experimental design } & 83\end{array}$

$\begin{array}{lll}4.4 & \text { Data and descriptive statistics } & 85\end{array}$

4.5 Estimation strategy and empirical findings 91

$\begin{array}{lll}\text { 4.5.1 Estimation strategy } & 91\end{array}$

4.5.2 Empirical findings 92

4.5.3 Heterogeneous treatment effects 93

$\begin{array}{ll}\text { 4.5.4 Bounding exercise } & 95\end{array}$

$\begin{array}{lll}4.6 & \text { Discussion } & 96\end{array}$

5 The relationship between criminal involvement of parents and educational attainment of their children 99

5.1. Introduction 99

$\begin{array}{lll}\text { 5.2. Literature } & 101\end{array}$

$\begin{array}{lll}\text { 5.3. Data and descriptive statistics } & 104\end{array}$

$\begin{array}{ll}\text { 5.4. Estimation strategy and empirical findings } & 107\end{array}$ 
$\begin{array}{ll}\text { 5.4.1. } \text { Model description } & 107\end{array}$

5.4.2. Results from the MNL model 108

$\begin{array}{ll}\text { 5.4.3. Matching analysis } & 110\end{array}$

$\begin{array}{lll}\text { 5.5. } & \text { Robustness analyses } & 115\end{array}$

5.5.1. How sensitive are the estimates to selection on unobservables? 115

5.5.2. How do the empirical findings depend on the definition of the outcome measure? 122

5.5.3. Does it matter if mothers or fathers are criminally involved? 124

5.5.4. Does it matter if one of the parents was convicted? 125

$\begin{array}{ll}\text { 5.5.5. Measurement error } & 126\end{array}$

$\begin{array}{lll}\text { 5.6. Conclusion } & 129\end{array}$

6 General conclusions $\quad 133$

$\begin{array}{lll}6.1 & \text { Key conclusions } & 135\end{array}$

6.2 Policy implications and valorization of the research findings 140

$\begin{array}{lll}6.3 & \text { Limitations and suggestions for further research }\end{array}$

$\begin{array}{lr}\text { References } & 145\end{array}$

$\begin{array}{lr}\text { Appendix } & 159\end{array}$

$\begin{array}{lr}\text { Summary } & 165\end{array}$

$\begin{array}{lr}\text { Samenvatting } & 173\end{array}$

$\begin{array}{lr}\text { Biography } & 181\end{array}$ 



\section{List of Tables}

Table 1-1: Structure of the dissertation

Table 2-1: Summary of studies examining early childhood interventions on youth crime and educational outcomes

Table 2-2: Summary of studies examining early school-age interventions on youth crime and educational outcomes

Table 2-3: Summary of studies examining adolescent interventions on youth crime and educational outcomes

Table 2-4: Summary of studies examining the effect of education on youth crime

Table 2-5: Summary of studies examining the effect of criminal behavior on educational outcomes

Table 3-1: Descriptive statistics

Table 3-2: The relationship between criminal involvement and early school leaving (accumulative)

Table 3-3: The relationship between criminal involvement and early school leaving (separate)

Table 3-4: The relationship between criminal involvement and early school leaving across different demographic groups

Table 3-5: The relationship between age at first criminal involvement and early school leaving

Table 3-6: The relationship between criminal involvement and early school leaving across different samples (no fixed effects models)

Table 4-1: Comparing juveniles in the treatment and the control group

Table 4-2: Frequency table of group sizes

Table 4-3: Family and educational characteristics of juveniles in the treatment and the control group 
Table 4-4: Characteristics of juveniles who completed the Halt program and juveniles who terminated their participation $\quad 89$

Table 4-5: Characteristics of the non-linkable observations 90

Table 4-6: The effects of Halt on early school leaving (ESL) and years of education (YE) 92

Table 4-7: The effects of Halt on early school leaving (ESL) and years of education (YE) across different demographic groups

Table 4-8: Lower bound estimates for early school leaving (ESL) and years of education

Table 5-1: Descriptive statistics of households with parents who have no criminal record and households with parents who have a criminal record ${ }^{1} \quad 106$

Table 5-2: Multinomial logit estimates in the full sample 109

Table 5-3: Descriptive statistics for the matched sample 113

Table 5-4: Educational outcomes of children in the matched sample 113

Table 5-5: Multinomial logit estimates in the matched sample 115

Table 5-6: Estimates for primary education and higher education in a probit model 117

Table 5-7: Estimation results of bivariate probit models for different $\rho$-values 119

Table 5-8: The relative amount of selection on unobservables required to explain the probit estimate

Table 5-9: Multinomial logit results for the restricted sample of children older than 25123

Table 5-10: Multinomial logit estimates in the matched sample

Table 5-11: Multinomial logit estimates in the matched sample of children whose parents were convicted

Table 5-12: Sensitivity of the outcome to underreporting of criminal involvement

Table 6-1: The main findings of the dissertation per chapter

Table A-1: Halt-worthy offenses related to law sections

Table A-2: Assignment characteristics of juveniles in each Halt bureau 160

Table A-3: Age distribution for Participants in the Halt Experiment 


\section{List of Figures}

Figure 1-1: Framework for the determination of criminal involvement and educational outcomes of adolescents 7

Figure 3-1: Distribution of first criminal involvement by age 59

Figure 3-2: Distribution of early school leaving by age 59

Figure 3-3: Factors that explain the relationship between criminal involvement and

early school leaving

67 



\section{Introduction}

"He who opens a school door, closes a prison"

-Victor Hugo-

\subsection{Motivation}

Criminal involvement and low educational attainment among young people are two social problems with common roots and overlapping features. Not much is known about how these two problems are interrelated. Criminal involvement may causally influence educational attainment, and vice versa. At the same time, criminal involvement and educational attainment outcomes can both be driven by multiple, potentially overlapping, observed and unobserved factors, such as behavioral and socio-economic characteristics. As a consequence, it is unclear whether policy measures that aim to reduce crime among young people affect their educational attainment as well, and whether interventions that positively affect education have a spillover effect on youth crime. This dissertation sheds light on these aspects and provides insights into how education and youth crime are related.

There is awareness among researchers (e.g. Cunha, Heckman, Lochner and Masterov, 2006; Doyle, Harmon, Heckman and Tremblay, 2009) and policy makers (e.g. 'The No Child Left Behind Act'; 'Investing in children: breaking the cycle of 


\section{Chapter 1}

disadvantage') ${ }^{1}$ that there is a need to invest in socio-economically disadvantaged children. Such children do not have the same opportunities as other children, and they are much more likely to experience different adverse outcomes during their lifetime, including unemployment, criminal involvement and bad health. The underlying determinants of these outcomes may already express themselves at a young age, in particular, through low educational performance and juvenile delinquency. Adolescence is the period in which criminal activity peaks (Farrington, 1986; Piquero, Farrington and Blumstein, 2007; Bosick, 2009), and also in which many young people drop out of compulsory education (Stillwell and Sable, 2013; European Commission, 2014). Across the European Union member states, the average school dropout rate is above 10 percent (European Commission, 2014). Simultaneously, around 30 percent of juveniles in EU countries report to have been involved in some type of delinquent behavior (e.g. shoplifting, vandalism, harassment, assault) over the past year (Enzmann et al., 2010; Van der Laan and Blom, 2011).

The life prospects of delinquent juveniles and persons with low educational attainment are poor. Low educational attainment reduces later chances of employment and predicted earnings (Oreopoulos, 2007). Early criminal involvement may lead to repeated crime, which in turn is associated with a similar range of negative outcomes (Mulder, Brand, Bullens and Van Marle, 2011; Grogger, 1995). Among the externalities of crime are school disruptions, unemployment, and a decrease in income and losses in the quality of life (Grogger, 1995). Anderson (1999) estimates that the net cost of crime for US society is $\$ 1.3$ trillion per year, with a per capita cost of $\$ 4,818$ per year. The total social costs of early school leaving over the course of an individual's lifetime, estimated for a set of EU countries, ranges in the region between $€ 100,000$ and 1.1 million per capita (European Commission, 2011). ${ }^{2}$

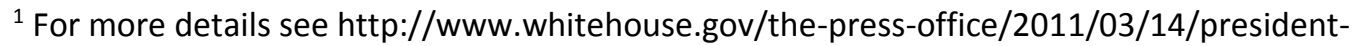
obama-calls-congress-fix-no-child-left-behind-start-next-schoo and http://ec.europa.eu/justice/fundamental-rights/files/c_2013_778_en.pdf, respectively.

2 Depending on the differences in social welfare systems, salary differences and the estimation methods.
} 
The cost of young people who are not in employment, education or training is estimated to be 0.96 percent of GDP in the average EU country (Mascherini, Salvatore, Meierkord and Jungblut, 2012). ${ }^{3}$ Given the high social costs of criminal involvement and low educational attainment (see also McCollister, French and Fang, 2010; Psacharopoulos, 2007), even small improvements are economically important, also because they can have positive spill-over effects on other societal outcomes, such as youth employment and social inclusion (Lochner and Moretti, 2004; Lochner, 2011).

Criminal behavior and educational outcomes appear to have common origins. Both delinquent involved individuals and school dropouts are more likely than others to come from lower socio-economic backgrounds (e.g. Junger-Tas and Block, 1988; Lee and Burkam, 2003). Peers can both negatively affect juveniles' educational outcomes and encourage them to become involved in crime (e.g. Gaviria and Raphael, 2001; Calvó-Armengol and Zenou, 2004; Calvó-Armengol, Patacchini and Zenou, 2009). Socio-emotional skills, such as conscientiousness, motivation, selfdiscipline, and time preference can simultaneously affect juveniles' decisions to engage in criminal behavior and to leave school earlier (Heckman, Stixrud and Urzua, 2006). Furthermore, intergenerational connections can also determine both educational and criminal behavior outcomes. It is well-documented that there are intergenerational links from parental criminal behavior to children's criminal involvement (e.g. Farrington, Coid and Murray, 2009; Van de Rakt, Ruiter, De Graaf and Nieuwbeerta, 2010) and from parental education to children's education (De Haan and Plug, 2009; Holmlund, Lindahl and Plug, 2011). In addition, there can be effects from parental criminal behavior to children's education and from parental education to children's criminal involvement, but research in these areas is rather scarce.

Many studies show that there is at least a statistical association between criminal involvement and education. Criminally involved individuals often do not have a secondary school diploma (e.g. Morgan and Kett, 2003; Harlow, 2003),

\footnotetext{
${ }^{3}$ For the Netherlands, this share is estimated to be 0.52 percent
} 
whereas school dropouts are more likely to become involved in delinquent behavior than high-school graduates (Fagan and Pabon, 1990; Pettit and Western, 2004). This relationship, however, does not reveal which of the forces described above drive this relationship. Does this relationship operate through common factors, and if so, what are these factors? If there is a causal effect between youth crime and education, then in which directions does it run and how large is it?

Criminal involvement and education can reinforce each other at one point in time and across time. In particular, early criminal involvement in adolescence can have an impact on educational outcomes, which in turn may affect criminal activity in later stages of life. Juveniles in detention disconnect themselves from the traditional educational process, which ultimately creates gaps in their education. There is evidence showing that educational achievement gaps are persistent across ages and are difficult to remediate later (Cunha et al., 2006). In turn, lower educational attainment, as a result of educational achievement gaps, is likely to decrease future legitimate work opportunities and returns from the legitimate sector, which can motivate young people to fall back on criminal activities. Therefore, the relationship between criminal behavior and education of young people can be seen as a highly dynamic and complementary process.

Insight into the link between education and criminal behavior of young people is important for several reasons. If there is a true causal relationship between crime and educational outcomes, then investments and improvements in one domain can lead to positive spillovers in other areas. Such potential benefits need to be taken into account in cost-benefit analyses of interventions that aim to improve either of these two outcomes. Alternatively, certain common factors, such as bad peers, low parental income and low school quality, may determine both outcomes. Even if there is no direct causal link between crime and education, an intervention targeted towards improving one outcome can still lead to simultaneous improvements in the other, when it addresses or repairs one of these underlying factors. Our research sheds more light on whether the relationship between youth crime and education is further related to school, family and individual factors. 


\subsection{Previous studies and identified research gaps}

Previous empirical research has primarily focused on criminal involvement in adulthood (see a review by Lochner, 2010). These studies address the relationship between education and crime, both theoretically and empirically. They tend to apply Becker's conceptual framework that considers criminals as rational individuals who seek to maximize their own well-being through criminal activity, instead of participation in the legitimate sector (Becker, 1968). At the same time, accumulation of human capital increases future legitimate work opportunities, and as a consequence discourages participation in crime. To address the endogeneity problem, in particular the correlation between educational attainment and other factors that determine criminal involvement, several studies have applied changes in compulsory schooling laws as a source of exogenous variation in educational attainment (Lochner and Moretti, 2004; Machin, Marie and Vujić, 2011; Meghir, Palme and Schnabel, 2012). This research generally concludes that there is a negative casual effect of educational attainment on criminal involvement of adults.

The nature of juvenile delinquency, such as the patterns and motives, can be different from the nature of adult crime (e.g. Loeber, Hoeve, Slot and Van der Laan, 2013). It is likely that more than just economic incentives underlie the relationship between criminal activity and education of juveniles. For instance, adolescents' emotional and intellectual development as well as peer interactions can play an important role in their decision-making processes (e.g. Leve and Chamberlain, 2005). Different studies propose alternatives to Becker's neo-classical theory in order to explain criminal involvement of young people, including biological, psychoanalytical and sociological theories.

Juveniles' criminal involvement is more likely than the criminal involvement of adults to precede educational attainment, making it difficult to identify the effect of education on youth crime because of possible reverse causality. The effect of criminal involvement in adolescence on educational outcomes has not yet been studied extensively. Research on what factors drive the relationship between criminal involvement and education is also limited. Because exogenous variation in 


\section{Chapter 1}

criminal activity among adolescents (e.g. policy changes affecting youth crime) is rare, recent empirical studies face the challenge of addressing both endogeneity and reverse causality problems.

The effects of school quality on educational outcomes are commonly emphasized. Despite the fact that out-of-school factors that can influence either educational or criminal outcomes are often controlled for in the analyses, the specific effects of these factors have been examined less often. In particular, there is little empirical work that assesses the effect of parents' criminal involvement on educational attainment of children. Furthermore, studies that analyze the effects of juvenile justice programs on educational outcomes are scarce, even though there is literature that examines the effect of such programs on reoffending (see, for example, Bradshaw and Rosenborough, 2005; Hayes, 2005; Sherman and Strang, 2007).

Finally, the current literature on the relationship between youth criminal involvement and education lacks a systematic and synthesized review. Existing critical literature reviews on the relationship between crime and education generally consider criminal involvement among adults or a mixed-age research population (see reviews by Lochner, 2010; Hjalmarsson and Lochner, 2012).

\subsection{Research objectives}

This dissertation aims to address several of the identified research gaps. We define our four research objectives. The first objective is to analyze and document existing evidence on the relationship between youth crime and education, and to disentangle correlational and causal evidence. The second objective is to analyze to what extent the relationship between criminal involvement in adolescence and early school leaving is explained by confounding factors, and to identify what are those factors. The third objective is to examine whether an intervention aimed to reduce recidivism has an effect on educational outcomes. Finally, we analyze the 
relationship between criminal involvement of parents and the educational attainment of their children.

Figure 1-1: Framework for the determination of criminal involvement and educational outcomes of adolescents

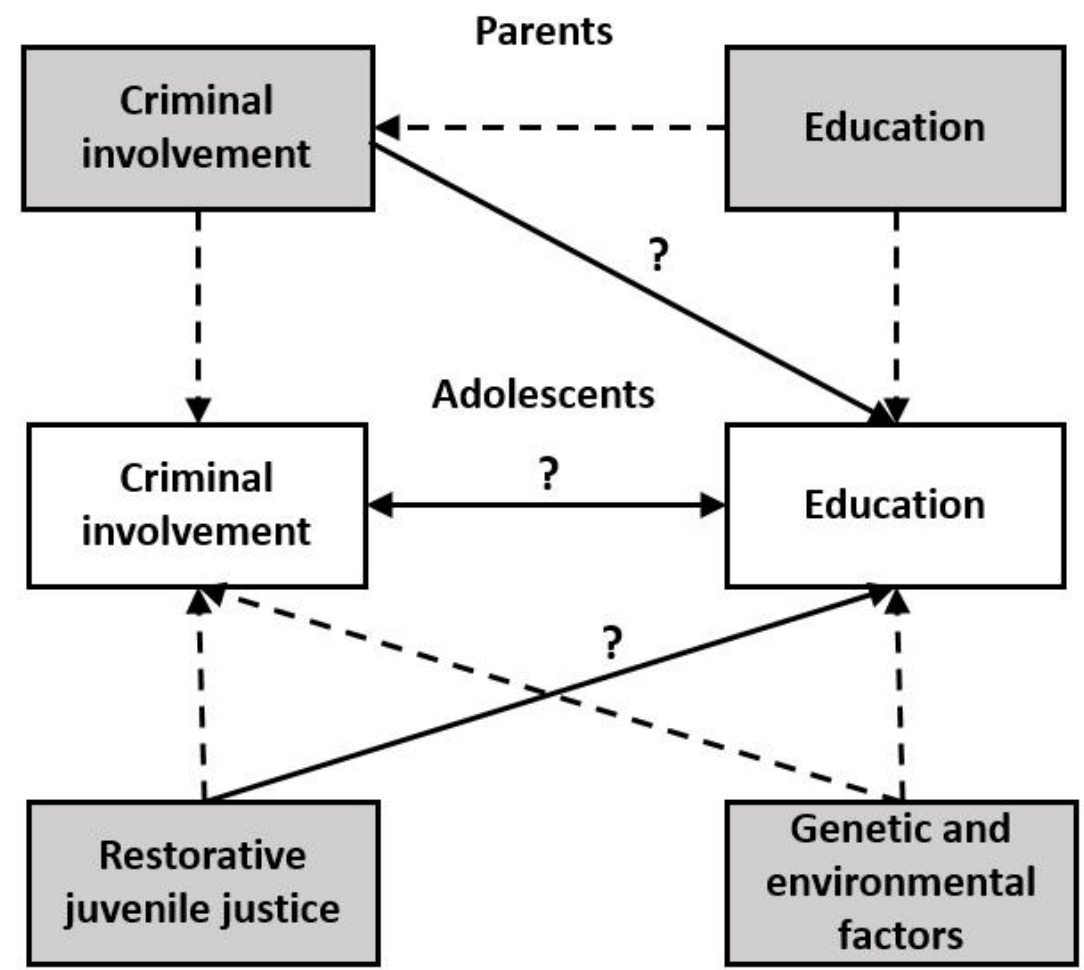

Figure 1 presents a framework for the determination of criminal involvement and educational outcomes of young people. The dashed arrows in the figure show the expected relationships, or those relationships already known from the literature, whereas the solid arrows represent the effects that we aim to estimate.

We first document the effects between education and criminal involvement of adolescents. Second, we try to reveal what explains the link from juveniles' criminal involvement to early school leaving. Third, we assess the effect of a 


\section{Chapter 1}

restorative juvenile justice program on the educational outcomes of adolescents. Juveniles' criminal behavior and education can be determined by parental influences. Therefore, we analyze the impact of criminal involvement of parents on education of their children. In addition to parental influences, both criminal behavior and education of young people can be affected by other genetic (e.g. cognitive ability, personality traits) and environmental factors (e.g. socio-economic status, school characteristics, peer effects), which can be observable and unobservable. Failure to account for these factors can lead to a biased interpretation of the relationship between youth crime and education, because part of the observed correlation can be produced by these factors.

\subsection{Contributions of this dissertation}

\section{Scientific contributions}

This dissertation links together two research areas: the economics of education and the economics of crime. The main scientific contribution of this dissertation lies in examining the relationship between educational attainment and criminal involvement of young people using rich data, while exploring a combination of different econometric methods.

In this dissertation, we use extensive survey data, administrative data and data from a large field experiment on a Dutch restorative justice program that allow us to address our research objectives. Good data on youth crime are rare and misclassification (i.e. underreporting) of criminal involvement is common, which can lead to biased estimates through the presence of measurement error. Exploiting different types of data can provide a more precise and comprehensive picture of the relationship between education and criminal involvement of young people. 
Empirical evidence from the Netherlands contributes to the external validity of existing studies, which have been primarily conducted using data from AngloSaxon countries (see Anderson, 2014; Hjalmarsson, 2008; Webbink, Koning, Vujic and Martin, 2013). In these countries, the system of juvenile justice and school dropout rates are different from those in other countries (e.g. Greenwood and Turner, 2011; Dünkel, Grzywa, Horsfield and Pruin, 2011; OECD, 2014).

This dissertation also provides important contributions by applying different econometric methods, including a randomized control trial, Mahalanobis matching, fixed effects estimation and a method that assesses the impact of selection on unobservables (see Altonji, Elder and Taber, 2005). Using these methods enables us to move beyond descriptive and correlational findings.

\section{Societal contributions}

Evidence on the relationship between education and youth crime is important from a policy perspective for at least two reasons. Causal evidence on the relationship between educational attainment and criminal behavior of young people can provide a path to integrated programs that can address both youth delinquency and low educational attainment in a more effective and efficient way. If criminal behavior and education of young people indeed affect each other, then the benefits of such programs can increase strongly over an individual's lifetime because of complementarity between skills related to education and skills related to criminal behavior. For example, policy interventions that improve educational outcomes can favorably affect criminal behavior outcomes, which in turn can prevent individuals from future criminal involvement and may have a positive spill-over effect on their labor market opportunities.

Second, if the relationship between education and criminal behavior of young people is driven entirely by association, knowledge of the main factors that drive this association can be helpful in establishing interventions that simultaneously address the causes of criminal behavior and lower educational outcomes of young people. 
Furthermore, this dissertation reveals a group of young people at particular risk of having poor educational outcomes. More specifically, we can identify whether persons with criminally involved parents are at risk of having lower educational attainment, above and beyond the increased risk these persons already run because their families have less favorable socio-economic circumstances. This identifies them as a vulnerable target group.

This research also sheds more light the effect of restorative juvenile justice in relation to educational outcomes. Evaluation of the effect of the Dutch restorative juvenile justice program Halt on educational outcomes can contribute to an ongoing discussion on the value and cost-effectiveness of restorative justice programs, which takes place in many countries. Assessing the educational effects of the Halt program can provide a broader and more informative view of its overall effectiveness. ${ }^{4}$

\subsection{Thesis outline}

The outline of this thesis is presented in Table 1. The table illustrates that our research combines four main studies: one systematic literature review study and three empirical studies. The introduction and the conclusion are the first and the last chapter of this dissertation, respectively. Below, we briefly discuss the structure of each of the following chapters.

Chapter 2 presents a systematic literature review of international studies investigating the relationship between education and criminal behavior of young people. We use multiple bibliographic databases and scientific journals to collect evidence on this relationship and we conduct a qualitative analysis of studies that meet our inclusion criteria. In this chapter, we first discuss the nature of youth crime and the differences between youth crime and adult crime. Then, we refer to the literature on intervention programs for children and adolescents that evaluates their

\footnotetext{
${ }^{4}$ Halt is an acronym for 'Het Alternatief'. Halt is created as an alternative of the traditional juvenile justice. For more details, see Chapter 4.
} 
educational and criminal behavior outcomes. Finally, we assess evidence from studies that examine the effect of education on criminal behavior of young people, and the impact of early criminal involvement on educational outcomes.

Chapter 3 provides evidence on the relationship between early criminal involvement and school dropout rates of adolescents in the Netherlands. In this study, we use two administrative data sources on criminal involvement: the Halt data and the Suspect Identification System (HKS) data. We link these data to administrative data on educational careers and demographic characteristics of all students in the Netherlands. To address potential endogeneity, i.e. the correlation between criminal behavior and unobservable determinants of educational outcomes, we use sibling and twin fixed effects analyses. Moving from an unconditional correlation model to the models with fixed-effects allows us to analyze to what extent the relationship between criminal involvement and early school leaving is driven by school-, family- and individual-specific characteristics.

In Chapter 4, we provide an evaluation of the Halt program, on early school leaving and educational attainment of juveniles. We use data from the Halt experiment conducted in 2003 and we link these data to administrative information on educational careers of juvenile offenders who participated in the experiment. To evaluate the effects of the Halt intervention on educational outcomes, we adopt an instrumental variable approach to address selective dropout of the participants from the treatment group.

Chapter 5 presents our final study, examining the relationship between criminal behavior of parents and the educational attainment of their children. We consider the fact that parents with a criminal past are a selective group. We adopt a statistical matching approach that establishes a sample of children with comparable observable characteristics but with a difference in the treatment status, i.e. criminal involvement of parents. We estimate a multinomial logit model of educational attainment. This model can simultaneously estimate the effect of treatment on the probabilities of obtaining any of five categories of educational attainment. The possible effect of selection on unobservables is taken into account by using the 


\section{Chapter 1}

techniques proposed by Altonji et al. (2005). This robustness analysis assesses the sensitivity of the results to selection on unobservables, based on the identified selection on observable characteristics.

Chapter 6 is the concluding chapter of this dissertation. It presents the key findings and conclusions from chapters 2 through 5 . The policy implications of the findings are discussed. Furthermore, study limitations are indicated. Finally, recommendations for future research are provided. 
Table 1-1: Structure of the dissertation

\begin{tabular}{|c|c|c|c|}
\hline Chapter & Subject of interest & Source & Method \\
\hline Chapter 1 & Introduction & & \\
\hline Chapter 2 & $\begin{array}{l}\text { The relationship between } \\
\text { youth crime and education }\end{array}$ & $\begin{array}{l}\text { Bibliographic } \\
\text { databases and search } \\
\text { engines }\end{array}$ & Literature review \\
\hline Chapter 3 & $\begin{array}{l}\text { What explains the } \\
\text { relationship between } \\
\text { criminal involvement in } \\
\text { adolescence and early school } \\
\text { leaving? }\end{array}$ & $\begin{array}{l}\text { Administrative data on } \\
\text { criminal involvement } \\
\text { and education from } \\
\text { the Netherlands }\end{array}$ & $\begin{array}{l}\text { OLS, school, sibling and } \\
\text { twin fixed effects } \\
\text { analyses }\end{array}$ \\
\hline Chapter 4 & $\begin{array}{l}\text { The effect of a restorative } \\
\text { juvenile justice program on } \\
\text { educational outcomes of } \\
\text { juvenile offenders }\end{array}$ & $\begin{array}{l}\text { Data from a } \\
\text { randomized filed } \\
\text { experiment, } \\
\text { administrative data on } \\
\text { education from the } \\
\text { Netherlands }\end{array}$ & Randomized control trial \\
\hline Chapter 5 & $\begin{array}{l}\text { The relationship between } \\
\text { parents' criminal involvement } \\
\text { and children's educational } \\
\text { attainment }\end{array}$ & $\begin{array}{l}\text { Survey data from the } \\
\text { Netherlands }\end{array}$ & $\begin{array}{l}\text { Matching, multinomial } \\
\text { logit model; method } \\
\text { that uses selection on } \\
\text { observables to address } \\
\text { selection on } \\
\text { unobservables }\end{array}$ \\
\hline Chapter 6 & Conclusion & & \\
\hline
\end{tabular}





\section{The relationship between youth crime and education: an empirical literature review ${ }^{5}$}

\subsection{Introduction}

As we have outlined in the previous chapter, it is important to provide evidence on the relationship between education and youth crime, and also to shed more light on what factors underlie this relationship. Such knowledge can be useful in finding a more effective and efficient way to reduce the high rates of criminal involvement and early school leaving among young people, and to prevent negative externalities that result from these issues.

This chapter aims to provide a comprehensive literature review on the relationship between education and criminal behavior among young people. Previous reviews have documented the link between education and adult crime (see Lochner, 2010; Hjalmarsson and Lochner, 2012). This is the first systematic literature review focused on specifically youth crime in its relation to education.

In order to synthesize the best evidence, we analyze and discuss experimental and quasi-experimental studies. Because criminal involvement of young people and adults can differ, we start by discussing the nature of youth crime. In general, crime has been considered from different theoretical perspectives that emphasize the role of various factors (e.g. genetic, psychological, social, and economic) in determining criminal behavior. Both education and youth crime reflect

\footnotetext{
${ }^{5}$ This chapter is based on Rud, I., Van Klaveren, C., Groot, W. and Maassen van den Brink, H. (2013). Education and Youth Crime: a Review of the Empirical Literature. TIER Working Paper Series 13/06, 1-31
} 


\section{Chapter 2}

young people's cognitive and socio-emotional development that has its roots in early childhood and can be sensitive to environmental inputs. There is clear evidence that children with low socio-economic status are more likely to have adverse lifetime outcomes and it has been shown that effective early interventions for socioeconomically disadvantaged can improve their future perspectives (see e.g. Cunha and Heckman, 2010; Durlak, Weissberg, Dymnicki, Taylor and Schellinger, 2011).

In this literature review, we discuss studies that assess such interventions with respect to both criminal involvement and educational outcomes of young people. This evidence can provide insight into processes that play a role in forming these both outcomes. We further review studies that examine the effect of education on youth crime and the literature that examines the link from early criminal involvement to educational outcomes. We contribute by distinguishing between causal and correlational research. This evidence is important for policies that address early school leaving and criminal behavior among young people.

\subsection{The nature of youth crime in comparison to adult crime}

Youth crime, also referred to as juvenile crime, juvenile delinquency, and juvenile offending, generally denotes illegal behavior committed by young people. 6 The upper age of delinquent individuals in the juvenile justice system varies between 16 and 21 years old across countries, and sometimes also within countries, for examples across states in the U.S. (e.g. Kurtz, 2008; OJJDP, 2013; Ministry of Justice, 2014). It has been noted that the peak age of criminal behavior is between age of 15 and 19 (Bosick, 2009; Farrington, 1986; Piquero et al., 2007).

Juveniles appear to be involved in a greater variety of criminal activities, but also in less serious offences, compared to adults (Junger-Tas et al., 2010). This is related to the motives of criminal behavior among young people compared to the

\footnotetext{
${ }^{6}$ We use these terms interchangeably.
} 
motives of adult criminals. Adults are likely to have an economic interest to be involved in crime (Becker, 1968; Lochner, 2010). Although adolescents tend to report that the main motivation of their criminal behavior are economic benefits, there are many other reasons for their criminal involvement, such as, enjoyment, excitement, entertainment and pleasure (Farrington, 2001; Muncie and Goldson, 2006). Luallen (2006) considers that mischief crimes (e.g. property destruction) committed by juveniles 'often result from boredom rather than calculated criminal thought' (p. 88). Similarly, Scitovsky (1999) suggests that violence in school largely occurs due to feelings of boredom and a lack of activities at school. Peer group pressure, mood swings, and lack of reflection on emotional situations are significant factors that have been argued to stimulate offending behavior of juveniles (McCord, Widom and Crowell, 2001). In addition, a criminal act can be viewed by young people as a risktaking adventure that gives offenders status and particular respect within their group of peers (Cohen, 1955).

Adolescents are relatively more likely to commit crime with others compared to adults (Greenwood, 1995; Reiss, 1988). In contrast to adult criminal associations, groups of juvenile offenders are typically formed by territorial affiliation, and they are often random and less stable over time (Reiss, 1988). Juveniles are more likely to co-offend with individuals of the same gender and the same age group compared to adults (Reiss, 1988). However, similar to adult crime, young men participate in criminal activities more often than young women (Levitt and Lochner, 2001).

Finally, the timing of youth crime varies with the type of offence (Gottfredson and Soulè, 2005; Taylor-Butts, 2010). Violent offences typically occur during school hours (Gottfredson and Soulè, 2005) or after school between three and six o'clock in the afternoon (Newman, Fox, Flynn and Christeson, 2000; Snyder and Sickmund, 1999; Taylor-Butts, 2010). By contrast, the peak of violent crime among adults is between midnight and three o'clock in the morning (Taylor-Butts, 2010). Youth violent crime tends to decrease on weekends when young people are interacting less with their (school) peers (see e.g. Jacob and Lefgren, 2003), whereas violent adult 


\section{Chapter 2}

offences are more likely to be committed during weekends (see e.g. Briscoe and Donnell, 2003; Falk, 1952).

We conclude that the motives and patterns of youth crime differ from that of adult crime. A variety of different reasons can lead adolescents to criminal behavior. Young people also tend to be involved in criminal behavior more often than adults, but their crimes are less serious. These factors and also timing of youth crime can be important determinants of the relationship between youth crime and education.

\subsection{Literature search strategy and selection criteria}

In order to outline the literature search strategy and the selection criteria, we first provide the definition of some concepts that are used throughout the literature review. The concept of education is defined in a broad sense and, depending on the context, can refer to educational attainment, school attendance and academic performance. Youth crime refers to any interaction with the criminal justice system as a result of criminal behavior, and can also denote antisocial or risky behavior of juveniles such as substance abuse and risky sexual behavior.

Literature selection

In order to identify evidence on the relationship between youth crime and education, we have conducted a systematic literature review. In our search, we have used different combinations of keywords which are grouped as follows: a) children, juvenile(s), adolescent(s), youths, young people; b) crime, delinquency, offending, arrest, incarceration, antisocial, risk-taking, violence, substance abuse, behavior, involvement, engagement, activities; c) education(al), school(ing), academic, school dropout, early-school leaving, truancy, (non-)cognitive abilities, IQ, performance, attendance, attainment; d) early childhood, adolescence, after-school, out-of-schooltime, stimulation, intervention, program, experiment, causal, correlational. 
We have used the following electronic databases and search engines to find empirical evidence on the relationship between youth crime and education: Elsevier, Google Scholar, Google Search, ERIC, EconLit, PsychLit, Science Direct, SAGE's, JSTOR, Social Science Research Network, Economic Papers, Wiley, Springer, and Taylor and Francis. We considered peer-reviewed studies, discussion papers, working papers, reviews and research reports that were accessible online before June 2014 . Nonpublished empirical studies on the relationship between education and youth crime were included if they fulfill the defined inclusion criteria.

\section{Inclusion criteria}

We qualitatively analyzed the content of the literature. We look at three specific types of evidence: evidence from intervention studies on crime and education, evidence on the effects of education on crime and evidence on the effects of early criminal involvement on educational outcomes. There are two major criteria for inclusion of intervention studies. Firstly, only interventions that have follow-ups in adolescence or young adulthood (up to 23 years old), and that measure effects on both educational and criminal behavioral outcomes were selected. Secondly, only studies that use a randomized controlled trial or that employ a comparable control group are included. A random assignment should ensure that characteristics between the treatment and control group participants are balanced. The treatment is the only difference between these two groups and any differences in outcomes after interventions are assumed to be due to the treatment. With regards to studies that examine the effects of education on youth crime, and literature that assesses the effects of early criminal involvement on educational outcomes, only studies that intended to establish causal inferences are included.

As a result of these search and selection procedures, nine childhood interventions, three early school-age interventions and eight adolescent interventions were identified as relevant for this systematic literature review. With regards to studies that examine the effects between education and youth crime, we document and discuss 13 studies that analyze the effects of education on youth 


\section{Chapter 2}

crime and five studies that examine the link from early criminal involvement to educational outcomes.

\subsection{Childhood and adolescent interventions}

During the last decades, several social interventions have been implemented with the aim of developing skills and preventing problem behavior of at-risk youth, predominantly from families with a low SES and from ethnic minority groups. ${ }^{7}$ Many of these interventions have been shown to simultaneously improve different lifetime outcomes.

We discuss the selected interventions and studies that evaluate them below. Tables 2.1, 2.2 and 2.3 provide concise information on early childhood interventions, early school-age interventions and adolescent interventions, respectively, which were evaluated with respect to criminal behavior and educational outcomes of young people. In left to right order, the columns in these tables illustrate the name of the intervention, studies that have examined this intervention, when and where an intervention was carried out, the target group, age of the participants, content of the intervention, evaluation design (i.e. random assignment), duration of the intervention (in years), number of observations in the sample and the follow-us period (years after the intervention or the age of participants at follow-up). The last three columns show the effects of the interventions on educational outcomes, namely academic performance and educational attainment, and on reduction in criminal behavior.

\footnotetext{
${ }^{7}$ See reviews by Blau and Currie (2006), Deković, Asscher, Slagt and Boendermaker (2012), Olds, Sadler and Kitzman (2007), Kautz, Heckman, Diris, Ter Weel and Borghans (2014).
} 


\subsubsection{Early childhood interventions}

A significant share of interventions has been aimed at children aged between 0 and 6 years. Typically, early childhood interventions do not only target the children, but also the environment that surrounds the child's development. We consider a number of early childhood interventions which have been evaluated with respect to educational and criminal behavior outcomes in the short and long run.

The Nurse-Family Partnership (NFP) and the Infant Health Development Program (IHDP) are programs provided to low socio-economic status families with new-born children. Both programs include home visits during the mother's pregnancy and services for infants and toddlers (from birth to three years old). The IHDP also offers center-based care for children and parent group meetings. The main aim of these programs has been to reduce negative intergenerational effects that are transmitted (e.g. low education, risky behavior, unemployment) from parents to their children. These programs have been extensively evaluated using randomized controlled trials and assessed in studies that follow the participants of the treated and control group in adolescence and young adulthood. Evidence shows that there is no effect of the NFP on academic performance or educational attainment, but the program does reduce offending behavior of girls (Eckenrode et al., 2010). With regards to the IHDP, the intervention did not have a statistically significant effect on the criminal behavior of the participants when they were aged 18 and did not have an effect on educational attainment (McCormick et al., 2006). At the same time, the effects on academic performance were positive for math but not for reading.

The Jamaican Study is another infant intervention with similar content. It was targeted at children aged between 9 and 24 months from poor disadvantaged neighborhoods in Jamaica (Walker, Powell and Grantham-McGregor, 1990). The program provided nutritional supplementation and psychological stimulation by weekly home visits by community health assistants. The psychological stimulation was based on mother-child interaction. It included play sessions with children and mothers, and sessions only for mothers to teach them how to promote child development through play. The results show that the intervention, especially 
Chapter 2

psychological stimulation, has a positive effect on educational outcomes at age 11 to 12 years and that the effect is sustained through age 22 (Walker, Chang, Powell and Grantham-McGregor, 2005; Walker, Chang and Grantham-McGregor, 2011). In particular, Walker et al. (2011) find that participants in the Jamaican program who received stimulation were less involved in fights and in serious violent behavior by the age of 22 years old.

The Carolina Abecedarian Project $(A B C)$ and the Carolina Approach to Responsive Education (CARE) are early childhood interventions targeted at children aged between 6 weeks and 8 years old. The sample of children in the $A B C$ project included developmentally at-risk children, while children in the CARE were from high-risk and low-risk families. The $A B C$ project offered full-time center-based childcare. The CARE project had two types of interventions: (1) center-based childcare combined with home visits, and (2) home visits only. The results show that the $A B C$ program has positive effects on educational outcomes but no effect on criminal behavior on young people. CARE positively affected academic performance and reduced marijuana use among treated individuals (Campbell, Ramey, Pungello, Miller-Johnson and Sparling, 2002; Clarke and Campbell, 1998).

Other types of interventions are specifically aimed at preparing children for school. The most well-known is the High/Scope Perry Preschool Program. Children from deprived African American families whose mothers have low IQ scores (below 85) were randomly assigned to a treatment and a control group. The Perry Preschool Program was aimed to improve the IQ's of these children. Participants of the treatment group regularly - biweekly during four years - received home visits by the teacher until they were of school age. Even through the program did not affect IQ, it had positive effects on many long-run outcomes. Evaluation studies have shown that the intervention had favorable effects on educational attainment of women, but not of men, and on criminal behavior of all participants (Heckman, Pinto and Savelyev, 2013; Heckman, Moon, Pinto, Savelyev and Yavitz, 2010; Schweinhart et al., 2005; Schweinhart and Weikart, 1997). Heckman et al. (2013) find that a specific noncognitive skill, namely Academic Motivation, was a channel for the treatment effect 
on education of women, whereas Externalizing Behavior is the main channel that underlies the positive effect of the intervention on several lifetime outcomes, including the reduction in criminal involvement among both male and female participants.

The large-scale Chicago Child-Parent Center (CPC), and Head Start programs and the small-scale Syracuse Family Development Research Program (FDRP) were not based on randomized control trials. However, these interventions were evaluated rigorously. All three programs provide home visits for children from low socio-economic families with the aim to better prepare them for school. In addition, day care was provided in the FDRP program. Studies that evaluated Head Start often employ sibling fixed effects to evaluate the effects of the program. These evaluations show positive effects of Head Start on the educational attainment of participants, whereas the effects on criminal behavior are ambiguous (i.e. some studies find reducing effect on criminal behavior, while other studies find no effects) (Currie, 2001; Deming, 2009; Garces, Thomas and Currie, 2002). In the evaluation of CPC another disadvantaged area of Chicago was used as the control group (Reynolds, Temple, Robertson and Mann, 2001). The CPC program positively affected academic performance, educational attainment and reduced arrest rate (Barnett et al., 2008; Campbell et al., 2002; Reynolds et al., 2001). In the evaluation of the FDRP intervention, participants were compared to 'similar' children in other neighborhoods (Lally, Manggione and Honig, 1988). The results of this evaluation have shown that the program improved academic performance of participants and reduced their criminal involvement.

It can be concluded that the common feature of early childhood interventions is that they improve the cognitive and socio-emotional development of at-risk children from the earliest stages of life. This evidence shows that later life outcomes, such as education and criminal involvement, are closely related to skills developed in early childhood. Non-cognitive skills play an important role in affecting these outcomes (Kautz et al., 2014). There is also evidence that conscientiousness, a non-cognitive skill (that can be broadly defined as the ability to delay gratification, to 


\section{Chapter 2}

control impulses, to follow socially prescribed norms and to be goal-directed) is strongly correlated to many socio-economic outcomes in adulthood, including criminal behavior and wages (Prevoo and Ter Weel, 2013).

It is unclear which exact components of early childhood interventions are the most effective. More research is therefore needed on identifying what particular factors - or combination of factors - improve future educational outcomes and reduce criminal behavior. Finding whether these factors have a direct effect on longterm outcomes or an indirect impact that operates through other factors is of great importance because it can provide recommendations for more targeted policies.

\subsubsection{Early school-age interventions}

Early school-age interventions are usually aimed at improving academic performance of students and at facilitating the communication between students on the one hand, and their peers, teachers, and parents, on the other. There are relatively few

early school-age interventions that meet our research criteria, compared to early childhood interventions.

The Seattle Social Development Project (SSDP) is a long-term project aimed at children's development in public elementary schools. The SSDP is considered as one of the best evaluated school-age interventions and one of the very few with longterm follow-ups (Durlak et al., 2011). The SSPD includes in-service teacher trainings, parenting classes for parents and social competence training for children. This project targeted pupils who were enrolled in fifth grade. The follow-ups suggest that the SSDP improved education while the effect on criminal behavior is mixed (the intervention improved behavior during adolescence but not during young adulthood) (Hawkins, Guo, Hill, Battin-Pearson and Abbott, 2001; Hawkins, Kosterman, Catalano, Hill and Abbott, 2005).

The Montreal Longitudinal Experimental Study (MLES) was conducted amongst at-risk boys aged between seven and nine years from low socio-economic status families. The intervention provided social skills trainings to children, parents and teachers by professional social workers. For example, parents received special 
training programs on how to better supervise children's behavior, train their noncognitive skills, use non-abusive discipline strategies and manage family crises. At the end of primary school, boys from the treatment group had a statistically significantly lower incidence of fighting and were less likely to have serious behavioral and performance problems at school compared to the boys in the non-treated groups. They were also less likely to commit thefts and delinquent acts involving trespassing (Tremblay et al., 1992). Another study shows that children who participated in the program were more likely to graduate from high school. There was no effect on the probability of having a criminal record (Boisjoli, Vitaro, Lacourse, Barker and Tremblay, 2007).

The Los Angeles Better Educated Students for Tomorrow program (LA's BEST) is an after-school enrichment program that aims to provide a safe and supervised environment for at-risk students in disadvantaged neighborhoods. It is designed for children in kindergarten through fifth/sixth grade. LA's BEST focuses on cognitive, non-cognitive and physical development of children and include a number of learning and social (e.g. enrichment and recreation) activities such as a homework assistance, tutoring services, library services, sports, arts and crafts and group activities. The LA's BEST program is not evaluated by means of a randomized control trial, but instead the evaluation studies apply a propensity score matching method. The evaluation results suggest that the program has a positive effect on reduction of high school dropout, but not on academic performance overall (Huang, Kim, Marshall and Perez, 2005). Another study finds that the program had a favorable impact on criminal behavior, but only for those who attended the program most frequently (Goldschmidt and Huang, 2007). This study, however, does not address the issue of selective program attendance.

In addition to existing evidence from the LA's BEST program, there is research suggesting that adult supervision during after-school hours can positively affect different outcomes, including education and behavior characteristics of young people (see reviews by Durlak et al., 2011; Riggs and Greenberg, 2004). Aizer (2004) finds that children supervised by adults during after-school hours are less likely to be 


\section{Chapter 2}

truant and less often involved in offending behavior. They are less likely to use alcohol and drugs and to participate in property and violent offences. Durlak et al. (2011) conclude in their review that after-school programs are also likely to help young people solve behavioral problems and have positive effects on their social skills and emotional development.

The reviewed studies suggest that well-established early school-age interventions can contribute considerably to improving educational outcomes through adolescence while only few studies identify statistically significant effects on criminal behavior. More such interventions need to be evaluated in order to draw stronger conclusions with regards to its effect on criminal behavior. Similarly to studies on early childhood interventions, more evidence is needed on the channels that underlie positive effects of early school-age interventions on educational and criminal behavior outcomes.

\subsubsection{Adolescent interventions}

Adolescent interventions are generally aimed at preventing criminal involvement or low educational attainment of at-risk juveniles. They are so-called remedial interventions that target already existing problems that young people have. Seven remedial interventions meet our inclusion criteria and are discussed in the subsequent sections.

The Big Brothers Big Sisters program (BBBS) is a mentoring program for juveniles aged between 10 and 16 who live in socially disadvantaged families (e.g. single-parent). The program provided regular meetings of volunteer mentors with participants of the program. The empirical results suggest that the program has a strong effect on academic performance (however, only for girls) and reduces violence in school and substance abuse (Tierney, Grossman and Resch, 1995; Grossman and Tierney, 1998).

The Quantum Opportunity Project (QOP) provided mentoring, educational services and financial rewards to juveniles at-risk aged 14 or 15 . The program's activities were performed during out-of-school time. Students from the treated 
group were promised that they would receive a financial reward if they obtain a high school diploma (the General Educational Development or GED) and if they continue their education at the postsecondary level. The results of the program show that adolescents in the treatment group graduated high school earlier and were more likely to continue postsecondary education compared to adolescents in the control group. The intervention had a reducing effect on criminal activity for youth in the top-half of the risk distribution and this effect persisted up to five years after the program. Later follow-up evaluations have shown that the effects on education and risky behavior fade away (Rodríguez-Planas, 2012a; 2012b). Furthermore, the program was also not effective for youth in the bottom-half of the risk distribution.

The National Guard ChalleNGe and Job Corps are large-scale programs that provided residence-based education and job training for young people at-risk (often school drop-outs). These are both large-scale programs. Evaluation studies show that participants were more likely to obtain a GED certification, but not a high school diploma (Bloom, Gardenhire-Crooks and Mandsager, 2009; Millenky, Bloom, MullerRavet and Broadus, 2011; Schochet, Burghardt and McConnell, 2008). However, we know from other literature that GED qualifications are associated with a range of adverse outcomes (Heckman, Humphries and Kautz, 2012). The favorable effect on arrest and conviction of the National Guard ChalleNGe and Job Corps was only observed during the intervention when young people were enrolled in residencebased education and training and show no lasting effect on crime in the long-run (Millenky et al., 2011; Schochet et al., 2008). Hence, these impacts seem to represent incapacitation effects of the programs and do not operate through sustained improvements in the skill development of participants.

The Education Maintenance Allowance (EMA) program was designed to increase participation and achievement and decrease retention rates in postcompulsory education among young people aged 16 to 18 in the U.K. by means of a weekly monetary allowance provided to young people or their parents. Areas with low participation in post-compulsory education and areas with higher levels of economic deprivation were selected for this intervention. In evaluation studies, 


\section{Chapter 2}

individuals from areas that participated in the EMA program were matched to individuals from control areas with similar characteristics. The results show that the EMA had a positive effect on participation in education, in particular for youth in urban areas (Ashworth et al., 2002; Ashworth et al., 2001; Heaver et al., 2002). The program also had a negative effect on burglary and theft conviction rates among young people aged 16-18, while there was no effect on convictions rates for violent crime (Feinstein and Sabates, 2005). The authors explain this effect by a direct income impact on crime reduction due to the income support provided to youth and by incapacitation effects of education.

Becoming a Man (BAM) is an intervention for at-risk young boys from lowincome, racially segregated and high crime neighborhoods that attend high schools in the Chicago Public School system. The intervention included either in-school sessions, after-school sessions, or both. Young people were exposed to pro-social adults, kept occupied during the high-risk after-school hours, and participated in cognitive behavioral therapy sessions. The results of an evaluation study suggest that program participation reduced violent-crime arrests one year after the program and generated substantial gains in schooling outcomes, leading to higher graduation rates (Heller, Pollack, Ander and Ludwig, 2013).

The Neighborhood School Program (NSP) is an intervention targeted at school dropouts in the Dutch city Rotterdam. It was aimed to help young people aged 16-23 years old to return to school or to become employed. The program consists of educational and job related services, as well as care services (e.g. counselling). Additionally, young people who participated in the program were formally enrolled in education and received a student grant. The average duration of the program was 10 months. The effects of the program are evaluated with respect to school enrolment, employment, and criminal behavior three years after the start of the intervention (Van Elk, Van der Steeg and Webbink, 2013). The outcomes of the NSP participants are compared to the outcomes of young people who participated in a regular reintegration program. The assignment to treatment (the NSP) and to the control group (the regular program) was conditional on the timing of 
application. There was, however, crossover between the treatment and the control group after assignment. Additionally, some young people decided do not participate after they were assigned either to the treatment or to the control group. These issues are addressed by using an instrumental variable approach. The evaluation study by Van Elk et al. (2013) shows that the NSP program has an increasing effect on criminal involvement of participants, especially among those who were already suspected of committing a crime at the time of entry. The effect of the program on school enrolment and employment is statistically insignificant.

The restorative juvenile justice program Halt ('Het Alternatief', in Dutch) is another Dutch intervention that aims to prevent delinquent juveniles aged 12-18 from re-offending and aims to improve their social behavior. Participants of the treatment group had to perform various working and learning activities during afterschool time, such as community work, apologizing for their behavior and conducting some learning assignments. An evaluation study shows no overall effect on the reduction of criminal behavior among juvenile offenders (Ferwerda, Van Leiden, Arts and Hauber, 2006). Chapter 4 of this thesis evaluates the effect of the Halt intervention on educational outcomes and shows that the intervention has a statistically significant positive effect on educational attainment and reduces the probability of early school-age leaving.

We conclude that adolescent interventions aimed at at-risk juveniles can improve their educational outcomes, but the effects on criminal behavior outcomes are mixed, ranging from a positive to no effect, and even to a negative effect. If there is a favorable effect of adolescent interventions on criminal involvement it is likely to be due to incapacitation effects of the program and not as a result of improving individual skills. This explains why the effect of adolescent interventions on criminal participation is not lasting in the longer run. We observe from the reviewed interventions studies that adolescent interventions are less successful than interventions in early childhood. This is in line with Cunha et al. (2006) who find that investing in young disadvantaged children bring higher economic returns than 


\section{Chapter 2}

investing in disadvantaged adolescents. They conclude that remediating interventions in later stages of life is more costly than early preventive interventions.

\subsection{Empirical studies on the relationship between youth crime and education}

In this section, we further explore how youth crime and education are related. We start with documenting the empirical results of studies that examine the effect of education on delinquent involvement and then discuss the empirical results of studies that evaluate the link from criminal involvement in adolescence to educational outcomes. Table 2.4 and Table 2.5 present these two types of studies, respectively. These tables provide the following information: name of the study, country of the study, research population, sample size, the evaluation method of the study, information on the input variable, and the effects on criminal behavior outcomes (Table 2.4) or educational outcomes (Table 2.5).

\subsubsection{The effects of education on youth crime}

Many studies suggest that truancy and school dropout are negatively related to the probability of criminal behavior (e.g. Elliott, 1966; Jarjoura, 1993, 1996; Thornberry, Moore and Christenson, 1985). However, this association is often statistically insignificant after controlling for certain background characteristics (Krohn, Thornberry, Collins-Hall and Lizotte, 1995). Therefore, studies that establish a causal relationship between education and youth crime are of particular importance.

Empirical evidence that shows that educational attainment negatively affects adult crime is growing (Lochner and Moretti, 2004; Machin et al., 2011; Meghir et al., 2012). However, little empirical research has been conducted on the relationship between youth crime and education (see reviews by Hjalmarsson and Lochner, 2012; Lochner, 2011). This can be explained by the fact that youth crime is not always measured accurately and that there can be many confounding factors and potential 
reverse causality such that isolating a single chain of causality is difficult (Belfield and Levin, 2009).

There are several studies that focus on the incapacitation effect of education on criminal involvement of youth. Jacob and Lefgren (2003) use teacher in-service days during the regular school year in the U.S. as a source of exogenous variation in students' school attendance. Students do not attend school on teacher in-service days, but teachers do in order to conduct organizational tasks. The authors argue that these days are unlikely to be correlated with factors that influence criminal activity. The results of their study suggest that in-service days, compared to normal school days, lead to increases in property crime committed by young people between the age of 10 and 19 by 14 percent and decreases in incidents of violent crime by 28 percent.

Luallen (2006) expresses doubts on whether teacher in-service days are an exogenous source of variation in student absence from school. He argues that such days are usually known in advance and therefore parents can plan different activities to keep their children busy on a free school day. He replicates the study by Jacob and Lefgren (2003) using teacher strikes as an unexpected source of school closing. He applies data that measure criminal activities reported at the zip code level by linking them to the corresponding school districts. The results of his study are similar to those of Jacob and Lefgren (2003), but the magnitude of the effects is larger. In particular, Luallen (2006) shows that school incapacitation reduces property crime with approximately 29 percent, and that violent crime increases with a percentage that lies between 32 and 37 percent. Additional analyses show that these effects only hold for urban communities. Finally, the study suggests that the decrease in violent crime during teacher strike-days mainly results from offenders who commit multiple crimes, whereas the increase in property crime is driven by school absenteeism of both one-time and repeat offenders.

Landers $\varnothing$, Nielsen and Simonsen (2013) explore the relationship between schooling and criminal behavior of adolescents, using variation in school starting ages that occur because of differences in month of birth. The authors use Danish 
register-based data. The study shows that higher age at school start lowers the propensity of criminal behavior before age 18 . This reduction is caused by incapacitation effects of education. In particular, the effect of being born in December relatively to being born in January is associated with a 30 percent reduction in crime for girls and a 21 percent reduction in crime for boys. The effects on property crime is concentrated among boys, while the effects of violent crime is stronger for girls. The effect for boys with high levels of latent ability is higher. Finally, the study shows that the mean age of peers has no statistically significant effect on the outcome, and this effect is caused by one's own school starting age only.

Cook and Kang (2013) investigate the effect of relative age at school entry on the relationship between schooling and crime using a regression discontinuity design created by a legal minimum age requirement to school entry. In particular, they use the interaction between the child's birthdates and the minimum school entry age as a source of variation in the probability of dropout. The study is based on administrative data from the North Carolina public school system and other administrative sources. The study shows that young people born just after the cutoff age, which mean that they are relatively older in the class, tend to have higher endof-grade test scores in middle school, lower rates of retaining in grade between ages 11 and 15 and lower juvenile delinquency between ages 13 and 15 (3 percentage points of reduction in delinquency rates). But by age 19 these individuals are more likely to drop out and be convicted for serious offences committed. The explanation for the dropout finding is that these students have greater exposure to the legal opportunity to drop out, as they reach the legal dropout age earlier in time. The effect on committing serious crimes can be explained by a higher dropout rate for these students. The study also finds that women are much more likely to drop out of high school if born after the cutoff age. Furthermore, the effect is stronger among adolescents who are traditionally considered disadvantaged.

Another stream of the literature focuses on the effects of increased educational attainment on criminal behavior probabilities. Åslund, Grönqvist, Hall, 
2.The relationship between youth crime and education: an empirical literature review

and Vlachos (2014) study the impact of a large scale Swedish reform in vocational education on criminal convictions among youth. The reform extended upper vocational secondary education from two to three years and added more general theoretical content to it. The authors argue that this reform concerned age groups, in which criminal activity is relatively high and students who are overrepresented in crime statistics. The results of this study show that increased access to prolonged and more theoretical vocational education leads to a persistent reduction in property crime, but not to a statistically significant decrease in violent crime. In particular, three-years vocational programs led to a reduction in property crime among students by 1.8 percentage points, compared to no three-year vocational programs.

Anderson (2014) analyzes the relationship between education and youth crime using state-level variation in the minimum dropout age (from age 16 to 17 or 18) in the U.S. In particular, changes in the compulsory schooling law are used in a difference-in-differences framework to control for unobserved heterogeneity and endogeneity bias. The results show that a minimum dropout age of 18 has decreased arrest rates among 16- to 18-year-olds by approximately 17 percent.

Marie, Traag and Van der Velden (2015) explore the relationship between educational attainment and youth crime. They combine information from a survey for young people in the Netherlands and administrative data on criminal involvement. Similarly to Landers $\varnothing$ et al. (2013), they apply an IV strategy using variation in timing of birth. From the first stage regression results they find that relatively older students are more likely to leave secondary school without a degree (starter qualification). The results from the second stage regression suggest that secondary school qualification reduces the probability of arrest after leaving school by about 30 percent. This effect is due to changes in male offending behaviour. This study also suggests that the effect of school qualification on the probability of arrest is almost twice as larger for property crime.

Machin, Marie and Vujić (2012) identify the effect of educational attainment on youth crime using a reform in post-compulsory education system in the late 


\section{Chapter 2}

1980s and early 1990s in the U.K. as a source of exogenous variation in educational participation of young individuals aged between 16 and 21. This reform has increased the number of individuals that stayed in education. The study shows that a one percent increase in the proportion of men in full time education and a one percent increase in the proportion of men staying in education after the compulsory school leaving age reduces criminal behavior of young men by around 1.9 percent and 1.7 percent, respectively. This reduction is also observed for women, although smaller in magnitude, 1.1 percent and 1.3 percent, respectively.

Brugård and Falch (2012) exploit Norwegian data on educational characteristics and detailed data on imprisonment for persons aged between 21 and 22 to analyze the relationship between education and youth crime. They use grades from the external exit examination (either Norwegian, English, or mathematics) as an instrument for skills measured by grade point average, and they use the study track structure together with proximity to high schools as instrument for the number of semesters in high school education. The results of this study suggest that an additional semester in high school reduces the probability of imprisonment by 0.44 percentage points.

Aoki (2014) examines the effects of educational attainment on juvenile delinquency exploiting exogenous variation in schooling caused by the public support granted to students and teachers in specific municipalities in Japan after the Kobe earthquake in 1995 . Using arrest rate variations between municipalities that were exposed to similar degrees of earthquake damage but with a different level of financial support, the author finds that a one percentage point increase in the high school participation rate reduces juvenile violent arrests in the municipalities affected by the earthquake by approximately 0.11 per 1,000 juvenile population on average. The estimated effect on property crime is not statistically significant.

Merlo and Wolpin (2009) provide a comprehensive analysis of the dynamic interactions among a youth's schooling, employment and criminal behavior decisions and criminal involvement outcomes. They use individual-level panel data reported by African-American men aged between 13 and 22 in the U.S. To estimate youth's 
2.The relationship between youth crime and education: an empirical literature review

decisions to engage in schooling, employment and criminal behavior (including all possible combinations of these three activities), they apply a multinomial discrete choice vector autoregression model. The authors simulate the effect of changing schooling status at age 16 for the same individuals and compare their criminal involvement. They conclude that not attending school at age 16 (implying school dropout) increases the likelihood of committing crime and being incarcerated at age 19-22 by up to 14.8 percentage points and up to 8.1 percentage points, respectively.

A third stream of the literature focuses on the effects of post-secondary school attendance on the criminal behavior of young people. Cullen, Jacob and Levitt (2006) evaluate the effects of winning a lottery that allows high school admission in the Chicago Public Schools on educational and criminal behavior outcomes. The study shows that although winning the lottery increases enrollment and attendance in the high schools, there are no positive effects on other educational outcomes. This can be because of a mismatch between student ability and school requirements (Lochner, 2010). There is, however, a negative effect on self-reported disciplinary incidents and self-reported arrest rates. Self-reported arrest rates are reduced among lottery winners relative to lottery losers (3.8 percent versus 8.9 percent).

Deming (2011) examines the effect of winning a school lottery that allows to attend a first-choice school (middle or high school in the U.S.) on criminal activity. The results of this study suggest that winning the lottery reduces crime, which is measured seven years after random assignment. More specifically, at-risk young people who won the lottery committed around 50 percent less crime compared to youth who did not win the lottery. The reduction in crime occurs after juveniles have graduated from their preferred school. This effect persists four to seven years after random assignment, in both the middle and high school. This effect can be explained by increases in the returns to investments in schooling, higher educational attainment and an increase in the opportunity cost of crime for young people who won the lottery (Deming, 2011; Lochner, 2004).

To sum up, the studies reviewed and documented above reveal causal evidence on the negative effect of education, including school attendance and 


\section{Chapter 2}

educational attainment, on criminal involvement in adolescence and young adulthood. Furthermore, these studies suggest that the effect of education can be direct (through incapacitation) as well as indirect (e.g. through skill acquisition).

\subsubsection{The effects of criminal behavior on educational outcomes}

There are relatively few studies that have examined the effect of criminal involvement of adolescents on educational outcomes, compared to the existing literature on the effect of education on youth crime. This is partly because exogenous variation in criminal involvement is extremely rare and this limits the available research strategies. Hence, studies that aim to provide rigorous findings on the link from criminal involvement to education are challenged. They tend to apply different econometric techniques in order to address the problem of endogeneity with respect to the relationship between criminal behavior and educational outcomes. This section summarizes the empirical results of such studies.

Hjalmarsson (2008) examines the effect of criminal involvement on high school graduation for young people under the age of 19, using the National Longitudinal Survey of Youth 1997. In this study, a linear probability model with a large set of observable characteristics is used, and state and household fixed effects are employed. Furthermore, adopting the approach proposed by Altonji et al. (2005), this study explores how sensitive the estimates are to selection on unobservables. This robustness analysis links selection on observed factors to selection on unobserved factors. Hjalmarsson (2008) finds that arrest and incarceration at age 16 or earlier reduce the probability of graduating from high school by about 11 and 26 percentage points, respectively. However, only the effect of incarceration is likely to be robust to the sensitivity of the estimates to selection on unobservables. The author further suggests that the mechanism of this effect can be explained by the impact of stigma's that arise from interactions with juvenile justice.

Ward and Williams (2014) study the relationship between self-reported delinquency and educational outcomes. They find that delinquency by age 16 appears to reduce the likelihood of graduating from high school by up to 10 
percentage points and graduating from college by up to 13 percentage points. This study also uses the approach by Altonji et al. (2005) and suggests that selection on unobservables would have to be 2.6 times as large as selection on observables for the entire estimated effect to be completely attributed to selection bias. Additionally, the study finds that the relationship between delinquency and educational outcomes is driven by those who were criminally involved at age 14 or before, frequent offenders and those who commit property offences.

Kirk and Samson (2013) use propensity score matching to examine the relationship between juvenile arrest and high school graduation as well as college enrollment. The analyses are conducted for two cohorts of students from Chicago public school who were followed from aged 12 and 15 until approximately age 18 and 21, respectively. Their results suggest that arrested adolescents drop out of high school 22 percent more than not arrested adolescents with similar background characteristics, whereas enrollment in four-year college is 16 percent lower for arrested individuals relative to not arrested individuals. Using Rosenbaum's (2002) bounding approach, Kirk and Samson (2013) find that these results are robust to the effect of unobserved heterogeneity.

Webbink et al. (2013) analyze the relationship between early criminal involvement of twins and educational attainment using data from the Australian Twin Register. They employ a twin fixed effects model in order to control for environmental and genetic factors that are similar for twins. The results based on the analysis of fraternal twins suggest that arrest before the age of 18 reduces educational attainment with up to 0.99 years of education and lowers the probability of completing senior high school with up to 24 percentage points. The estimates based on the sample of identical twins are, however, not statistically significant: -0.025 years of education (with a standard error of 0.583 ) and reduction in 12 percentage points (with a standard error of 0.115 ) with regards to senior high school graduation. The authors suggest that this is because of the number of identical twins with variation in their criminal involvement status is low and statistical power is insufficient. 
Aizer and Doyle (2013) examine the effect of incarceration in adolescence on high school graduation, using the incarceration tendency of randomly-assigned judges as an instrumental variable. They use administrative data for more than 35,000 juvenile offenders over a ten-year period. The study shows that incarceration decreases high school completion by around 13 percentage points. It further shows that the effects are strongest for juvenile offenders aged between 15 and 16 .

To conclude, the available evidence suggests that criminal involvement in adolescence is negatively related to educational outcomes. Although this relation is driven for a large part by selection, it appears that incarceration has a causal effect on school graduation. There can be two main underlying mechanisms of the effect of incarceration on education: the first is by encouraging the accumulation of criminal capital and hindering the accumulation of social capital, and the second is by interrupting high school education and reducing years of schooling (Aizer and Doyle, 2013). What are these exact mechanisms that underlie the effect of incarceration on education, however, still need to be further explored.

\subsection{Discussion}

This chapter has provided a systematic literature review on the relationship between education and criminal behavior of young people. Evidence shows that early childhood programs for children with low SES positively affect their future educational and criminal behavioral outcomes. Some interventions improve one of these outcomes specifically, while other improve both crime and educational outcomes simultaneously. Early school-age interventions and adolescent interventions appear to be more successful in improving educational outcomes, as the effects on youth crime are at best limited to incapacitation effects of the program. The existing evidence also suggests that early interventions for children with low socio-economic status are more effective with respect to both educational and criminal behavior outcomes than later interventions, which is in line with 
2.The relationship between youth crime and education: an empirical literature review

theoretical arguments provided by Cunha et al. (2006). This is because skill attainment at one stage of the life cycle raises skill attainment at later stages of the life cycle. The effectiveness of investments (e.g. financial incentives, parental style, social environment, peer effects) depends on skills in the previous period, which in turn are dependent on earlier investments (Cunha and Heckman, 2007).

The channels through which interventions improve criminal behavior and educational outcomes mainly run through improvements in skill development. Especially non-cognitive skills appear to have a crucial role in improving these outcomes. For example, there is evidence that shows that early conscientiousness is responsible for many socio-economic outcomes, among them criminal behavior and wages (Prevoo and Ter Weel, 2013). Heckman et al. (2013) find that the Perry Preschool program increased Academic Motivation of girls (a non-cognitive skill that determines educational outcomes), and improved Externalizing Behavior (a noncognitive skill that determines criminal behavior outcomes) of both girls and boys. This, in turn, improved a number of lifetime outcomes, including reduction of criminal behavior.

More research is, however, needed to find other specific skills that can be developed through additional investments (i.e. intervention programs), and that in turn improve educational and behavioral outcomes. Furthermore, it is important to identify the specific aspects of interventions that are responsible for improvements in these outcomes.

The studies that examine the effects of education on criminal behavior of young people clearly show that there is a causal link from education to crime. The findings from these studies can be systematized as follows. Firstly, being in school keeps juveniles from being engaged in crime, in particular property crime. Secondly, not attending school increases the probability of interaction with juvenile justice. Both types of findings can be explained by the incapacitation effects of school. Thirdly, increased educational attainment reduces the probability of criminal involvement in adolescence and young adulthood. The mechanisms of this effect are, however, not entirely clear. It is possible that higher educational attainment 
favorably influences emotional development, patience, risk aversion and related skills of young people that correlate negatively to criminal behavior. Also, the opportunity costs of participating in criminal activities for higher educated people are higher. Finally, being in post-compulsory education, which involves higher quality education and/or better peers, has a reducing effect on criminal behavior for juveniles with low SES.

In comparison, less is known about the effect of criminal involvement on educational outcomes. Evidence is relatively limited because it is difficult methodologically to identify this effect due to other factors that can simultaneously affect criminal behavior and educational outcomes, and because exogenous variation in youth crime is generally scarce. The reviewed studies, however, provide strong correlational evidence on the negative relationship between early criminal involvement and educational outcomes. Moreover, it appears that incarceration of juveniles is likely to have a causal effect on educational attainment, which can be explained by incapacitation effects as a result of interactions with juvenile justice.

A considerable amount studies on the relationship between education and crime have been conducted on data from the U.S. The systems of education and juvenile justice in European countries differ substantially from those in the U.S (e.g. see Dünkel et al., 2011; OJJDP, 2006; OECD, 2014). In addition, the rates of early school leaving and the rates of self-reported criminal involvement among young people are higher in the U.S. compared to the average EU country (see also European Commission, 2014; Enzmann et al., 2010). This can reflect that the distribution of skills in the U.S. is more dispersed than in the average EU country (OECD, 2013). In particular, the distribution of skills in the U.S. has longer tails. Furthermore, the types of youth crime between European countries and the U.S. also differ (OJJDP, 2006; Enzmann et al., 2010). In particular, delinquent juveniles in the U.S. are more often involved in more serious criminal behavior than juveniles in Europe. Despite these differences we find evidence that there are no strong differences in the estimated effect of education on youth crime between the US and other developed countries, including the Netherlands. 
2.The relationship between youth crime and education: an empirical literature review

Policies that target criminal behavior or lower educational outcomes among young people should be aware of the relationships that can operate between education and youth crime. Improving education is expected to have a benign spillover effect on youth crime, and therefore policies that aim to prevent low educational outcomes can be effective in reducing criminal involvement of juveniles as well. Cost-benefit analyses should always consider both outcomes when evaluating the efficiency of such policies, even when the policy is mainly targeted at one specific outcome. Furthermore, this literature review has revealed that youth that is at-risk of dropping out from school is also at-risk of committing crime. Therefore, policies that target such at-risk youth, in particular, factors that are behind juveniles' criminal involvement and low educational attainment can potentially be very effective and efficient in addressing both outcomes simultaneously. 
Chapter 2

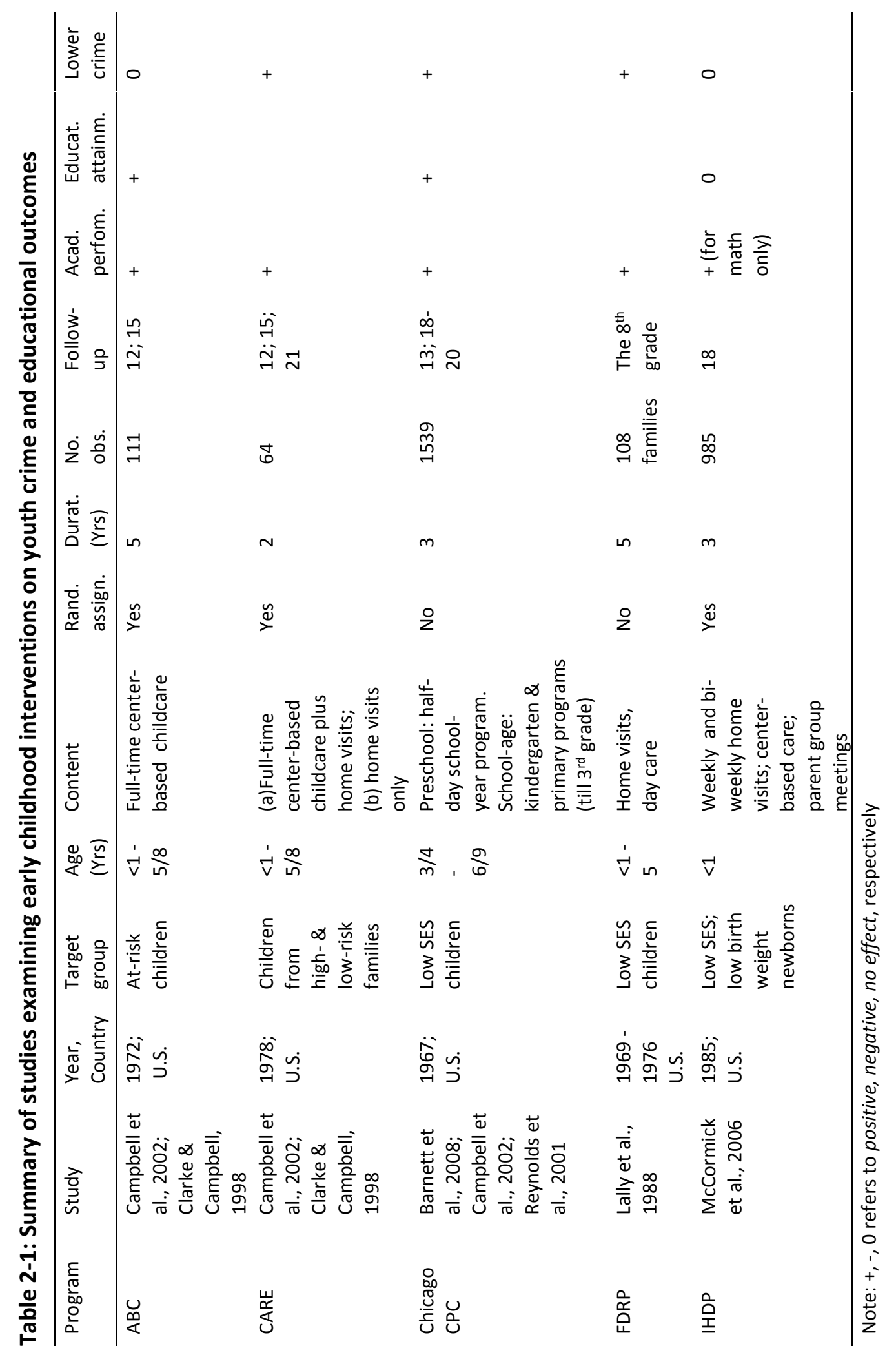


2.The relationship between youth crime and education: an empirical literature review

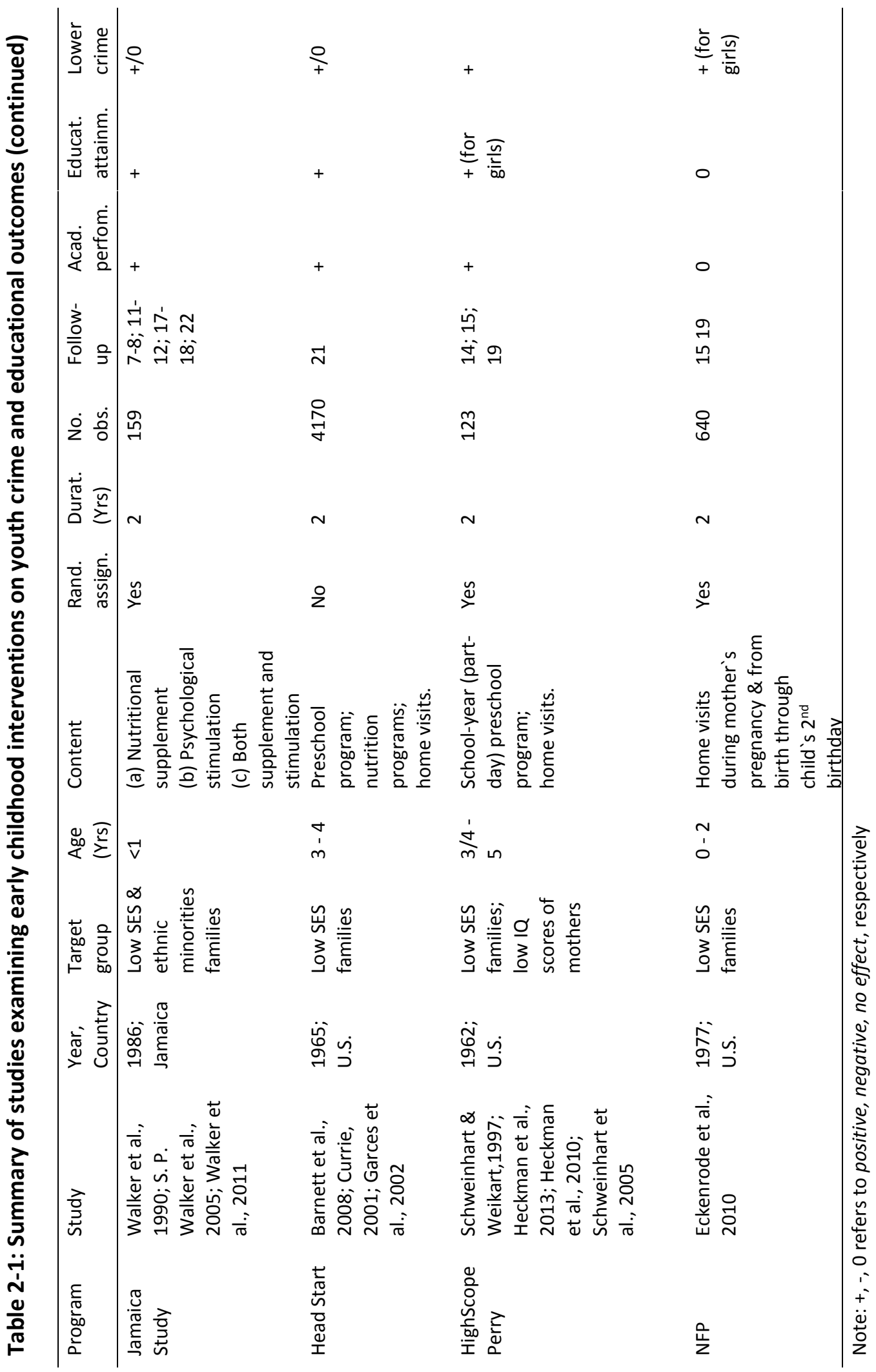


Chapter 2
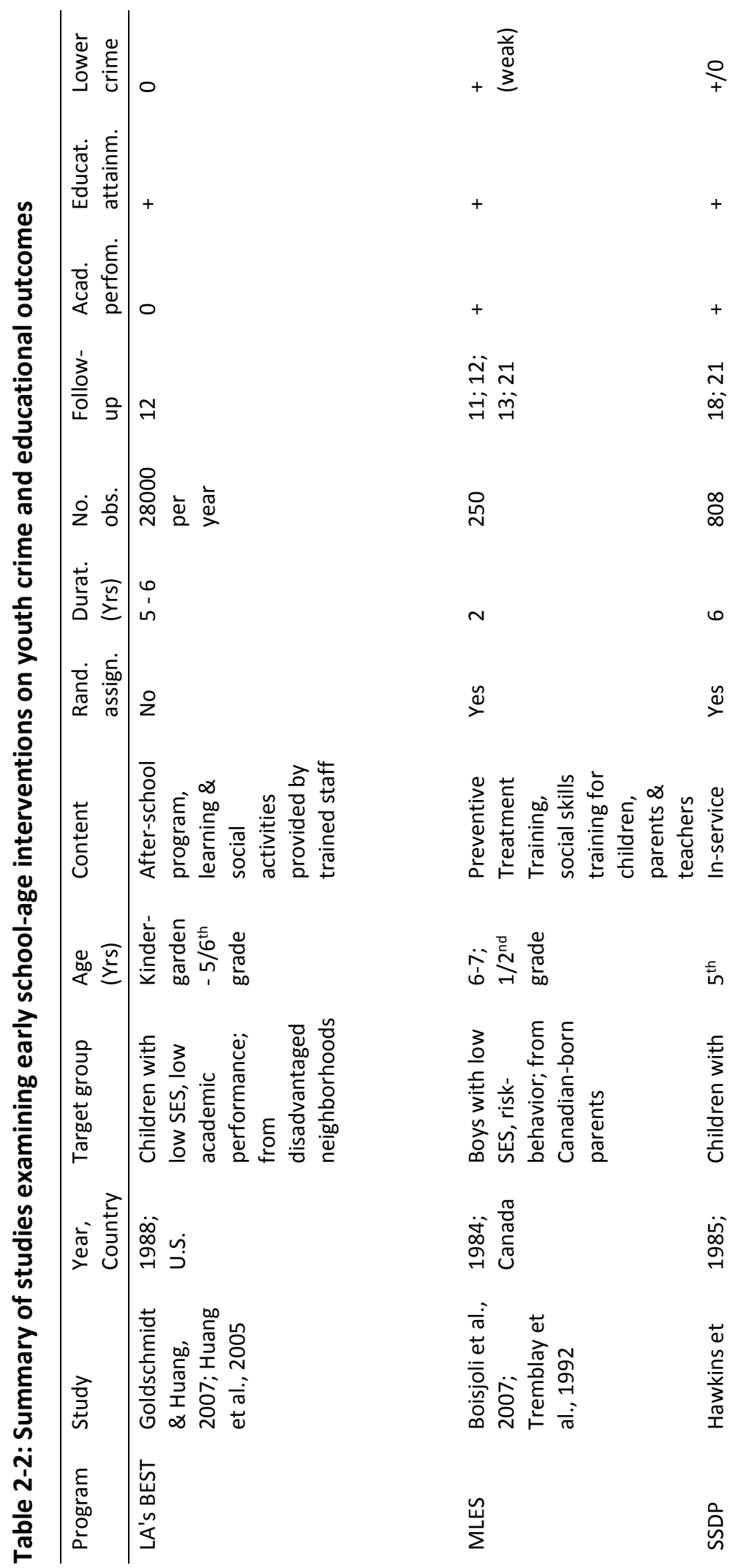

ํํำ

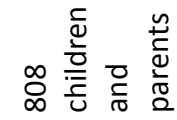

$\sim \quad 6$

$\stackrel{2}{2}$

$\stackrel{\text { ข }}{2}$

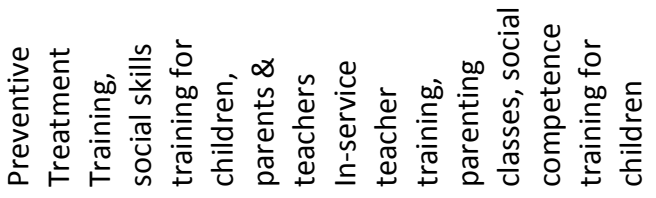

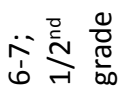

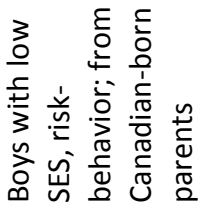

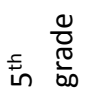

离离

ஸें
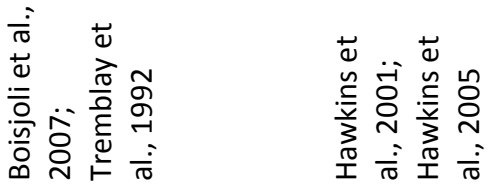

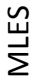

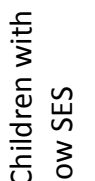

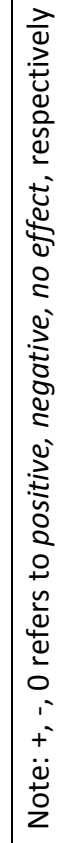


2.The relationship between youth crime and education: an empirical literature review

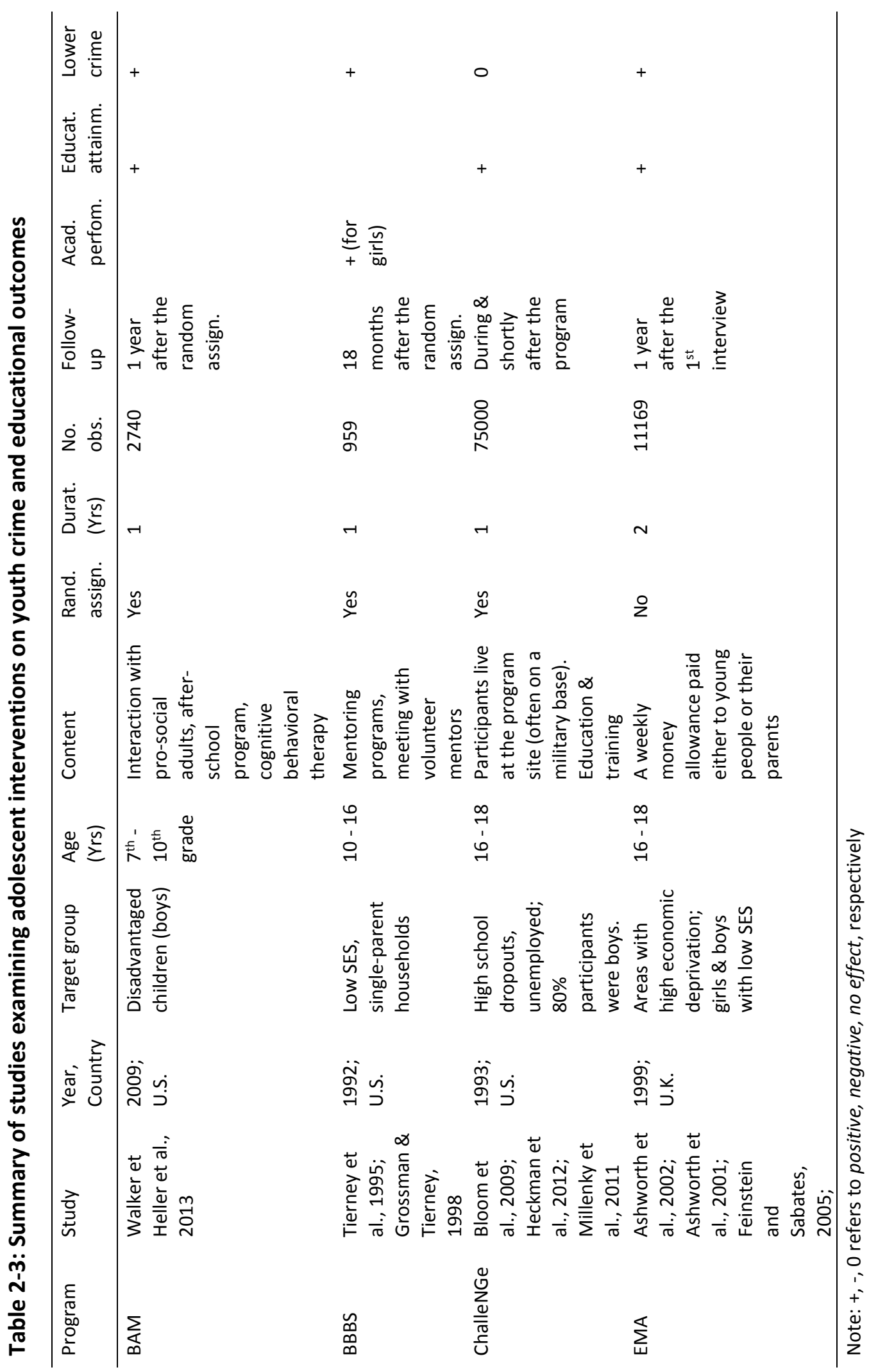


Chapter 2

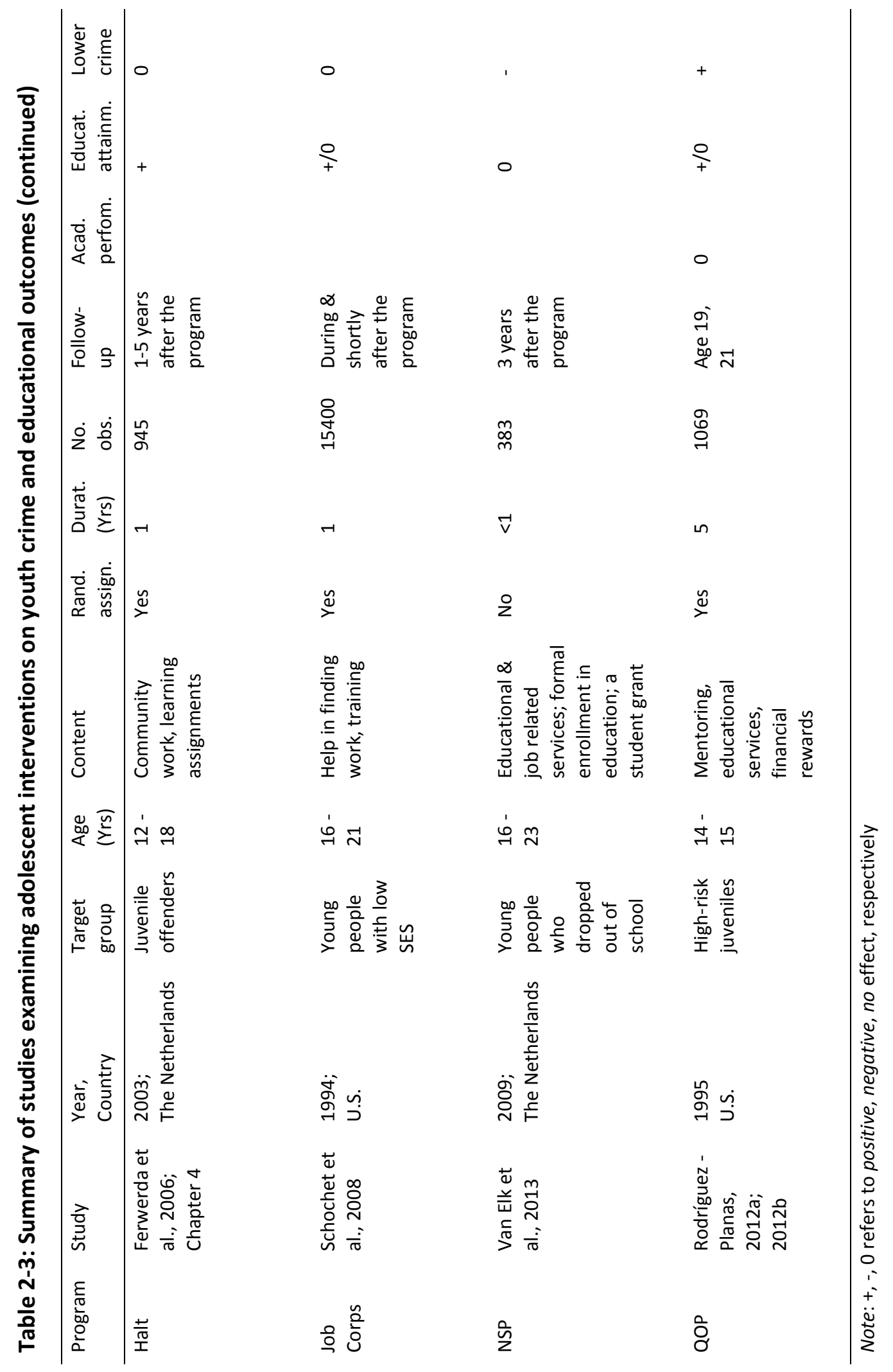




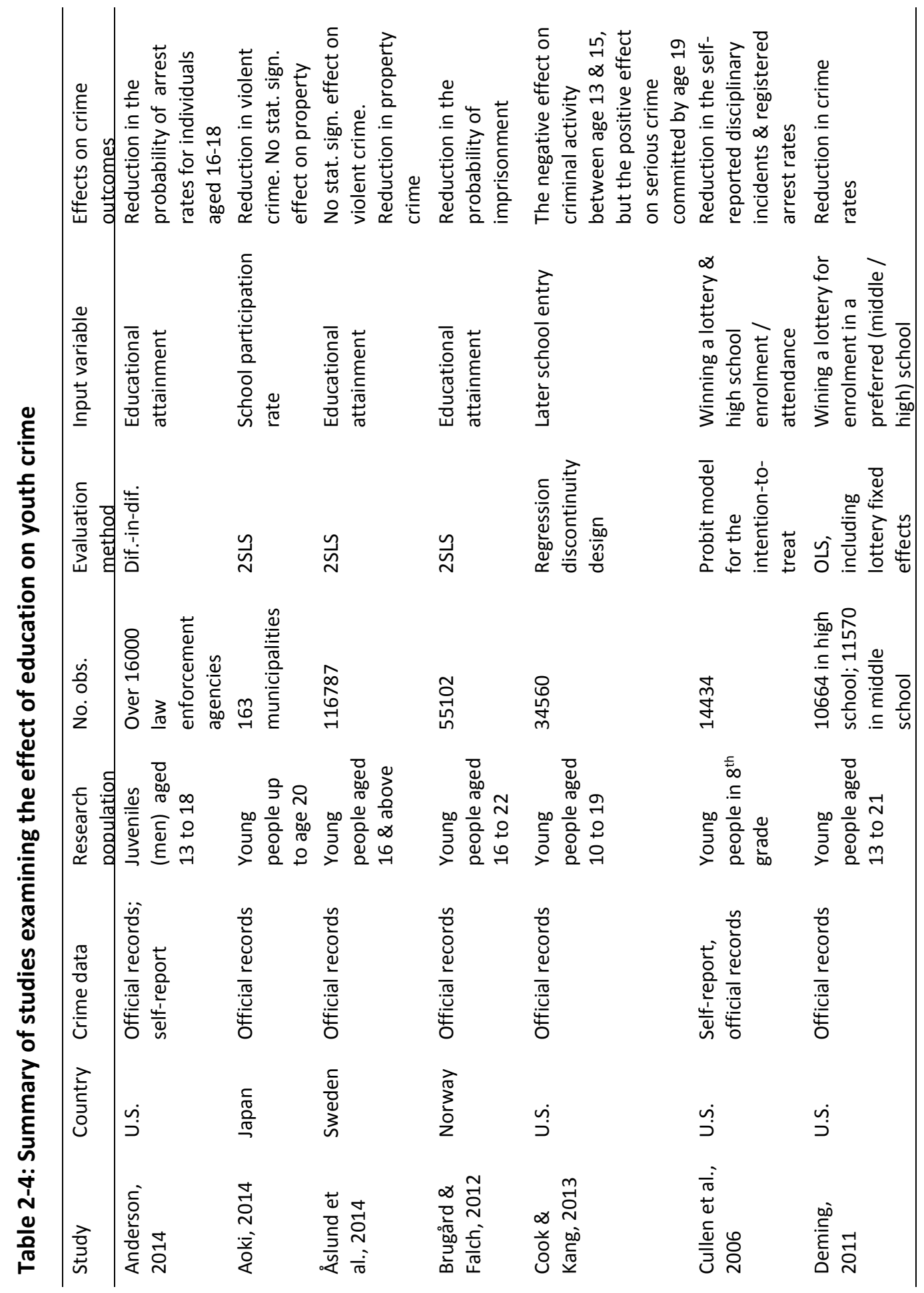


Chapter 2

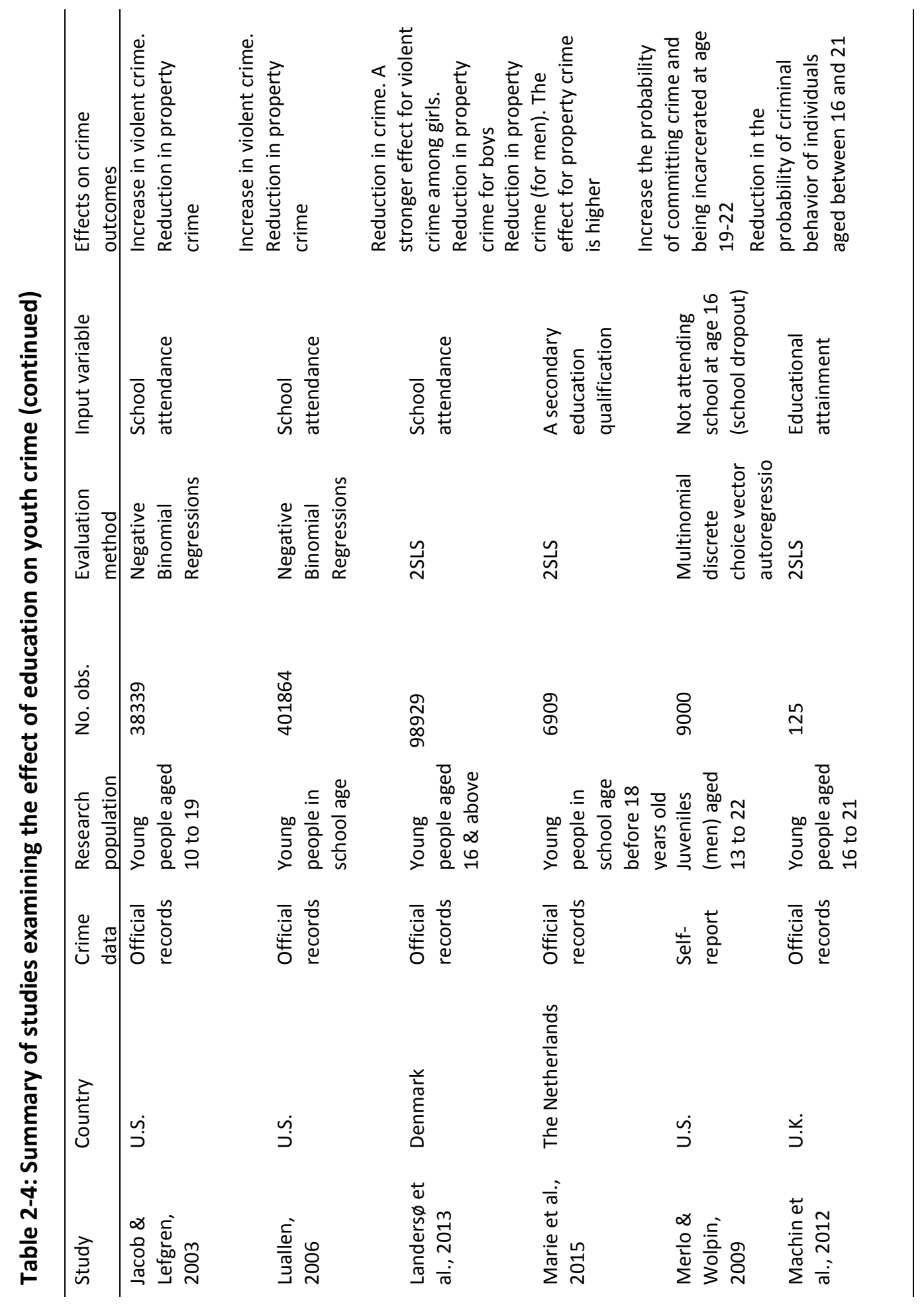


2.The relationship between youth crime and education: an empirical literature review

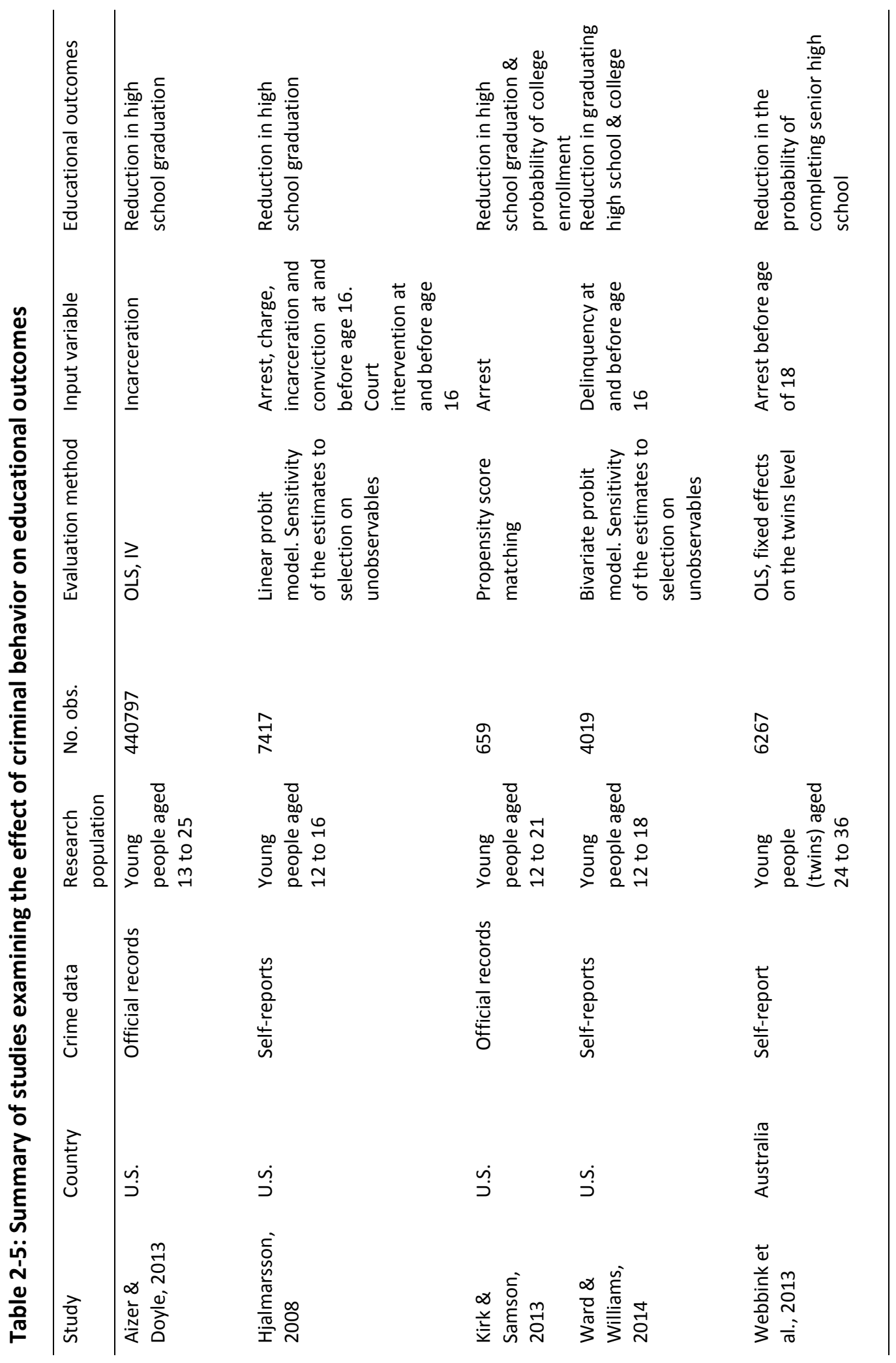





\section{What drives the relationship between criminal involvement and early school leaving?}

\subsection{Introduction}

Chapter 2 has reviewed empirical evidence on the relation between youth crime and education. There is ample evidence of a negative causal effect from education to youth crime. Much less is known from the literature about the reverse relationship, especially for European countries. Juvenile crime can precede educational attainment and it can be a determining risk factor for educational outcomes among the population of young people. This reverse causality is less likely in the relationship between education and criminal involvement among the adult population, because the educational attainment of adults has generally been completed (especially for their expected to be at-risk of criminal involvement and/or early school leaving). Existing research that examines whether early criminal involvement causally affects educational outcomes of young people is not extensive, mainly because exogenous variation in criminal involvement is difficult (or impossible) to find, which limits causal inference. Therefore, new evidence on the relationship between criminal involvement of adolescents and their educational outcomes as well as evidence on which factors drive this association is of great importance. Such evidence can be helpful in establishing interventions that simultaneously address the causes of youth crime and lower educational outcomes. 
In this chapter, we analyze how criminal involvement in adolescence is related to early school leaving (ESL). We do this by using longitudinal administrative data from the Netherlands on criminal involvement, on educational careers, on a wide range of individual and family characteristics, and on siblings and twins. These data allow us to take into account the timing of criminal involvement and ESL, and measure the status of criminal involvement before the status of ESL is identified. We exploit information of all students in the Netherlands who were enrolled in the first three grades of secondary school in the academic year 2005 and we follow these students until the academic year 2011.

Earlier studies on the relationship between criminal involvement and educational outcomes control for various observed characteristics and establish a negative relationship between criminal involvement of adolescents and educational outcomes (see Sweeten, 2006, and references within). The findings of these studies, however, may be subject to selection bias as the estimated association may be driven by unobserved factors. More recent studies (see Chapter 2) apply different econometric techniques to address the problem of endogeneity in the relationship between criminal behavior and educational outcomes (see e.g. Hjalmarsson, 2008; Webbink et al., 2013; Aizer and Doyle, 2013; Ward and Williams, 2014).

We want to find which factors underlie the relationship between adolescent criminal involvement and ESL. Therefore, we examine to what extent the unconditional correlation between criminal involvement and ESL can be explained by school-, by family- and by individual characteristics. First, we determine the unconditional correlation between criminal involvement and ESL using a basic OLS model without controls. We acknowledge that this association is likely to be driven by observed and unobserved factors. Second, we estimate this association by including an extensive set of observable family and individual characteristics. We then proceed to estimation models that take into account unobserved heterogeneity by estimating school, sibling and twin fixed effects estimators. The registration data do not allow us to identify whether twins are identical or fraternal, and therefore following the twin fixed effect model, we estimate a same-gender twin fixed effect 
model. Same-gender twins have a higher probability to be identical twins and the proportion of identical twins in the latter sample must therefore be higher, which increases the average genetic overlap.

We find that even after we control for same-gender twin fixed effects, the estimated relationship between criminal involvement and ESL remains positive and statistically significant. This can be due to selection, for example because of individual characteristics of students, such as cognitive and non-cognitive skills, that we cannot control for after taking into account twin fixed effects, but it can also reflect a true treatment effect, for example from spending time on criminal activities (rather than education) and from interactions with juvenile justice.

The literature distinguishes four potential mechanisms that explain why criminal involvement may influence ESL, both directly and indirectly. Criminal involvement and interactions with the justice system disrupt individuals from educational (and learning) processes, which can eventually lead to lower educational performance, and in turn to school dropout (Sweeten, 2006; Hjalmarsson, 2008; Lochner, 2011). Accumulation of 'criminal capital' can replace the need to invest in education and can reduce the effort put to the learning process (Grogger, 1998; Lochner, 2004; Ward and Williams, 2014). Furthermore, stigma as a result of criminal involvement can negatively affect educational outcomes (Sweeten, 2006; Hjalmarsson, 2008; Webbink et al., 2013). For example, teachers and parents might spend less time and effort on children who were criminally involved. Additionally, having a criminal record can provide a negative signal to employers (Apel and Sweeten, 2010). Anticipating this, individuals who were arrested can become less motivated to attain higher levels of education. Finally, interactions with the criminal justice system can potentially provide shocks to non-cognitive skills of young people, such as motivation or aspiration that, in turn, negatively affect educational outcomes (Behncke, 2009; Webbink et al., 2013).

This chapter provides more insight into what factors underlie the relationship between criminal behavior and ESL. More precisely, we examine to what extent observable and unobservable characteristics drive the association between criminal 
Chapter 3

involvement and ESL and, if we control for these factors, what part of this association is left unexplained. This research contributes to the existing literature by exploring longitudinal data, which allow us to ensure that criminal involvement

predates ESL, thereby reducing concerns about reverse causality. Finally, by examining data from the Netherlands, this research contributes to the external validity of already existing evidence that is predominantly established using data from Anglo-Saxon countries.

The reminder of this chapter is organized as follows. Section 3.2 describes the data we use in this chapter. Section 3.3 discusses the empirical strategy. Section 3.4 discusses the results. Section 3.5 provides heterogeneity analysis. Section 3.6 presents robustness checks. Finally, Section 3.7 concludes.

\subsection{Data}

We use longitudinal administrative data on the educational careers of all Dutch students in (upper) secondary education between 2005 and 2011. These data are linked to registration data on criminal involvement of all adolescents in the Netherlands from 2005 to 2010, and to registration data that contain information on individual and family background characteristics for the period 1999 to 2010. This results in a sample of 534,432 students who are enrolled in the first, second or third grade in secondary school in 2005 (registered in October). For convenience, we refer to these grades as the first, second and third cohort. We observe whether students were criminally involved in 2005 or any of the next five years and we follow them in (upper) secondary education.

Students in the Netherlands normally start their secondary education at age 12. They are tracked into different curriculum levels within secondary education largely based on the results of a cognitive test taken at the end of primary education 
3. What drives the relationship between criminal involvement and early school leaving?

(Cito score) ${ }^{8}$ and on the advice of the primary school. There are three main educational tracks: pre-vocational education (4 years), upper secondary general education (5 years) and pre-university education (6 years). It is common (mainly in upper secondary or pre-university education) that students are not immediately tracked but that they remain in a mixed track in the first one or two years of secondary education. Students who finish pre-vocational education usually continue their secondary education in upper secondary vocational education.

This chapter focuses on ESL as an outcome of educational attainment. ESL is measured using the definition of the Dutch Ministry of Education, which states that students are considered as early school leavers unless they are registered in secondary or upper secondary education, or unless they finished upper secondary general education, pre-university education, or level 2 of upper secondary vocational education with a diploma (and hence obtained starter's qualification). ${ }^{9}$ The data allow us to measure criminal involvement prior establishment of ESL status.

Juvenile offenders in the Netherlands who are apprehended by the police are registered in one of two administrative sources. The first source is annual registration data on juvenile offenders who are sent by the police to participate in the restorative juvenile program Halt. Halt is an organization that is responsible for restorative juvenile justice interventions targeted at first-time offenders and juveniles who committed minor offences. ${ }^{10}$ All juvenile offenders registered in the Halt data have agreed upon their participation in the program and they avoid a criminal record if they complete the program. The second source is the Suspect Identification System (HKS in Dutch) ${ }^{11}$ which contains information on individuals who were arrested on suspicion of committing a crime. ${ }^{12}$ Both the Halt and HKS data

\footnotetext{
${ }^{8}$ For more details see the Ministry of Education, Culture and Science http://www.government.nl/ministries/ocw

9 'Startkwalificatie' in Dutch. For more details see Ministry of Education, Culture and Science (2012).

${ }^{10}$ For more details see http://www.halt.nl and Chapter 4.

${ }^{11}$ HKS is an acronym for Dutch HerKenningsdienstSysteem.

${ }^{12}$ Around 90 percent of individuals in the HKS data plead guilty to the crime they were accused of.
} 
sources contain information on criminal involvement of juveniles aged 10 and older, information of criminal behavior in the past and the severity of the criminal activity.

The explanatory variable is criminal involvement of juveniles. The status of criminal involvement is measured on a yearly basis from 2005 to 2010. The status of criminal involvement has been measured at least one academic year before the establishment of ESL status. This is to make sure that ESL does not precede criminal involvement. We label students as 'criminally involved' if they are observed in either the HKS or Halt data before the event of either ESL or school completion (i.e. obtaining starter's qualification), thereby addressing potential reverse causality. If criminal involvement takes place after the ESL status is defined, the explanatory variable is coded as 0 .

Table 3.1 shows descriptive statistics of the student sample. Panel A presents information on criminal involvement and ESL. 15.4 percent of students were criminally involved between 2005 and 2010. The average registered juvenile crime rate per year in our data is around 3.5 percent, of which around one percent consists of Halt participants. This is in line with the statistics on registered youth crime in the Netherlands for the given period (Van der Laan and Blom, 2011). 0.7 percent of the juveniles in our data were involved in serious criminal activities. ${ }^{13}$ The data also show that six percent of juveniles have repeated criminal involvement. ${ }^{14}$ Figure 3.1 presents the distribution of first criminal involvement by the age of the students in the sample. It shows that students most often become involved in crime when they are aged 15. This is similar to the peak of criminal involvement of individuals in other countries (e.g. Farrington, 1986; Piquero et al., 2007). Figure 3.2 shows the distribution of ESL by the age of students. It is clear from the figure that most students who are early school leavers leave school without obtaining starter qualification when they are 17.

\footnotetext{
${ }^{13}$ Serious criminal behavior is defined using information on two categories of criminal involvement in the HKS data: a serious type and persistent serious type (translated from Dutch). Other two categories: petty criminals and first offenders.

${ }^{14}$ Repeated criminal involvement is also mentioned as recidivism in this chapter.
} 
3. What drives the relationship between criminal involvement and early school leaving?

Table 3-1: Descriptive statistics

\begin{tabular}{|c|c|c|}
\hline Panel A & Mean & Std. Dev. \\
\hline Criminal involvement & 0.154 & 0.361 \\
\hline Serious criminal involvement & 0.007 & 0.085 \\
\hline Recidivist & 0.060 & 0.237 \\
\hline ESL & 0.112 & 0.316 \\
\hline ESL among offenders & 0.203 & 0.402 \\
\hline ESL among non-offenders & 0.096 & 0.294 \\
\hline \multicolumn{3}{|l|}{ Panel B } \\
\hline Grade 1 & 0.332 & 0.471 \\
\hline Grade 2 & 0.335 & 0.472 \\
\hline Grade 3 & 0.333 & 0.471 \\
\hline Age (in October, 2005) & 13.507 & 1.062 \\
\hline Women & 0.494 & 0.500 \\
\hline Born in the Netherlands & 0.947 & 0.223 \\
\hline Parents born in the Netherlands & 0.794 & 0.405 \\
\hline Single parent household & 0.182 & 0.386 \\
\hline More than 5 household members & 0.110 & 0.313 \\
\hline More than one child in household & 0.609 & 0.390 \\
\hline Household with no income & 0.009 & 0.093 \\
\hline Both parents work & 0.630 & 0.483 \\
\hline Primary education mother & 0.056 & 0.231 \\
\hline Secondary education mother & 0.656 & 0.475 \\
\hline Higher education mother & 0.305 & 0.460 \\
\hline Household income (gross) & 62649.63 & 46535 \\
\hline House ownership & 0.683 & 0.465 \\
\hline Urbanized area & 0.501 & 0.500 \\
\hline Sibling (in grade $1,2,3$ ) & 0.242 & 0.429 \\
\hline Twin & 0.026 & 0.159 \\
\hline Same-gender twins & 0.017 & 0.131 \\
\hline Pre-vocational, theoretical & 0.099 & 0.299 \\
\hline Pre-vocational, general & 0.268 & 0.443 \\
\hline Secondary general & 0.106 & 0.308 \\
\hline Pre-university & 0.146 & 0.353 \\
\hline Mixed tracks & 0.380 & 0.485 \\
\hline Retention before 2005 & 0.265 & 0.441 \\
\hline \multicolumn{3}{|l|}{ Panel C } \\
\hline Criminal involvement among siblings & 0.146 & 0.353 \\
\hline Criminal involvement among twins & 0.121 & 0.326 \\
\hline Criminal involvement among same-gender twins & 0.115 & 0.319 \\
\hline ESL among siblings & 0.111 & 0.314 \\
\hline ESL among twins & 0.096 & 0.294 \\
\hline ESL among same-gender twins & 0.093 & 0.292 \\
\hline ESL among sibling offenders & 0.198 & 0.398 \\
\hline ESL among twin offenders & 0.184 & 0.388 \\
\hline ESL among same-gender twin offenders & 0.174 & 0.379 \\
\hline No. obs. & 534.432 & \\
\hline
\end{tabular}


Panel A also shows that 20.3 percent of juvenile offenders become early school leavers whereas this percentage is 9.8 for non-offenders. The average percentage of ESL rate is 11.2. Panel B in Table 3.1 shows the descriptive statistics of individual and household background characteristics, namely, grade cohort, age, gender, the level of urbanization of the area where the student lives, educational level of students, retention status in previous years, working status of (both) parents, single-parent household, household income (gross), education level of the mother, house ownership and the size of the household. Students in our data are on average aged 13.5 in 2005 (12, 13 and 14 years old in the three cohorts, respectively), most of them are born in the Netherlands (95\%) and around half of the students are girls (49\%). The largest share of students in 2005 is still in the mixed track (38\%). Around 37 percent of students are in the pre-vocational education $19.9 \%$ in the theoretical track and $26.8 \%$ in other tracks of pre-vocational education). Around 11 percent of students are in the secondary general education track and around 15 percent of students are in the pre-university track.

We label students as grade repeaters if they are older than they are supposed to be in a certain grade in 2005 (i.e. they turn 13, 14 or 15 in the first, second and third grade of secondary school, respectively, before the $1^{\text {st }}$ of October, which is the cut-off date for school entry in the Netherlands). ${ }^{15}$ From Panel B in Table 3.1. it follows that 26.5 percent of the students repeated a grade before 2005 . As grade retention status is informative about students' academic performance before 2005 , we control for retention status in our analysis, in addition to the covariates presented above.

Using information on the date of birth and the personal identifiers of parents, we identify if students in our sample have (non-)twin siblings studying in the first, second or third cohorts. ${ }^{16}$ Panel B shows that 24.2 percent of the students have a sibling. 2.6 percent of the students are twins (2.159) and 1.7 percent of students are twins of the same-gender (1.187). Panel C presents descriptive statistics for ESL and

\footnotetext{
${ }^{15}$ Retention in this case can also refers to those who delayed school enrolment.

${ }^{16}$ All siblings and twins are identified using information on their legal parents. We assume here that legal parents are also the biological parents.
} 
3. What drives the relationship between criminal involvement and early school leaving?

criminal involvement among siblings, twins and same-gender twins. The rates of ESL and criminal involvement are slightly lower among twins and same-gender twins, but relatively small.

Figure 3-1: Distribution of first criminal involvement by age

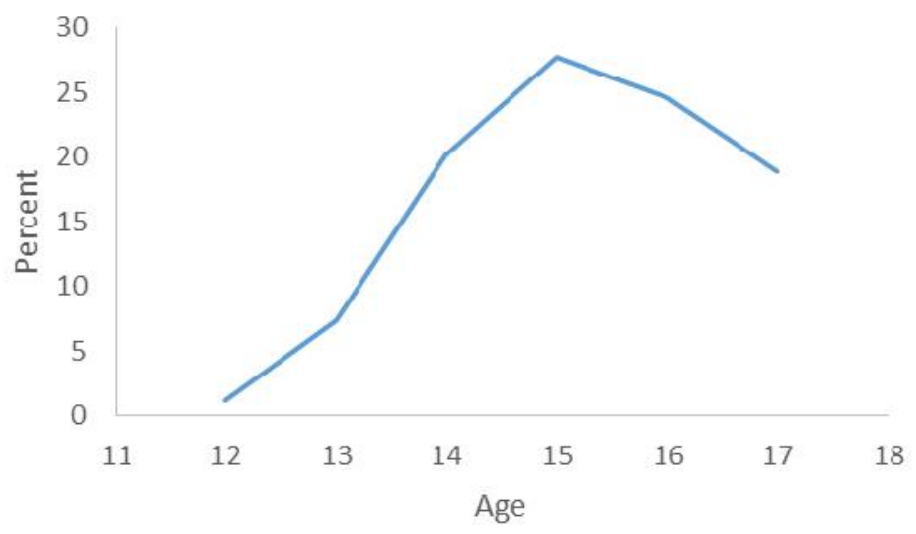

Figure 3-2: Distribution of early school leaving by age

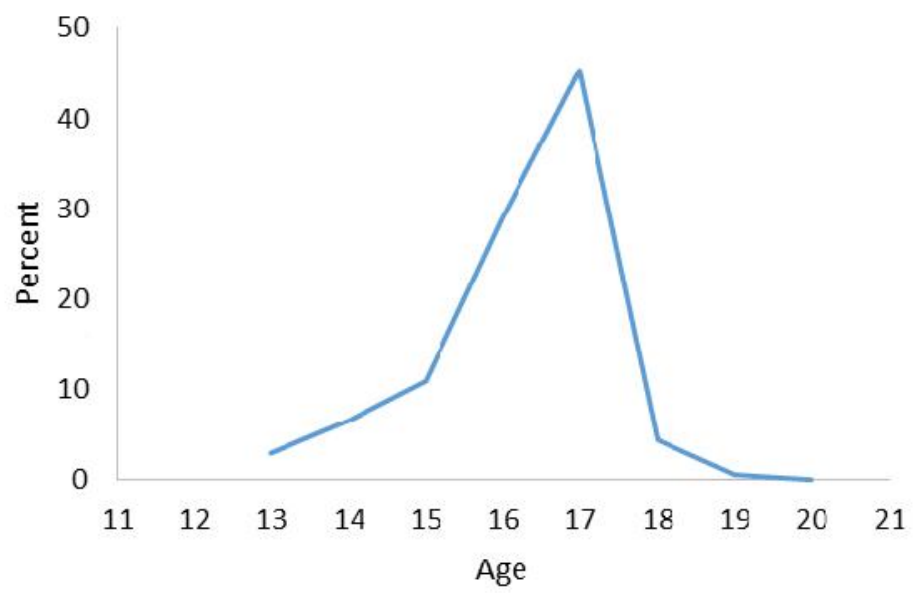




\subsection{Empirical strategy}

ESL is a binary variable and we can use linear probability models or use nonlinear probit models to estimate the effect of criminal involvement on ESL. Angrist and Pischke (2009, p. 103) comment that the estimated marginal effects of a nonlinear model are very similar to the OLS estimates, even though nonlinear (probit, tobit) models may fit the conditional expectation function for limited dependent variables more closely than a linear model. However, they recommend that choosing between non-linear and OLS models, the latter would be more robust and straightforward. ${ }^{17}$ Therefore, we estimate the relationship between criminal involvement and ESL using the following linear regression model: ${ }^{18}$

$$
Y_{i j}=\alpha_{0}+\alpha_{1} D_{i j}+\alpha_{2} X_{i j}+u_{i j}+\varepsilon_{i j}
$$

where $Y_{i j}$ is a variable which indicates 1 if individual $i$ in family $j$ is early school leaver and zero otherwise. The variable $D_{i j}$ indicates if individual $i$ was criminally involved, $X_{i j}$ represents a vector of observed individual and household characteristics, and $\varepsilon_{i j}$ is a random (zero mean) error term. In our baseline model (Model 0), we estimate the association between criminal involvement and ESL without including controls. In Model 1, we include an extensive set of controls (i.e. the household, parent and student characteristics shown in Table 3.1). The estimated relationship may still be influenced by characteristics that are not observed, such as school effects, the family environment, peer effects and genetic endowments. The term $u_{i j}$ represents this unobserved heterogeneity.

In the economic literature, sibling and twin fixed effects approaches have been extensively used to better control for unobserved confounding factors (see an overview in Miller, Mulvey and Martin; Kohler, Behrman and Schnittker, 2010;

\footnotetext{
${ }^{17}$ See also http://www.mostlyharmlesseconometrics.com/2012/07/probit-better-than-lpm/

${ }^{18}$ We have also estimated the marginal effects with a probit model and verified that the results were indeed similar to the OLS results.
} 
Holmlund et al., 2011). The intuition of these analyses is that siblings and twins have an overlap in their genetic makeup (Bouchard, Lykken, McGue, Segal and Tellegen, 1990) and share a similar social environment from the earliest years of life (e.g. McGuire and Segal, 2013). Therefore, using information on siblings and twins provides an opportunity to control for many genetic and socio-economic endowments.

We partially address unobserved heterogeneity by estimating the following fixed effect model:

$$
Y_{i j}=\beta_{0}+\beta_{1} D_{i j}+\beta_{2} X_{i j}+\phi_{j}+e_{i j}
$$

The variables $Y_{i j}, D_{i j}, X_{i j}$ and $\varepsilon_{i j}$ are similar to those in Equation 3.1. The term $\phi_{j}$ represents an unobservable family effects common to all siblings (twins) in family $j$. We estimate four different models in which we use the following specifications of the fixed effects term: school fixed effects (Model 2); sibling fixed effects (Model 3), twin fixed effects (Model 4), and same-gender twin effects (Model $5)$.

We compare the estimation of the parameter of interest of each model with that of the baseline model. In this way, we determine what proportion of the unconditional correlation can be explained by controlling for observable and unobservable factors. Model 2 absorbs unobserved school fixed effects. Model 3 absorbs unobserved (and constant) family effects by controlling for sibling fixed effects.

It is frequently argued that the social environment of non-twin siblings is less similar than the social environment of twins. The timing of birth and the period in which children are raised are different and there can also be parental life-cycle differences, such as parents' age and socio-economic conditions (see Behrman and Taubman, 1976; Behrman, Hrubec, Taubman and Wales, 1980). Dizygotic (DZ, or fraternal) twins share at least 50 percent of their genes, similar to non-twin siblings, while monozygotic ( $\mathrm{MZ}$, or identical) twins share 100 percent of their genes. 
Chapter 3

Additionally, twins are more likely to grow up in a more similar environment than non-twin siblings (see Kohler et al., 2010). We estimate Model 4 and include a fixed effect for twins (both $M Z$ and DZ), which will capture any unobserved heterogeneity specific to twins and not to non-twin siblings. Ideally, we would like to continue in this fashion and estimate a model where we include a fixed effect for $M Z$ twins. The economic literature often uses information on $\mathrm{MZ}$ twins to make inferences about causality (see Holmlund et al., 2011, and references therein). In addition to the higher genetic overlap, MZ twins tend to generate their own environments more similarly than DZ twins (Stenberg, 2013). Parents, moreover, treat MZ twins more similarly (Borkenau et al., 2002). Therefore, the inclusion of a MZ twin fixed effect accounts better for individual-specific effects, in addition to family-specific effects. Our data do not allow identifying identical twins. Nevertheless, we can identify same-gender twins, which increases the share of identical twins in the sample. Therefore, in Model 5, we include a fixed effect for same-gender twins. ${ }^{19}$ It is known that one-third of twins are $\mathrm{MZ}$, one-third are $\mathrm{DZ}$ with the same-gender, and onethird are DZ twins of the opposite gender (e.g. Keith, Papiernik, Keith and Luke, 1995; Torrey, Bowler, Taylor and Gottesman, 1994). We can deduce that around half of the same-gender twins in our sample are expected to be identical. ${ }^{20}$

The relationship between criminal involvement and ESL across subgroups may be different and therefore we estimate the following model:

$$
Y_{i j}=\delta_{0}+\delta_{1} D_{i j}+\delta_{2} D_{i j} Z_{i j}+\delta_{3} Z_{i j}+\delta_{4} X_{i j}+\phi_{j}+e_{i j}
$$

The variables in Equation (3.3) are similar to those included in (3.2) but now interaction terms $Z_{i j}$ are included between the criminal involvement indicator variable and either of the following characteristics: juveniles who committed serious

\footnotetext{
${ }^{19}$ This method has been also used by Holmlund et al. (2011).

${ }^{20}$ Our sample confirms this; the twin sample reduces by exactly one third when we drop twins with different gender.
} 
offenses, recidivists, juveniles who were sent to a restorative justice program, girls, juveniles who live in urban areas and students in vocational education.

Finally, we are interested in how the relationship between criminal involvement and ESL is influenced by the age of first criminal involvement. For this purpose, we generate a set of dummy variables that indicates for each age (in years) whether the student was criminally involved for the first time. We include these indicator variables in the estimation model instead of $L_{i}$. The estimation model thus becomes:

$$
Y_{i j}=\theta_{0}+\sum_{a=12}^{17} \tau_{a} D_{a i j}+\theta_{1} X_{i j}+\phi_{j}+e_{i j}
$$

We note that subscript $a$ in Equation 3.4 denotes the age when a student was criminally involved for the first time, where $a=12$ refers to criminal involvement at age 12 and earlier, and the reference is 'no criminal involvement'.

\subsection{Results}

Our main estimation results are shown in Table 3.2. The unconditional correlation in the first column of Table 3.2 shows that criminal involvement is associated with a 10.7 percentage points increase in ESL. This difference is statistically significant at the one percent level. When we include the extensive set of control variables this association becomes 8.0 percentage points, and remains statistically significant at the one percent level. Model 1, hence, suggests that 25 percent of the unconditional correlation is explained by including observed family and individual background characteristics. 
Chapter 3

Table 3-2: The relationship between criminal involvement and early school leaving (accumulative)

\begin{tabular}{|c|c|c|c|c|c|c|}
\hline & $\begin{array}{l}\text { Without } \\
\text { controls } \\
\text { (0) }\end{array}$ & With controls & $\begin{array}{l}\text { School } \\
\text { FE } \\
(2)\end{array}$ & Sibling FE & Twin FE & $\begin{array}{l}\text { Same- } \\
\text { gender } \\
\text { twin FE } \\
(5)\end{array}$ \\
\hline Crime & $\begin{array}{l}0.107^{* * *} \\
(0.001)\end{array}$ & $\begin{array}{l}0.080^{* * *} \\
(0.001)\end{array}$ & $\begin{array}{l}0.077^{* * *} \\
(0.002)\end{array}$ & $\begin{array}{l}0.051^{* * *} \\
(0.004)\end{array}$ & $\begin{array}{l}0.043 * * * \\
(0.013)\end{array}$ & $\begin{array}{l}0.030^{*} \\
(0.016)\end{array}$ \\
\hline Girl & & $\begin{array}{l}0.008^{* * *} \\
(0.001)\end{array}$ & $\begin{array}{l}0.008^{* * *} \\
(0.001)\end{array}$ & $\begin{array}{l}0.006^{* * * *} \\
(0.002)\end{array}$ & $\begin{array}{l}0.007 \\
(0.008)\end{array}$ & \\
\hline Age & & $\begin{array}{l}0.024^{* * *} \\
(0.001)\end{array}$ & $\begin{array}{l}0.025^{* * *} \\
(0.001)\end{array}$ & $\begin{array}{l}0.020^{* * *} \\
(0.003)\end{array}$ & & \\
\hline Born in NL & & $\begin{array}{l}-0.022^{* * *} \\
(0.002)\end{array}$ & $\begin{array}{l}-0.021^{* * *} \\
(0.003)\end{array}$ & $\begin{array}{l}-0.005 \\
(0.015)\end{array}$ & & \\
\hline $\begin{array}{l}\text { Parents born in } \\
\mathrm{NL}\end{array}$ & & $\begin{array}{l}-0.006^{* *} \\
(0.001)\end{array}$ & $\begin{array}{l}-0.006 * * * \\
(0.002)\end{array}$ & $\begin{array}{l}0.049 \\
(0.096)\end{array}$ & & \\
\hline $\begin{array}{l}\text { Pre-vocational, } \\
\text { theoretical }\end{array}$ & & $\begin{array}{l}-0.022^{* * *} \\
(0.002)\end{array}$ & & $\begin{array}{l}-0.031 * * * \\
(0.005)\end{array}$ & $\begin{array}{l}-0.016 \\
(0.018)\end{array}$ & $\begin{array}{c}-0.046 * * \\
(0.023)\end{array}$ \\
\hline $\begin{array}{l}\text { Pre-vocational, } \\
\text { other tracks }\end{array}$ & & $\begin{array}{l}-0.031 * * * \\
(0.001)\end{array}$ & & $\begin{array}{l}-0.034 * * * \\
(0.004)\end{array}$ & $\begin{array}{c}-0.023^{*} \\
(0.014)\end{array}$ & $\begin{array}{c}-0.017 \\
(0.017)\end{array}$ \\
\hline Senior general & & $\begin{array}{l}-0.051^{* * *} \\
(0.002)\end{array}$ & & $\begin{array}{l}-0.049 * * * \\
(0.004)\end{array}$ & $\begin{array}{l}-0.068^{* * *} \\
(0.016)\end{array}$ & $\begin{array}{c}-0.076^{* * *} \\
(0.020)\end{array}$ \\
\hline Pre-university & & $\begin{array}{l}-0.029 * * * \\
(0.001)\end{array}$ & & $\begin{array}{l}-0.014 * * * \\
(0.004)\end{array}$ & $\begin{array}{l}-0.026 \\
(0.016)\end{array}$ & $\begin{array}{l}-0.030 \\
(0.021)\end{array}$ \\
\hline Other controls & & Yes & Yes & Yes & Yes & Yes \\
\hline Constant & $\begin{array}{l}0.096 * * * \\
(0.001)\end{array}$ & $\begin{array}{l}0.526^{* * *} \\
(0.016)\end{array}$ & $\begin{array}{l}0.514^{* * *} \\
(0.016)\end{array}$ & $\begin{array}{c}-0.142 \\
(0.360)\end{array}$ & $\begin{array}{l}-0.004 \\
(0.156)\end{array}$ & $\begin{array}{l}0.913 * * * \\
(0.113)\end{array}$ \\
\hline $\begin{array}{l}\text { R-sq./R-sq. } \\
\text { (within) }\end{array}$ & 0.0149 & 0.0884 & 0.0780 & 0.0309 & 0.0370 & 0.0339 \\
\hline No. obs. & 534.432 & 534.432 & 534.432 & 129.593 & 13.816 & 9.278 \\
\hline No. variations & & & 63.060 & 25.725 & 2.159 & 1.187 \\
\hline
\end{tabular}

Note: Other controls include retention status, working status of parents, single-parent household, log household income (gross), household with no income, education of mother, house ownership, number of household members, more than one child in the household, the level of urbanization, grade cohort. The reference group for educational levels is practical pre-vocational education. Robust standard errors are presented in parentheses. No. variations refers to variations in criminal status within a set (i.e. set of siblings, twins). Rsq. is estimated for Models $0-1, \mathrm{R}$-sq. within is estimated for Models 2-5. The mean ESL is 0.112 (see Table 3.1). ${ }^{*} \rho \leq 0.1$. ${ }^{* *} \rho \leq 0.05 .{ }^{* * *} \rho \leq 0.01$ 
Model 2 presents the results when we account for school fixed effects. The last row in Table 3.2 presents the number of students whose criminal status varies within a set (i.e. school, siblings and twins). There are 63,060 students that differ in their criminal status within the schools they belong to. The coefficient for criminal involvement is now estimated to be 7.7 percentage points. This suggests that unobserved heterogeneity within schools adds little to the previous estimate in explaining away the unconditional correlation between criminal involvement and ESL (3\%). We further add sibling fixed effects in the analysis to account for family effects. The number of siblings in our sample is 129,593 and in 25,725 cases siblings have a different criminal involvement status (see the last two rows in Table 3.2). ${ }^{21}$ There is a statistically significant positive association between criminal involvement and ESL in the magnitude of 5.1 percentage points. This indicates that an additional 24 percent of the unconditional correlation can be attributed to unobservable family specific characteristics. Model 3 examines twin fixed effects for a sample of 13,816 twins, where 2,159 twins (both $\mathrm{MZ}$ and $\mathrm{DZ}$ ) have a different criminal involvement status. The estimated association for this subsample is now 4.3 percentage points and it is statistically significant. We conclude that eight percent of the unconditional correlation between criminal involvement and ESL can be attributed to genetic and environmental factors that are twin specific. Model 5 uses information on samegender twins, as the probability that we observe more identical twins in the sample becomes higher. The same-gender twin sample contains information on 9,278 twins and 1,187 of them differ in their criminal involvement status. The estimated positive association of three percentage points is marginally statistically significant. This result implies that an additional 12 percent of the unconditional correlation can be

\footnotetext{
${ }^{21}$ The number of observations used in the analysis reduces when we estimate the sibling and twin fixed effects models. In the robustness section, we therefore estimate a simple OLS model for the different subsamples considered, and examine whether the estimated associations between criminal involvement and crime are similar for the different subsamples. The results are shown in Table 3.6.
} 
Chapter 3

attributed to genetic and environmental factors that are specific for same-gender twins.

The estimate that remains after controlling for same-gender twin effects can either represent factors that differ between same-gender twins and affect both crime and education or a true effect from the interaction with criminal justice. The difference between Models 4 and 5 represents an increase in the share of identical twins from 33 to 50 percent, which leads to a larger average genetic overlap (from approximately $67 \%$ to $75 \%$ ) as well as a possibly larger similarity in environmental factors. One could extrapolate from this that a sample of only identical twins would lead to a near-zero estimate. However, these are point estimates with a substantial confidence interval. In fact, the results from Models 4 and 5 are not statistically significantly different from each other. Nevertheless, Model 5 does not account for all possible confounding factors and therefore can still be driven by selection. Any possible direct causal effect from criminal involvement to ESL is likely to be very small.

Figure 3.3, graphically presents the factors that explain the relationship between adolescent criminal involvement and ESL. We emphasize that the values in the figure refer to the additional explained variation, compared to the model including only the previous factors. It is difficult however to decompose the role of school factors from family factors from the estimates presented in Table 3.2 and Figure 3.3, because observable characteristics included in the model with school fixed effects and family fixed effects (e.g. working status of parents, single-parent household, education of mother, household characteristics, see note to Table 3.2) can be already a part of school and family characteristics or correlated with these characteristics. The order in which the control variables are entered into the regression also matters. We therefore also analyze how much would school and family fixed effects explain if they are added separately, while controlling only for age, gender and ethnicity. The results are presented in Table 3.3. Model 1 shows that seven percent of the unconditional correlation between early criminal involvement and ESL is explained by controlling for the very basic controls, age, 
3. What drives the relationship between criminal involvement and early school leaving?

gender and ethnicity. Model 2 shows that using school fixed effects adds relatively little in further explaining the relationship between youth crime and ESL, only additional seven percent. Family characteristics, estimated using sibling fixed effects explain a large part of the unconditional correlation between early criminal involvement and ESL, 43 percent in addition to seven percent explained by Model 1. Using twin fixed effects shows very similar results compared to the results of the sibling fixed effects model: 44 percent of the unconditional correlation is explained next to the seven percent already explained by Model 1. Finally, controlling for same-gender twin fixed effects explains up to 65 percent of the unconditional correlation between criminal involvement and ESL, in addition to the already explained share from Model 1.

Figure 3-3: Factors that explain the relationship between criminal involvement and early school leaving

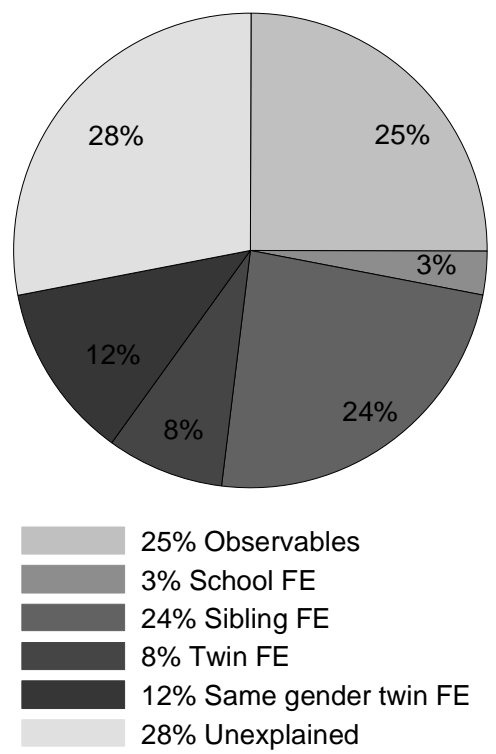


Table 3-3: The relationship between criminal involvement and early school leaving (separate)

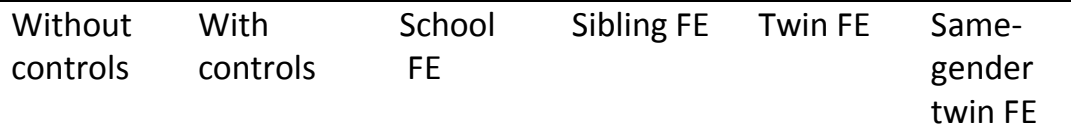

\begin{tabular}{lllllll} 
& $(0)$ & $(1)$ & $(2)$ & $(3)$ & $(4)$ & $(5)$ \\
\hline Crime & $0.107^{* * *}$ & $0.099^{* * *}$ & $0.093^{* * *}$ & $0.054^{* * *}$ & $0.052^{* * *}$ & $0.029^{*}$ \\
& $(0.001)$ & $(0.001)$ & $(0.002)$ & $(0.004)$ & $(0.013)$ & $(0.017)$ \\
Girl & & $0.010^{* * *}$ & $0.009^{* * *}$ & $0.006^{* * *}$ & 0.002 & \\
& & $(0.001)$ & $(0.001)$ & $(0.002)$ & $(0.008)$ & \\
Age & & $0.026^{* * *}$ & $0.023^{* * *}$ & $0.021^{* * *}$ & & \\
& & $(0.001)$ & $(0.001)$ & $(0.002)$ & & \\
Born in NL & & $-0.041^{* * *}$ & $-0.036^{* * *}$ & -0.003 & & \\
& & $(0.003)$ & $(0.003)$ & $(0.015)$ & & \\
Parents born in NL & & $-0.025^{* * *}$ & $-0.015^{* * *}$ & 0.056 & & \\
& & $(0.001)$ & $(0.002)$ & $(0.099)$ & & \\
Constant & $0.096^{* * *}$ & $-0.223^{* * *}$ & $-0.072^{* * *}$ & $-0.260^{* * *}$ & $0.086^{* * *}$ & $0.081^{* * *}$ \\
& $(0.001)$ & $(0.012)$ & $(0.015)$ & $(0.088)$ & $(0.015)$ & $(0.018)$ \\
R-sq./R-sq. & 0.0149 & 0.0213 & 0.0145 & 0.0052 & 0.0032 & 0.0011 \\
(within) & & & & & & \\
\hline No. obs. & 534.432 & 534.432 & 534.432 & 129.593 & 13.816 & 9.278 \\
\hline No. variation & & & 63.060 & 25.725 & 2.159 & 1.187 \\
\hline
\end{tabular}

Note: The reference group for educational levels is practical pre-vocational education. Robust standard errors are presented in parentheses. No. variations refers to variations in criminal status within a set (i.e. set of siblings, twins). R-sq. is estimated for Models 0-1, R-sq. within is estimated for Models 2-5. The mean ESL is 0.112 (see Table 3.1). ${ }^{*} \rho \leq 0.1$. ${ }^{* *} \rho \leq 0.05$. ${ }^{* * * *} \rho \leq 0.01$

\subsection{Heterogeneity in the relationship between early criminal involvement and early school leaving}

The estimation results of Equation 3.3 are presented in Table 3.4. Panel A of this table suggests that the association between criminal involvement and ESL is stronger (21.3 percentage points in the same-gender twin sample) if students were involved in severe criminal activities. This result is in line with previous studies that find that serious criminal activities in adolescence, measured by incarceration, are likely to reduce the probability of graduation from high school by 26 or 13 (compared to the mean incarceration rate 0.023 and 0.10 , respectively) percentage points 
3. What drives the relationship between criminal involvement and early school leaving?

(Hjalmarsson, 2008; Aizer and Doyle, 2013, respectively). ${ }^{22}$ Interestingly, the estimated difference in the effect between severe and overall criminal behavior is rather similar in all estimation models. Most importantly, the coefficient of the interaction term does not change much when moving from Model 1 to 3 , while there is a rapid change in the estimated effect of the overall criminal involvement, in particular from Model 2 to Model 3. Hence, the estimated difference appears not to be driven by observable characteristics or unobserved family fixed effects. The estimates from Model 4 and Model 5 are imprecisely estimated and therefore somewhat inconclusive. The consistency in the coefficient between Model 1, Model 2 and Model 3 relies on very small standard errors, however. Hence, the consistently stronger estimate for severe crime can possibly represent a true treatment effect of crime on ESL, for example through an interruption in the educational process due to interaction with criminal justice, stigma effects or accumulation of criminal capital.

Panel B shows how the association between criminal involvement and ESL differs between juveniles who were sent to the restorative justice program Halt for a minor criminal offense and students in traditional juvenile justice. Restorative justice is targeted at students who were involved in relatively less serious crimes. The Halt program can have a spillover effect on education outcomes, which can potentially counter any negative association between crime and ESL. In particular, in Chapter 4 we show that participation in the Dutch restorative justice program Halt reduces ESL among juvenile first offenders who committed a minor criminal offense. The coefficient for the interaction term indicates that ESL is lower for students who went to restorative justice. However, this coefficient is dropping steadily, and hence it is likely to reflect selection. Panel $\mathrm{C}$ compares reoffending juveniles with juveniles who were criminally involved only once. Recidivists more often leave school early but the results suggest that this is mainly due to selection.

Panel $D$ and $E$ show how the association between criminal involvement and ESL differs between boys and girls and students in urban and non-urban areas. The estimation results show that the associations between crime and ESL is stronger for

\footnotetext{
${ }^{22}$ See Chapter 2 for more details on the methods used in these two studies.
} 
Chapter 3

boys and those in urban areas, but these differences are low and become statistically insignificant in more extended models.

Table 3-4: The relationship between criminal involvement and early school leaving across different demographic groups

\begin{tabular}{|c|c|c|c|c|c|c|}
\hline & $\begin{array}{l}\text { Without } \\
\text { controls } \\
(1)\end{array}$ & $\begin{array}{l}\text { With } \\
\text { controls } \\
(2)\end{array}$ & $\begin{array}{l}\text { School FE } \\
(3)\end{array}$ & $\begin{array}{l}\text { Sibling FE } \\
(4)\end{array}$ & $\begin{array}{l}\text { Twin FE } \\
\text { (5) }\end{array}$ & $\begin{array}{l}\text { Same-gender } \\
\text { twin FE (6) }\end{array}$ \\
\hline \multicolumn{7}{|c|}{ Panel A } \\
\hline \multirow[t]{2}{*}{ Crime } & $0.096 * * *$ & $0.073 * * *$ & $0.071 * * *$ & $0.046 * * *$ & $0.040 * * *$ & $0.027^{*}$ \\
\hline & $(0.001)$ & $(0.001)$ & $(0.002)$ & $(0.004)$ & $(0.013)$ & (0.016) \\
\hline Crime * & $0.239 * * *$ & $0.164 * * *$ & $0.155^{* * *}$ & $0.161 * * *$ & $0.130 *$ & $0.183^{* *}$ \\
\hline Serious & $(0.008)$ & $(0.008)$ & (0.009) & (0.020) & $(0.076)$ & (0.091) \\
\hline \multicolumn{7}{|c|}{ Panel B } \\
\hline \multirow[t]{2}{*}{ Crime } & $0.141 * * *$ & $0.101 * * *$ & $0.099 * * *$ & $0.066 * * *$ & $0.066 * * *$ & $0.037^{*}$ \\
\hline & $(0.002)$ & $(0.002)$ & $(0.002)$ & $(0.006)$ & $(0.018)$ & $(0.020)$ \\
\hline Crime * & $-0.064 * * *$ & $-0.041 * * *$ & $-0.041 * * *$ & $-0.027 * * *$ & $-0.041^{*}$ & -0.012 \\
\hline \multirow[t]{2}{*}{ Halt } & $(0.003)$ & $(0.003)$ & $(0.003)$ & $(0.007)$ & $(0.022)$ & $(0.026)$ \\
\hline & \multicolumn{6}{|c|}{ Panel C } \\
\hline \multirow[t]{2}{*}{ Crime } & $0.061 * * *$ & $0.048 * * *$ & $0.046 * * *$ & $0.030 * * *$ & $0.033^{* *}$ & 0.025 \\
\hline & $(0.002)$ & $(0.002)$ & $(0.002)$ & $(0.005)$ & $(0.014)$ & (0.018) \\
\hline Crime $*$ & $0.119 * * *$ & $0.087 * * *$ & $0.085^{* * *}$ & $0.065 * * *$ & 0.038 & 0.017 \\
\hline \multirow[t]{2}{*}{ Recidivism } & $(0.003)$ & $(0.003)$ & $(0.003)$ & $(0.008)$ & $(0.026)$ & $(0.032)$ \\
\hline & \multicolumn{6}{|c|}{ Panel D } \\
\hline \multirow[t]{2}{*}{ Crime } & $0.111^{* * *}$ & $0.083 * * *$ & $0.079 * * *$ & $0.054 * * *$ & $0.038 * *$ & 0.020 \\
\hline & $(0.002)$ & $(0.002)$ & $(0.002)$ & $(0.005)$ & $(0.015)$ & (0.018) \\
\hline \multirow[t]{2}{*}{ Crime*Girl } & $-0.006^{*}$ & $-0.010 * * *$ & $-0.009 * * *$ & -0.013 & 0.017 & 0.037 \\
\hline & $(0.003)$ & $(0.003)$ & $(0.003)$ & $(0.010)$ & $(0.029)$ & $(0.038)$ \\
\hline \multicolumn{7}{|c|}{ Panel E } \\
\hline \multirow[t]{2}{*}{ Crime } & $0.093 * * *$ & $0.073 * * *$ & $0.069 * * *$ & $0.045^{* * *}$ & $0.040 * *$ & 0.023 \\
\hline & $(0.002)$ & $(0.002)$ & $(0.002)$ & $(0.006)$ & $(0.018)$ & $(0.021)$ \\
\hline Crime & $0.022 * * *$ & $0.012 * * *$ & $0.013 * * *$ & 0.011 & 0.006 & 0.013 \\
\hline \multirow[t]{2}{*}{ *Urban } & $(0.003)$ & $(0.003)$ & $(0.003)$ & $(0.008)$ & $(0.025)$ & $(0.032)$ \\
\hline & & \multicolumn{5}{|c|}{ Panel F } \\
\hline Crime & $0.098 * * *$ & $0.068 * * *$ & $0.066 * * *$ & $0.043 * * *$ & $0.031^{*}$ & 0.014 \\
\hline & $(0.002)$ & $(0.002)$ & $(0.002)$ & (0.005) & $(0.018)$ & $(0.022)$ \\
\hline Crime & $0.018 * * *$ & $0.027^{* * *}$ & $0.022 * * *$ & $0.018 * *$ & 0.026 & 0.033 \\
\hline *Vocat. edu & $(0.003)$ & $(0.003)$ & $(0.003)$ & $(0.008)$ & $(0.025)$ & (0.031) \\
\hline No. obs. & 534.432 & & & & & \\
\hline
\end{tabular}

Note: Controls include age, gender, country of birth, parents' country of birth, retention status, working status of parents, single-parent household, log household income (gross), household with no income, education of mother, house ownership, number of household members, more than one child in the household, the level of urbanization, grade cohort. Robust standard errors are presented in parentheses. " $\rho \leq 0.1,{ }^{* * *} \rho \leq 0.05,{ }^{* * * *} \rho \leq 0.01$ 
3. What drives the relationship between criminal involvement and early school leaving?

In Panel $\mathrm{F}$ we discarded information on criminal involvement from grades 1 and 2 because juveniles can still be assigned to a specific educational track after the first year of secondary education (see also Table 3.1). Accordingly, we have recoded the status of criminal involvement from grade 3 and higher to make sure that criminal involvement did not affect tracking. The estimation results suggest that the relation between criminal involvement and ESL is (slightly) higher for juveniles in vocational education. The coefficient of the interaction term changes little across the estimated models, although it is not statistically significantly different from zero in the last two columns, because of the relatively high imprecision of those estimates.

\subsection{First criminal involvement}

Webbink et al. (2013) find that arrest between the ages of 13 and 15 has a stronger effect on educational attainment compared to arrest at older ages. We estimate Equation 3.4 to examine whether the timing of first criminal involvement matters for the estimated association between criminal involvement and ESL. The estimates presented in Table 3.5 show that the unconditional correlation between criminal involvement at early ages and ESL is stronger compared to criminal involvement in later adolescence. These estimates, however, converge after we control for background characteristics, and sibling and twin fixed effects. Moreover, the estimate for first criminal involvement at age 17 and later becomes statistically insignificant when we include sibling fixed effects. The estimates for crime at other ages are all statistically insignificant in the final column, but this is because of the high imprecision of those results. 
Chapter 3

Table 3-5: The relationship between age at first criminal involvement and early school leaving ${ }^{23}$

$\begin{array}{llllll}\begin{array}{l}\text { Without } \\ \text { controls }\end{array} & \begin{array}{l}\text { With } \\ \text { controls }\end{array} & \text { School FE } & \text { Sibling FE } & \text { Twin FE } & \begin{array}{l}\text { Same- } \\ \text { gender } \\ \text { twin FE }\end{array}\end{array}$

\begin{tabular}{lllllll} 
& $(0)$ & $(1)$ & $(2)$ & $(3)$ & $(4)$ & $(5)$ \\
\hline Crime at age 12 & $0.185^{* * *}$ & $0.138^{* * *}$ & $0.140^{* *}$ & $0.088^{* *}$ & 0.203 & - \\
and earlier & $(0.018)$ & $(0.016)$ & $(0.016)$ & $(0.038)$ & $(0.181)$ & \\
Crime at age 13 & $0.144^{* * *}$ & $0.099^{* * *}$ & $0.100^{* * *}$ & $0.060^{* * *}$ & 0.004 & 0.069 \\
& $(0.007)$ & $(0.006)$ & $(0.006)$ & $(0.018)$ & $(0.060)$ & $(0.071)$ \\
Crime at age 14 & $0.121^{* * *}$ & $0.089^{* * *}$ & $0.084^{* * *}$ & $0.056^{* * *}$ & $0.084^{* *}$ & 0.069 \\
& $(0.004)$ & $(0.004)$ & $(0.004)$ & $(0.011)$ & $(0.034)$ & $(0.043)$ \\
Crime at age 15 & $0.093^{* * *}$ & $0.074^{* * *}$ & $0.071^{* * *}$ & $0.053^{* * *}$ & 0.032 & 0.033 \\
& $(0.003)$ & $(0.003)$ & $(0.003)$ & $(0.009)$ & $(0.029)$ & $(0.038)$ \\
Crime at age 16 & $0.068^{* * *}$ & $0.061^{* * *}$ & $0.056^{* * *}$ & $0.052^{* * *}$ & $0.065^{* *}$ & 0.059 \\
& $(0.034)$ & $(0.003)$ & $(0.003)$ & $(0.009)$ & $(0.027)$ & $(0.036)$ \\
Crime at age 17 & $0.034^{* * *}$ & $0.034^{* * *}$ & $0.032^{* * *}$ & 0.016 & 0.008 & -0.013 \\
and later & $(0.003)$ & $(0.003)$ & $(0.004)$ & $(0.010)$ & $(0.027)$ & $(0.031)$ \\
Constant & $0.096^{* * *}$ & $0.582^{* * *}$ & $0.570^{* * *}$ & -0.321 & -0.008 & 0.943 \\
& $(0.001)$ & $(0.016)$ & $(0.017)$ & $(0.288)$ & $(0.187)$ & $(0.121)$ \\
R-sq./R-sq. & 0.009 & 0.0779 & 0.0697 & 0.0249 & 0.0358 & 0.0383 \\
(within) & & & & & & \\
No. obs. & 534.432 & 534.432 & 534.432 & 129.593 & 13.816 & 9.278 \\
\hline
\end{tabular}

Note: Controls include age, gender, country of birth, parents' country of birth, retention status, working status of parents, single-parent household, log household income (gross), household with no income, education of mother, house ownership, number of household members, more than one child in the household, the level of urbanization, grade cohort. Robust standard errors are presented in parentheses. R-sq. is estimated for Models 0-1, Rsq. within is estimated for Models 2-5. ${ }^{*} \rho \leq 0.1,{ }^{* *} \rho \leq 0.05,{ }^{* * * *} \rho \leq 0.01$

${ }^{23}$ The reference group is 'no criminal involvement' 
3. What drives the relationship between criminal involvement and early school leaving?

\subsection{Sensitivity analysis}

The number of observations across Models 2 to 5 decreases in every step. Therefore, differences in estimates across the estimation models can also reflect differences in sample composition. In this section, we therefore estimate the model without fixed effects but with controls (i.e. Model 1) for the different sibling and twin subsamples that we consider. The results presented in Table 3.6 show that the estimates for all different subsamples are similar. In addition, we find (using interaction terms) that the effects of criminal involvement on ESL are not statistically significantly different between students who have a sibling, a twin sibling or do not have any siblings in the sample.

Table 3-6: The relationship between criminal involvement and early school leaving across different samples (no fixed effects models)

\begin{tabular}{llllll}
\hline & $\begin{array}{l}\text { Without } \\
\text { controls }\end{array}$ & $\begin{array}{l}\text { With } \\
\text { controls } / \\
\text { School }\end{array}$ & Siblings & Twins & $\begin{array}{l}\text { Same- } \\
\text { gender } \\
\text { twins }\end{array}$ \\
\hline Crime & $(0)$ & $(1-2)$ & $(3)$ & $(4)$ & $(5)$ \\
Constant & $0.107^{* * *}$ & $0.080^{* * *}$ & $0.081^{* * *}$ & $0.082^{* * *}$ & $0.079^{* * *}$ \\
& $(0.001)$ & $(0.001)$ & $(0.003)$ & $(0.010)$ & $(0.012)$ \\
R-sq. & $0.095^{* * *}$ & $0.526^{* * *}$ & $0.536^{* * *}$ & $0.672^{* * *}$ & $0.721^{* * *}$ \\
\hline No. obs. & $(0.001)$ & $(0.016)$ & $(0.033)$ & $(0.096)$ & $(0.114)$ \\
\hline & 0.0149 & 0.0884 & 0.0812 & 0.0934 & 0.1034 \\
\hline
\end{tabular}

Note: Controls include age, gender, country of birth, parents' country of birth, retention status, working status of parents, single-parent household, log household income (gross), household with no income, education of mother, house ownership, number of household members, more than one child in the household, the level of urbanization, grade cohort. Robust standard errors are presented in parentheses. " $\rho \leq 0.1, " * \rho \leq 0.05,{ }^{* * *} \rho \leq 0.01$

\subsection{Discussion}

In this chapter we have analyzed the relationship between adolescent criminal involvement and ESL and which factors underlie this relationship. Various models are estimated in which we control for observable family and individual characteristics, 
school fixed effects, sibling fixed effects, twin fixed effects, and same-gender twin fixed effects.

We find that around seven percent of the unconditional correlation between criminal involvement and ESL can be explained by the very basic background characteristics, age, gender and ethnicity (Model 1). Controlling for school fixed effects also explains seven percent in addition to the already explained share from Model 1. Controlling for sibling fixed effects adds 43 percent to explaining the unconditional correlation between criminal involvement and ESL, next to already explained seven percent from Model 1. The twin fixed effects model adds little to extra explanatory power of the unconditional correlation comparing to the sibling fixed effects model. At the same time, controlling for same-gender twin fixed effects explains up to 65 percent of the unconditional correlation between criminal involvement and ESL, in addition to already explained seven percent from Model 1. We conclude that the largest part (72\%) of the association between adolescent criminal involvement and ESL can be explained by observable and unobservable heterogeneity for which the same-gender twin model can account for. We also conclude that family-specific characteristics and factors that are common to samegender twin but not common to siblings play a crucial role in explaining the unconditional correlation between criminal involvement and ESL, while the role of school specific characteristics is relatively low. A part of the unconditional correlation (28\%) remains unexplained. This can either represent uncontrolled differences (e.g. remaining genetic differences in fraternal twins, differences in the generated environments among twins) or a true treatment effect of adolescent criminal involvement on ESL. The results show that, even if there is a true treatment effect of juvenile crime on ESL, it is likely to be small. One, however, can argue that criminal involvement of one twin in the family can affect the educational outcomes of another twin, and therefore it is also possible that the true treatment effect of criminal involvement on ESL is underestimated in models that use twin fixed effects (see Sacerdote, 2010). 
We further find that the association between serious criminal behavior and ESL is stronger than between overall criminal involvement and ESL. The heterogeneity analysis shows that the estimate for this difference remains constant across different estimation models, in contrast to the base estimate for general criminal involvement which strongly reduces in the sibling and twin fixed effect models. The estimated difference between overall and severe crime does not appear to be driven by selection. We conclude that it is likely that at least part of the association between severe crime and ESL represents a causal effect. If the difference between severe crime and overall crime is causal, then the total effect of severe crime would be causal as well, unless the base effect of overall crime is negative, which is very unlikely.

In this chapter, we do not measure crimes that remain undiscovered, which are substantially more prevalent, according to information from self-reported surveys (see Van der Laan and Blom, 2011). Future studies can assess how the estimates differ from our results for registered crimes, by combining information on registered and self-reported youth crime. Further research can also focus on assessing the relationship between criminal involvement and measures of school performance, like test scores. 



\section{The effect of restorative juvenile justice on future educational outcomes ${ }^{24}$}

\subsection{Introduction}

In Chapter 2, we have discussed evidence showing that intervention programs have the potential to favorably influence both criminal and educational outcomes, often simultaneously. In this chapter we empirically analyze whether an intervention study that is targeted towards criminally involved juveniles can affect their educational outcomes. In particular, we evaluate the effects of a Dutch restorative justice program on early school leaving (ESL) and years of education.

Restorative justice is frequently referred to as intermediate punishment (Morris and Tonry, 1990), community justice (Bazemore and Schiff, 1996) or alternative sanctions (Kahan, 1996), and it is becoming more prevalent in many developed countries (e.g. the US, Canada, Australia, the UK and the Netherlands, Denmark). It refers to a process of resolving crime by focusing on redressing the harm done to the victims, holding offenders responsible for their actions and engaging the community in the conflict resolution (Dandurand and Griffiths, 2006). Restorative juvenile justice programs aim to reduce recidivism among delinquent adolescents. Despite the growing popularity of these programs, the effect on recidivism is measured mainly for short-term outcomes and the evidence is rather ambiguous (e.g. Bradshaw and Roseborough, 2005; Hayes, 2005; Sherman and

${ }^{24}$ This chapter is based on Rud, I., Van Klaveren, C., Groot, W. and Maassen van den Brink, H. (2014). The effect of restorative juvenile justice on future educational outcomes. TIER Working Paper Series 14/01, 1-31 
Strang, 2007). To our knowledge, there are no (quasi)-experimental studies that have examined the effects of such programs on educational outcomes.

Halt is a Dutch organization that is responsible for restorative justice in the Netherlands and that is integrated in the national justice system. Halt deals with first-time offenders and petty offenders aged between 12 and 18 years who committed a non-violent crime. As most restorative juvenile justice programs, it relies on sociological theories of criminal behavior and aims to change the behavior and the attitudes of juvenile offenders by addressing their (cognitive and socioemotional) developmental problems. The main objectives of the program is reducing reoffending behavior among juvenile delinquents.

In 2003 a unique field experiment was conducted by the Dutch Ministry of Security and Justice to examine the effects of Halt on recidivism. The experimental results overall show that one year participation in the Halt program does not reduce criminality and behavioral problems for juveniles (Ferwerda et al., 2006). At the same time, the authors conclude that the effects of the Halt intervention are heterogeneous with respect to type of offenders and type of Halt assignment. In particular, Halt participants who either committed criminal offenses under peer pressure, or those who apologized to the victim, or juveniles who participated in the Halt learning assignments (or a combination of community service and learning assignments) committed statistically significantly fewer and less serious offenses than juveniles from the control group.

We link the Halt experimental data to educational registration data of Statistics Netherlands (CBS) to evaluate the long-term program effects on ESL and years of education. 1,064 juveniles who were apprehended by the police for firsttime, non-violent, and minor offenses were offered a chance to participate in the Halt experiment. Juveniles had an incentive to participate because it prevented further prosecution by a public prosecutor. 944 juveniles agreed to participate in the experiment and these juveniles were randomly assigned to Halt and to a control group. 
The empirical findings show that participating in the Halt program statistically significantly reduces ESL by 5.9 percentage points and statistically significantly increases completed years of education by 0.29 years. The estimated program effect on ESL is substantial and it represents a reduction in ESL by 30.4 percent (i.e. a reduction from 0.181 to 0.122 ). We find that the program is less effective for group offenders which may point to negative peer-offender effects. The other heterogeneous treatment effects are imprecisely estimated but allow for some suggestive conclusions. Halt appears to be more effective for boys and juveniles with non-Dutch parents. It also appears to be less effective for juveniles living in single parents household. Overall, our results support that criminal intervention programs can improve educational outcomes.

This chapter has several contributions to the literature. First of all, to our knowledge, the effect of a restorative juvenile justice program on educational outcomes has not been evaluated in experimental settings yet. The Halt intervention appears to be representative for restorative juvenile justice programs internationally, and therefore the results of this chapter are informative for the potential effects that such programs may have in other countries. Secondly, the data we use allow to examine the medium- and long-term program effects instead of only the short-term program effects, as is often the case in randomized field experiments (see e.g. Reynolds, Mann, Miedel and Smokowski, 1997). Finally, the empirical findings of this chapter contribute to the debate on the value of restorative juvenile justice programs around the world (Carreira Da Cruz, 2010). Restorative juvenile justice programs are implemented on a large scale, while there is no consistent evidence that they reduce reoffending (see Miers et al., 2001; Bradshaw and Roseborough, 2005; Sherman and Strang, 2007) or (until now) that they improve educational outcomes. Nevertheless, the costs of the Halt intervention per person are estimated to be $€ 485$ (and $€ 375$ per petty offences) (KPMG, 2011). We translate the estimated effect sizes into the costs per prevented early school leaver.

This chapter consists of six sections. Section 4.2 describes the restorative justice program Halt. Section 4.3 discusses the experimental design of the study. 
Chapter 4

Section 4.4 describes the data and descriptive statistics. Section 4.5 shows and discusses the estimation strategy and empirical findings. Finally, Section 4.6 concludes.

\subsection{Restorative juvenile justice intervention Halt}

In 1981, bureau Halt was initiated with the aim to combat and prevent vandalism among juveniles. In 1995 it was integrated into the Dutch juvenile justice system. According to the Dutch Ministry of Security and Justice, it is important to address these problems at an early stage to prevent juveniles from committing more serious offenses. As a consequence, Halt is intended for juvenile offenders who were apprehended by the police for committing a minor first-time offence. The program aims to change the behavior and attitudes of these juvenile by addressing their behavioral and development problems. In Appendix A, in Table A.1 we present the list of offenses for which juvenile offenders can be sent to Halt. ${ }^{25}$

Juvenile offenders who are apprehended by the police for a Halt-worthy offense are directly referred to the Halt bureau where they are screened by social work professionals and confronted with the motives and consequences of their criminal behavior. Then, they are presented with a choice of participating in the Halt program or being prosecuted in the traditional juvenile justice (i.e. being sent to the public prosecutor). Taking the committed offense into account, Halt professionals develop individual programs that include sessions with juvenile offenders and their parents. This results in a tailor-made punishment program that consists of the following components: community work (e.g. cleaning, repairing, administrative work in the neighborhood), learning assignments (e.g. writing an essay or apology letter, discussion sessions with a Halt professional, following Aggression Replacement Training), financially compensating the damage that was done, and meeting with the victims. A crucial component of the program is that juveniles have

\footnotetext{
${ }^{25}$ See also the website of Halt at http://www.halt.nl/index.cfm/site/Halt English
} 
to apologize to their victims. Victims explain how they were affected by the criminal offense, such that juveniles are directly confronted with the consequences of their behavior.

The average duration of the Halt program is one year and the average time spent on learning assignments and community work are 4 and 8 hours per week outside the school hours, respectively. Community work assignments vary between 1 and 20 hours and learning assignments vary between 1 and 8 hours per week. The variation in time-intensity depends on the committed criminal offense and on the diagnosed emotional or behavioral problems of the offender by the Halt professionals. For example, juvenile offenders who committed property crime, shoplifting, arson and demolition receive the longest working assignment (e.g. cleaning, working in the shop), which varies between 18 and 20 hours per week. The longest learning assignment ( 6 to 8 hours per week) is mainly given for offenses such as demolition, shoplifting, property crime, handling of stolen goods and reckless behavior.

The program is built on several sociological theories of criminal behavior (see Ferwerda et al., 2006). We shortly elaborate on the three main sociological theories that underlie Halt: (I) social learning theory (Bandura, 1969), (II) reintegrative shaming theory (Braithwaite, 1989), and (III) strain theory (Merton, 1957; Cloward and Ohlin, 1960). According to social learning theory, criminal behavior is acquired through observational learning and it depends largely on social and environmental factors. Therefore, Halt confronts juveniles with their criminal behavior through learning assignments. These learning assignments teach juvenile offenders how to reflect on their own behavior and show them behavioral 'role models' in order to improve their antisocial behavior. If necessary, first-time juvenile offenders receive training, such that they are better able to handle their behavioral disturbances. For example, juveniles who tend to behave aggressively follow an Aggression Replacement Training (ART), which is an evidence based cognitive behavioral intervention that aims to improve social skill competences and moral reasoning, 
Chapter 4

improve anger management, and reduce aggressive behavior (see, among others, Goldstein and Glick, 1994, 1999).

Reintegrative Shaming Theory (RST) emphasizes the important role of guilt and shame feelings for conscience formation and for the observed behavior of firsttime offenders. The neuropsychological literature shows that the part of the brain that controls reasoning and impulses (Prefrontal Cortex) does not fully mature until the age of 25 , and consequently adolescents are not able to oversee what the consequences of their actions are for others and for themselves (see, for example, Bogin, 1999; Paus, 2005). This explains why adolescents have a strong preference for high excitement and low effort activities (Steinberg, 2005). Because feelings of guilt and shame during adolescence play an important role in conscience formation, it is believed that a program that focuses on these feelings, instead of confronting adolescents only with the (long-term) consequences of their actions, is more effective in improving antisocial behavior. This is the reason why first-time juvenile offenders must apologize to their victims, if possible, so that they feel how victims were affected.

According to the strain theory individuals can be driven into criminal activities as a result of social pressure, or because it is not possible to achieve the desired status and goals in a legal way. It is well known that social deprivation highly correlates with juvenile delinquency (see, among others, Utting, Bright and Henricson, 1993), and the investments of parents in their children's education are relatively low in socially deprived neighborhoods. Evidence shows that many interventions for children and adolescents with low socio-economic status can simultaneously improve several social outcomes, among them, criminal behavior and educational attainment (e.g. Perry Preschool program, the Chicago Child-Parent Center, Head Start, the Seattle Social Development Project, see Chapter 2 for more details). 


\subsection{Experimental design}

The experiment was conducted in 2003 by Beke, a research bureau specialized in crime-related research, and was an initiative of the Dutch Ministry of Security and Justice with the aim to evaluate the effectiveness of Halt in reducing recidivism. ${ }^{26}$

In total, 1,064 juvenile delinquents who committed a Halt-worthy offense (see Appendix, Table A.1) and were apprehended by the police, received an invitation to participate in the experiment. A total of 944 participants (together with their parents) approved to participate in the Halt experiment, and 120 adolescents decided to participate in the restorative juvenile justice program Halt but not in the experiment. Juveniles in the latter group were, on average, more frequently nonDutch. The reasons for not participating in the experiment were: lack of motivation; a negative attitude towards the experiment; poor language skills; or dyslexia problems (see Ferwerda et al., 2006).

The 944 participants of the Halt experiment were randomly assigned to the treatment group (465) or to the control group (479). 12 of the 62 Halt bureaus in the Netherlands participated in this experiment. Juvenile offenders were assigned to the treatment within each of these Halt bureaus. The Halt bureaus were selectively chosen for participation in the experiment, so that bureaus in both the largest Dutch cities and outside high urbanized areas were included. The number of assigned juveniles within Halt bureaus varies between 20 and 166 juveniles (see Appendix, Table A.2 for the exact numbers). Group offenders were assigned to the Halt treatment randomly as one group in order to avoid contamination between the cooffenders. More detailed information on group sizes assigned to the treatment and control groups is given in Section 4.4.

The randomization was performed by Beke in four following steps. First, each Halt bureau was asked to appoint a representative Halt staff member. Second,

\footnotetext{
${ }^{26}$ Ferwerda et al. (2006) show that one year participation in the Halt program does not appear to reduce overall criminality and behavioral problems for juveniles (while there are some positive effects for subgroups of offenders). Because the study estimates the intend to treat and it does not control for the selective program dropout that occurs, the effects of Halt on recidivism are biased downwards.
} 
questionnaires were filled out by Halt representatives and juveniles. Third, Halt representatives provided researchers of Beke with background information on the juvenile offenders, and, conditionally on this, information whether juveniles were randomly assigned to the treatment or to the control group. Finally, Halt representatives received information about who was assigned to the program treatment and to the control group.

Juvenile offenders assigned to the control group received no treatment besides being apprehended by the police. In reality, non-enrollment in Halt can result in prosecution by the public prosecutor, and therefore the estimated Halt effect represents the impact on educational outcomes given that prosecution effects are excluded. These prosecution effects are, however, limited because the program targets adolescents who only committed minor first-time offenses. As a consequence, juveniles were never incapacitated during trial (punishment) and they could only receive a criminal record if they were aged 16 years or older. ${ }^{27}$ It is unlikely that prosecution effects will impose a large bias on the estimated program effects.

Six months after the Halt intervention started, all 944 juveniles from the treatment and the control group had to return to the Halt bureau together with their parents to complete a second-round questionnaire. Juveniles had an incentive to fill out the second questionnaire as it was a condition to complete the experiment successfully, and thus to be released from prosecution. For juveniles assigned to Halt, successful completion also meant completion of the entire program. Juveniles who did not complete the Halt program were considered as program dropouts. Even though there were strong incentives to complete the program successfully, 91 juveniles (9.6\%) from the total treatment group dropped out of the program.

\footnotetext{
${ }^{27}$ Adolescents who are 16 years or older receive a criminal record, but this record is preserved only for 2 or 4 years.
} 
4. The effect of restorative juvenile justice on future educational outcomes

\subsection{Data and descriptive statistics}

The experimental data contain background characteristics for all 944 juveniles, who participated in the experiment, and their parents. These data were linked to educational registration data of Statistics Netherlands such that information was obtained on the educational careers of all Dutch adolescents in secondary and vocational education between 2004 and 2010. By linking these data, we can observe whether juveniles dropped out of secondary or vocational education. We also observe the number of years of education up to six years after participation in the experiment. It was not possible to link the experimental data to the educational registration data for 118 juveniles (from the treatment and the control group). We return to this issue later in this section.

When children in Dutch education finish primary education (generally at the age of twelve), they are tracked into different secondary education levels. This is also the moment when children can enroll in Halt. Pre-vocational education (4 years) prepares children for vocational education (4 years). Secondary general education ( 5 years) prepares children for higher vocational education (4 years) and pre-university education (6 years) prepares children for universities (4 or 5 years). 'Secondary special needs education' refers to secondary education for children with learning problems. The number of years of education can be directly inferred from the educational registration data. We note that repetition of a school year is not considered as one year of education. ESL has been already defined in Chapter 3, using the definition of the Dutch Ministry of Education, Culture and Science. We shortly state that students are not considered as early school leavers if they are (1) registered in secondary or vocational education, or (2) finished senior general secondary, pre-university, or a level 2 post-secondary vocational education with a diploma. 
Chapter 4

Table 4-1: Comparing juveniles in the treatment and the control group

\begin{tabular}{llllll}
\hline & \multicolumn{2}{l}{ Control $(\mathrm{N}=479)$} & \multicolumn{2}{l}{ Halt $(\mathrm{N}=465)$} & \\
& Mean & Std. dev. & Mean & Std. dev. & p-val. \\
\cline { 2 - 6 } Age & 14.477 & 1.530 & 14.578 & 1.469 & 0.298 \\
Women & 0.307 & 0.462 & 0.265 & 0.442 & 0.150 \\
$\begin{array}{l}\text { Parents born in the } \\
\text { Netherlands }\end{array}$ & 0.653 & 0.477 & 0.708 & 0.453 & 0.071 \\
Group offense & 0.702 & 0.454 & 0.780 & 0.413 & 0.007 \\
$\begin{array}{l}\text { Offense Type: } \\
\text { Demolition }\end{array}$ & 0.166 & 0.375 & 0.195 & 0.399 & 0.245 \\
Graffiti & 0.025 & 0.156 & 0.032 & 0.177 & 0.497 \\
Shoplifting & 0.380 & 0.486 & 0.313 & 0.464 & 0.030 \\
Property crime & 0.141 & 0.352 & 0.156 & 0.362 & 0.535 \\
Handling stolen goods & 0.021 & 0.143 & 0.024 & 0.152 & 0.767 \\
Reckless behavior & 0.141 & 0.347 & 0.127 & 0.333 & 0.543 \\
Arson & 0.026 & 0.163 & 0.034 & 0.182 & 0.464 \\
Light abuse & 0.008 & 0.091 & 0.011 & 0.103 & 0.702 \\
Joint sign. test & Prob>F=0.293 & & & & \\
\hline
\end{tabular}

Table 4.1 shows background characteristics of the 479 juveniles in the Halt group and the 465 juveniles in the control group. Group offenders were assigned to the treatment as one group within each Halt bureau. We emphasize that information on group offenders in Table 4.1 is provided by juveniles themselves and it is not based on police data. Table 4.1. shows that the mean difference for group offense variable is statistically significant between the treatment and control group. The mean differences for the other characteristics are not statistically significant at the 95 confidence level, except for the proportion of juveniles who committed shoplifting (which is negatively correlated with group offense variable). In Appendix, we show a balancing table (Table A.2) for each Halt bureau. In most Halt bureaus, the number of observations in the treatment and control group is not the same. ${ }^{28}$ If some Halt bureaus are better or worse in terms of characteristics of juveniles than other Halt bureaus, these imbalances in the number of observations between the treatment and control groups can create differences in the overall characteristics even when characteristics are balanced within each Halt bureau. Therefore, we

\footnotetext{
${ }^{28}$ This is mainly caused by assigning juveniles to the treatment or the control group together with other co-offenders.
} 
correct for this by using weights. The weights are equal to the inverse of the relative size of the treatment and control group within each bureau.

Table 4.1 shows that participants in the experiment are on average 14.5 years old. In Appendix Table A.3, we show the exact age distribution of participants. Approximately, 30 percent of the offenders are girls and around 70 percent have parents who were both Dutch. About 70 percent of all offenders are group offenders. $^{29}$ The most common offenses are demolition, shoplifting, reckless behavior and property crime.

We show the group size distribution in Table 4.2. ${ }^{30}$ The first column indicates the group size and the second column indicates how many offenders were in this group size category. The last column indicates how many groups were assigned to the treatment for each group size. The table shows that 78.3 percent of the offenses are committed alone or with one fellow offender. We cluster the standard errors at the level of the group.

Table 4-2: Frequency table of group sizes

\begin{tabular}{lllll}
\hline Group size & Observations & Frequency & Cumulative \% & No. groups \\
\hline 1 & 441 & 46.72 & 46.72 & 441 \\
2 & 298 & 31.57 & 78.28 & 149 \\
3 & 117 & 12.39 & 90.68 & 39 \\
4 & 36 & 3.81 & 94.49 & 9 \\
5 & 40 & 4.24 & 98.73 & 8 \\
6 & 12 & 1.27 & 100.00 & 2 \\
No. obs. & 944 & 100.00 & & \\
\hline
\end{tabular}

Table 4.3 shows information that is related to the family and to the followed educational track. This information was obtained in the first-round questionnaire (see Section 4.3). None of the mean differences are statistically significant applying a 95 percent confidence interval. Approximately 75 percent of the first-time offenders

\footnotetext{
${ }^{29}$ Based on self-reported information.

${ }^{30}$ We define groups based on information on the type and date of offence.
} 
Chapter 4

are enrolled in pre-vocational education or a lower education type. This is higher than the country average, and therefore in line with the extensive literature that finds a negative correlation between education levels and criminal involvement (see Ellis, Beaver and Wright, 2009, and references therein).

91 of the 465 first-time offenders did not complete the Halt program. Table 4.4 characterizes the selective nature of this dropout. Of all the characteristics (see Tables 4.1 and 4.3 ), only those mean differences that were statistically significantly different are shown in Table 4.4. The selective program dropout is mainly characterized by differences in family background characteristics rather than by differences in committed offenses or education levels. Juveniles who complete Halt are somewhat more often enrolled in the theoretical path of pre-vocational education. Juveniles who dropped out of the Halt program tend to be older, are less likely to have parents born in the Netherlands, and are more frequently living in single-parent families. To take into account the potential effect of selection bias, we adopt an instrumental variable approach when estimating the program effect (see Section 5.1).

The experimental and educational data are linked based on family name, living address, date of birth, and gender. Statistics Netherlands link these data to the Municipal Register of Population, which we further link to the registered education data. Unfortunately, the experimental data could not be linked to the educational tracking data in 118 cases due to missing personal identification numbers. ${ }^{31}$ However, there is no reason to believe that this non-linkage is correlated with treatment status. We show mean differences in background characteristics of nonlinkable juveniles in the Halt group and the control group in Table 4.5. The table shows that the mean differences are not statistically significant. However, these differences may be statistically insignificant only because the groups are small. In Section 4.5.4, we perform a bounding exercise to examine whether the estimated program effects change when the issue of non-linkage is taken into account.

${ }^{31}$ Statistics Netherlands could not provide us with information on why these juveniles could not be linked to the education data, because providing these data would be a violation of the Dutch data protection and privacy laws. 
4. The effect of restorative juvenile justice on future educational outcomes

Table 4-3: Family and educational characteristics of juveniles in the treatment and the control group

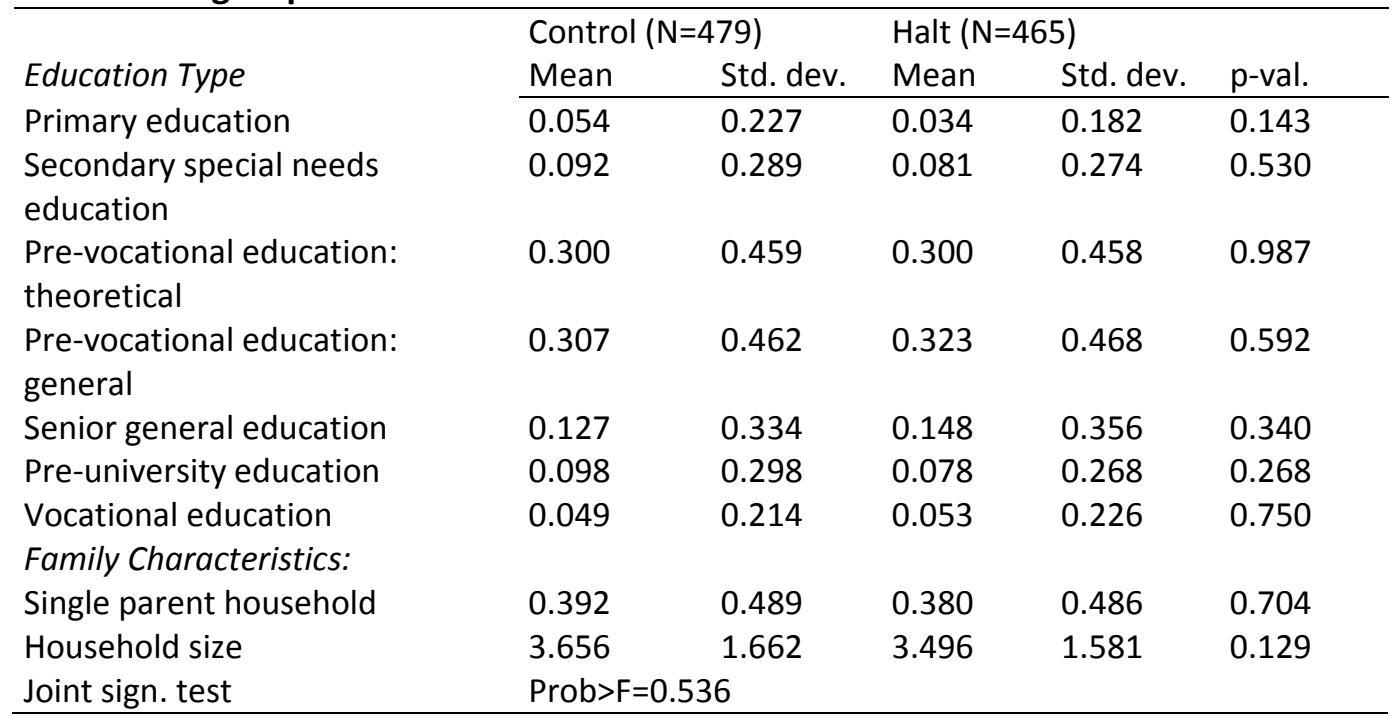

Table 4-4: Characteristics of juveniles who completed the Halt program and juveniles who terminated their participation

\begin{tabular}{|c|c|c|c|c|c|}
\hline & \multicolumn{2}{|c|}{ Completed $(\mathrm{N}=374)$} & \multicolumn{3}{|c|}{ Dropouts $(\mathrm{N}=91)$} \\
\hline & Mean & Std. dev. & Mean & Std. dev. & $\mathrm{p}$-val. \\
\hline Age & 14.495 & 1.493 & 14.912 & 1.322 & 0.015 \\
\hline Parents born in the Netherlands & 0.730 & 0.444 & 0.618 & 0.489 & 0.032 \\
\hline Single parent household & 0.353 & 0.479 & 0.495 & 0.503 & 0.013 \\
\hline $\begin{array}{l}\text { Pre-vocational education: } \\
\text { theoretical }\end{array}$ & 0.318 & 0.468 & 0.286 & 0.401 & 0.019 \\
\hline Joint sign. test & \multicolumn{5}{|c|}{ Prob $>F=0.031$} \\
\hline
\end{tabular}


Table 4-5: Characteristics of the non-linkable observations

\begin{tabular}{|c|c|c|c|c|c|c|}
\hline & Control & 65) & Halt $(\mathrm{N}=$ & & & \\
\hline & Mean & Std. dev. & Mean & Std. dev. & $|\Delta|$ & p-val. \\
\hline Age & 14.631 & 1.409 & 14.774 & 1.354 & -0.143 & 0.578 \\
\hline Women & 0.215 & 0.414 & 0.340 & 0.478 & -0.125 & 0.133 \\
\hline $\begin{array}{l}\text { Parents born in the } \\
\text { Netherlands }\end{array}$ & 0.677 & 0.471 & 0.726 & 0.445 & -0.049 & 0.562 \\
\hline Single parent household & 0.492 & 0.504 & 0.528 & 0.504 & -0.036 & 0.700 \\
\hline Household size & 3.492 & 2.151 & 3.642 & 2.158 & -0.150 & 0.709 \\
\hline Primary education & 0.046 & 0.211 & 0.019 & 0.137 & 0.027 & 0.420 \\
\hline $\begin{array}{l}\text { Secondary special needs } \\
\text { education }\end{array}$ & 0.200 & 0.403 & 0.113 & 0.320 & 0.087 & 0.205 \\
\hline $\begin{array}{l}\text { Pre-vocational education: } \\
\text { theoretical }\end{array}$ & 0.354 & 0.482 & 0.358 & 0.484 & -0.004 & 0.959 \\
\hline $\begin{array}{l}\text { Pre-vocational education: } \\
\text { general }\end{array}$ & 0.246 & 0.434 & 0.245 & 0.434 & 0.001 & 0.991 \\
\hline $\begin{array}{l}\text { Senior general secondary } \\
\text { education }\end{array}$ & 0.108 & 0.312 & 0.151 & 0.361 & -0.043 & 0.487 \\
\hline $\begin{array}{l}\text { Pre-university secondary } \\
\text { education }\end{array}$ & 0.046 & 0.211 & 0.094 & 0.295 & -0.048 & 0.304 \\
\hline $\begin{array}{l}\text { Regional training center } \\
\text { education }\end{array}$ & 0.015 & 0.124 & 0.057 & 0.233 & -0.042 & 0.222 \\
\hline Group offense & 0.662 & 0.477 & 0.736 & 0.445 & -0.074 & 0.388 \\
\hline Demolition & 0.154 & 0.364 & 0.226 & 0.423 & -0.072 & 0.318 \\
\hline Graffiti & 0.046 & 0.211 & 0.019 & 0.137 & 0.027 & 0.420 \\
\hline Shoplifting & 0.354 & 0.482 & 0.434 & 0.500 & -0.080 & 0.379 \\
\hline Property crime & 0.154 & 0.364 & 0.113 & 0.320 & 0.041 & 0.525 \\
\hline Handling stolen goods & 0.031 & 0.174 & 0.019 & 0.137 & 0.012 & 0.686 \\
\hline Reckless behavior & 0.185 & 0.391 & 0.113 & 0.320 & 0.072 & 0.287 \\
\hline Arson & 0.031 & 0.174 & 0.038 & 0.192 & -0.007 & 0.838 \\
\hline Joint sign. test & Prob $>\mathrm{F}$ & & & & & \\
\hline
\end{tabular}


4. The effect of restorative juvenile justice on future educational outcomes

\subsection{Estimation strategy and empirical findings}

\subsubsection{Estimation strategy}

An instrumental variable (IV) approach is used to control for selective dropout from the Halt treatment in order to obtain unbiased Halt estimates. The treatment effect is estimated using a two-stage least squares model (Angrist and Pischke, 2009). In the first stage the probability of Halt participation is estimated by regressing the participation status, $H_{i}$ on a set of covariates, $X_{i}$ and on a variable that indicates whether juveniles were assigned to Halt $\left(L_{i}=1\right)$ or to the control group $\left(Z_{i}=0\right):{ }^{32}$

$$
H_{i}=\alpha_{0}+\alpha_{1} Z_{i}+X_{i}^{\prime} \alpha_{2}+\varepsilon_{i}
$$

Subscript $i$ is a student indicator and $\varepsilon_{i}$ is a random error term that has mean zero and variance $\sigma_{\varepsilon}^{2}$. In the second stage, we regress the two educational outcome variables considered in this chapter $\left(Y_{i j} Y_{i j}\right)$ on the predicted probability of participating in Halt (i.e. $\left.\hat{H}_{i} \hat{H}_{i}\right)$ and on the set of covariates $\left(X_{i}\right)$ included the first stage regression:

$$
Y_{i j}-\beta_{0 j}+\beta_{1 j} \hat{H}_{i}+X_{i}^{\prime} \beta_{2 j}+\mu_{i j}
$$

Subscript $j$ refers to the fact we consider two educational outcomes and estimate two second stage models. The random errors $\mu_{i j}$ and $\varepsilon_{i}$ are correlated, and thus the first and second stage equations are estimated simultaneously (Wooldridge, 2009). The estimated treatment effect is unbiased because instrument $Z_{i}$ is assumed to be uncorrelated with the error terms $\mu_{i j}$ and $\varepsilon_{i}$ due to the randomization and can only influence the considered educational outcomes through $H_{i}$.

\footnotetext{
${ }^{32}$ The covariates included in the regression analysis are age, gender, ethnicity, living in a single-parent household, working status of both parents, household size, group offense indicator, offense type, educational level at the start of the program, if juveniles finished school before the program started, Halt bureau dummies.
} 


\subsubsection{Empirical findings}

The first two columns of Table 4.6 show the intention-to-treat (ITT) estimates for ESL and years of education (YE), estimated by using a reduced form model that regresses the outcome variable directly on assignment. Juveniles cannot be obligated to complete the program. Therefore, the ITT effect measures the effect of being assigned to the treatment group which however does not necessarily imply participation (Angrist and Pischke, 2009). It naturally follows that the estimated ITT effect is smaller than the average treatment effect on the treated. The estimation results show that being assigned to the treatment group reduces ESL by 5.2 percentage points and increases the years of education by 0.258 .

Table 4-6: The effects of Halt on early school leaving (ESL) and years of education (YE)

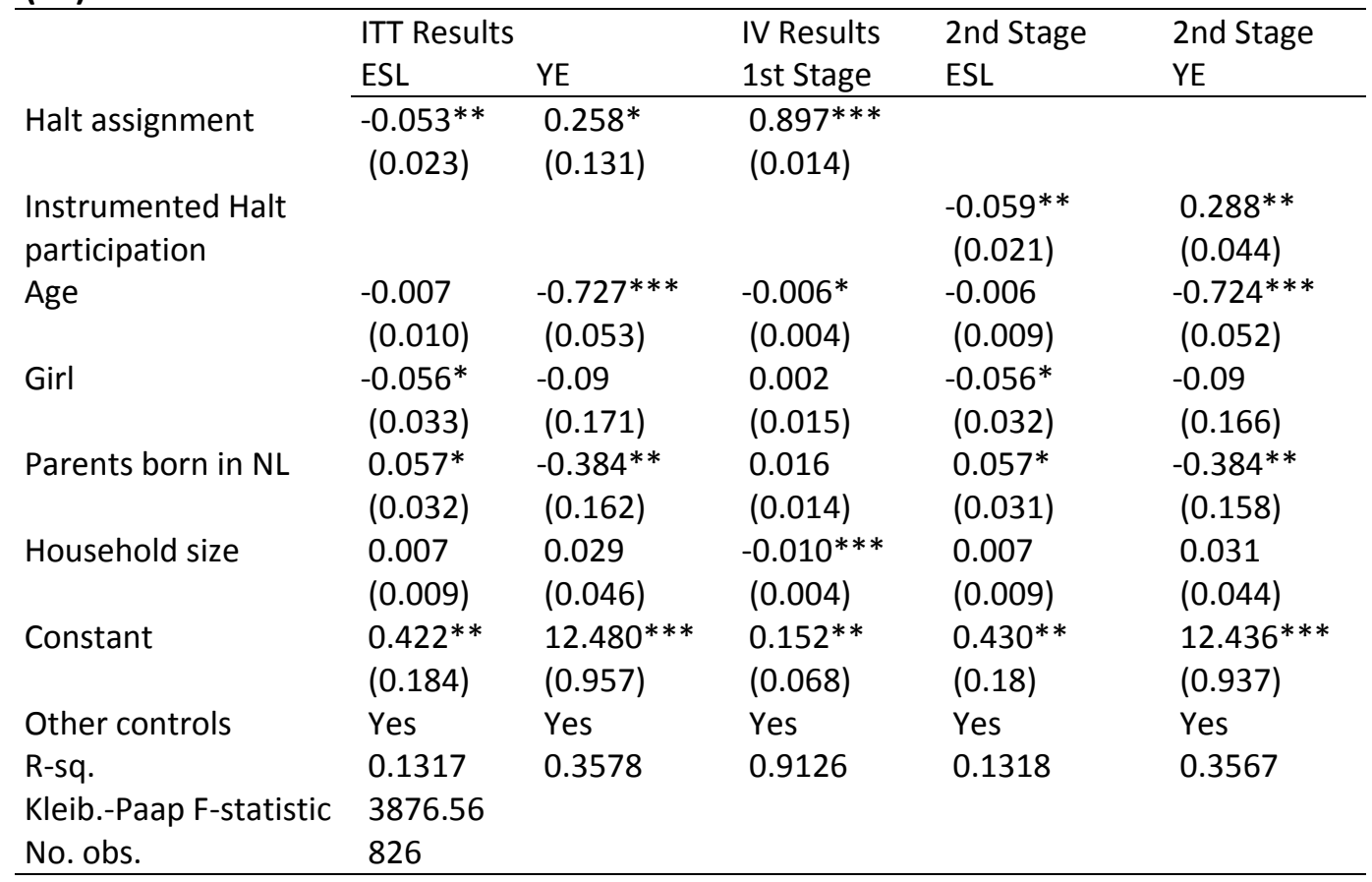

Note: Other controls are dummies for single-parent household, school graduation before Halt, offense type, group offender, working status of parents. SEs are clustered at the group offense level and printed in parenthesis. " $\rho \leq 0.1, " * p \leq 0.05,{ }^{* * * *} \rho \leq 0.01$ 
4. The effect of restorative juvenile justice on future educational outcomes

The first-stage estimation results are shown in Column 3. The high $K^{2}$ of 0.913, the Kleibergen-Paap (2006) F-statistic, which provides an under-identification test, and the coefficient of the Halt assignment variable, all clearly show that the Halt assignment variable is a very strong predictor of Halt participation. The second stage estimation results for ESL indicate that Halt participation reduced ESL by 5.9 percentage points. Given the control mean, this means that Halt participation reduces the probability of ESL from 0.181 to 0.122 . For years of education we find a positive and statistically significant treatment effect of 0.288 . Halt participation increased years of education from 3.56 to 3.85 years (as the mean of the control group is 3.56 years of schooling after the program).

\subsubsection{Heterogeneous treatment effects}

The direction and magnitude of the treatment effect may vary for different subgroups. Taking into account subgroup effects alters the empirical strategy, because the number of first-stage equations is equal to the number of subgroups considered in the regression model. If we take into account, for example, that Halt may affect boys differently than girls we estimate the following system of first stage equations:

$$
\begin{gathered}
H_{i}=\alpha_{01}+\alpha_{11} Z_{i}+\alpha_{21} Z_{i} \operatorname{Girl}_{i}+X_{i}^{\prime} \alpha_{31}+\theta_{i 1} . \\
H_{i} \text { Girl }_{i}=\alpha_{02}+\alpha_{12} Z_{i}+\alpha_{22} Z_{i} \text { Girl }_{i}+X_{i}^{\prime} \alpha_{32}+\theta_{i 2} .
\end{gathered}
$$

In the second stage, the educational outcome variables $\left(Y_{i j} Y_{i j}\right)$ are regressed on the set of covariates $\left(X_{i} X_{i}\right)$ and on the predicted participation probabilities resulting from the first stage regressions. The second stage regression for the model that includes subgroup effects with respect to gender then equals:

$$
Y_{i j}=\beta_{0 j}+\beta_{1 j} \hat{H}_{i}+\beta_{2 j} H_{i} \widehat{G i r} l_{i}+X_{i}^{\prime} \beta_{3 j}+\mu_{i j}
$$


Chapter 4

Again we estimate the first and second stage equations simultaneously, since the error terms $\theta_{i 1}$ and $\theta_{i 2}$ are positively correlated with $\mu_{i j}$. The term $\beta_{1 j}$ measures the treatment effect for girls on educational outcome $j$ and the term $\beta_{2 j}$ measures whether the treatment effect for boys differs from the estimated effect for girls.

Table 4-7: The effects of Halt on early school leaving (ESL) and years of education (YE) across different demographic groups

\begin{tabular}{llll}
\hline & & ESL & YE \\
\hline Girl & Halt & $-0.063^{* *}$ & 0.243 \\
& & $(0.031)$ & $(0.172)$ \\
& Halt*Girl & 0.014 & -0.157 \\
& & $(0.064)$ & $(0.356)$ \\
\hline Parents born in the Netherlands (PBN) & Halt & $-0.115^{* *}$ & $0.654^{* *}$ \\
& & $(0.049)$ & $(0.300)$ \\
& Halt* PBN & 0.080 & -0.517 \\
& & $(0.062)$ & $(0.367)$ \\
\hline Single Parent & Halt & $-0.076^{* *}$ & $0.385^{* *}$ \\
& & $(0.031)$ & $(0.174)$ \\
& Halt*Single & 0.051 & -0.277 \\
& & $(0.066)$ & $(0.333)$ \\
\hline Group offense (G) & Halt & $-0.215^{* * *}$ & $0.956^{* * *}$ \\
& & $(0.064)$ & $(0.314)$ \\
& Halt*G & $0.197^{*}$ & $-0.876^{* *}$ \\
No. obs. & & $(0.073)$ & $(0.369)$ \\
\hline
\end{tabular}

Note: Control variables are similar to those in Table 4.6. SEs are clustered at the group offense level and printed in parenthesis. " $\rho \leq 0.1, " * \rho \leq 0.05,{ }^{* * * *} \rho \leq 0.01$

Table 4.7 shows the second-stage estimation results that indicate whether the estimated program effect differs by gender, ethnicity, group offense and family composition. These interaction effects are generally not statistically significant. When estimating multiple first-stage equations more noise is included in the second stage regression, which in turn results in less precise estimates. The signs of the interaction terms suggest that the program is more effective for boys and juveniles with parents who are non-Dutch. On the other hand, the program appears to be less 
effective for juveniles in single-parent household. Furthermore, we find that the program is less effective for group offenders (this interaction effect is statistically significant). It might be that negative peer interactions undo any positive effects that Halt can have.

\subsubsection{Bounding exercise}

In the bounding exercise below we examine whether the estimated Halt effects are driven by the fact that 118 juveniles could not be linked to the education data. First, we calculate the average educational outcomes for juveniles in the Halt and the control group. Then we assigned the average educational outcome of juveniles in the control (intervention) group to non-linkable juveniles in the Halt (control) group. It implies that non-linkable juveniles in the Halt (control) group receive an unfavorable (favorable) educational outcome. By estimating the IV model again, we estimate the Halt effect while assigning unfavorable educational outcomes to non-linkable

juveniles with respect to the Halt estimate. Table 4.8 shows the estimation results of this bounding analysis and the obtained estimates can be viewed as lower bound estimates. The estimation results are, as expected, lower but still statistically significant. They indicate that Halt participation reduces ESL by 5.2 percentage points and increases years of education with 0.26 years. These estimation results are very similar to those presented in Table 4.6 and therefore we conclude that the estimates are unlikely to be strongly affected by non-linkage. 
Chapter 4

Table 4-8: Lower bound estimates for early school leaving (ESL) and years of education (YE)

\begin{tabular}{llll}
\hline & & IV Results \\
& 2nd Stage ESL & 2nd Stage YE \\
\hline Halt assignment & $0.901^{* * *}$ & & \\
& $(0.014)$ & $-0.052^{* *}$ & $0.263^{* *}$ \\
Instrumented Halt & & $(0.024)$ & $(0.129)$ \\
participation & & -0.010 & $-0.632^{* * *}$ \\
Age & $-0.007^{* *}$ & $(0.009)$ & $(0.046)$ \\
& $(0.004)$ & -0.043 & -0.147 \\
Girl & -0.007 & $(0.029)$ & $(0.145)$ \\
& $(0.015)$ & $0.049^{*}$ & $-0.352^{* *}$ \\
Parents born in NL & -0.007 & $(0.028)$ & $(0.143)$ \\
& $(0.013)$ & 0.005 & 0.039 \\
Household size & $-0.008^{* * *}$ & $(0.008)$ & $(0.035)$ \\
& $(0.003)$ & $0.476^{* * *}$ & $11.039^{* * *}$ \\
Constant & $0.154^{* *}$ & $(0.163)$ & $(0.827)$ \\
& $(0.068)$ & Yes & Yes \\
Other controls & Yes & 0.109 & 0.326 \\
R 2 & 0.915 & & \\
Kleibergen-Paap F- & 4420.82 & & \\
statistic & & & \\
No. obs. & 944 & & \\
\hline
\end{tabular}

Note: Control variables are similar to those in Table 4.6. SEs are clustered at the group

offense level and printed in parenthesis. ${ }^{*} \rho \leq 0.1,{ }^{* *} \rho \leq 0.05,{ }^{* * * *} \rho \leq 0.01$

\subsection{Discussion}

In this section, we have shown that the Dutch restorative justice program Halt has statistically significant favorable effects on ESL and years of education. Previous studies evaluated the effectiveness of childhood and adolescent interventions on criminal and educational outcomes, but evaluation studies on the effectiveness of criminal intervention programs for adolescents generally only evaluate program effects on recidivism, while the potential positive effects of the program on educational outcomes are ignored. There is evidence that criminal involvement at a young age is not only positively associated with future criminal involvement (see Ellis et al., 2009; Loeber et al., 2013), but it can also lead to lower educational outcomes (see Hjalmarsson, 2008; Webbink et al., 2013; Aizer and Doyle, 2013). 
The empirical findings show that the Dutch restorative justice program Halt reduces ESL by 5.9 percentage points and increases years of education by 0.29 years. The estimated program effect on ESL is substantial and represents a reduction in ESL of 30.4 percent (i.e. a reduction from 0.181 to 0.122 ). The program is less effective for group offenders which may point to the fact that there is a high potential for negative peer effects when adolescents are surrounded by peer-offenders. The program also appears to be less effective for girls, juveniles with Dutch parents and juveniles in single parents household (the estimates on these subgroups are sizable but rather imprecisely estimated).

The estimation results indicate that ESL is reduced by 27 juveniles if 465 juveniles are treated. The most recently estimated treatment costs for each juvenile are 485 euro (and 375 euro per petty offences) (KPMG, 2011), such that the total treatment costs are 225.525 euro (estimated as the highest bound). It follows that the costs per one prevented early school leaver, are equal to 8.352 euro. This seems to be worth the investment - even in the absence of any effect on recidivism - given that these juveniles leave school with at least a level 2 post-secondary vocational education and considering that the costs of one extra year of education are roughly similar to the program costs of Halt per early school leaver less. Additionally, the costs of being prosecuted by the public prosecutor are 1,983 euro higher than the program costs of Halt (KPMG, 2011).

This chapter has shown that the Dutch restorative justice program Halt reduces ESL and increases years of education. We conclude that investments in early intervention programs targeted at juvenile offenders can be considered as an effective policy tool to reduce ESL and increase years of education. More generally, our results indicate that programs that target behavioral problems can have positive spill-over effects on educational outcomes. These additional effects should not be ignored when behavioral programs are evaluated. 



\section{The relationship between criminal involvement of parents and educational attainment of their children ${ }^{33}$}

\subsection{Introduction}

The previous chapters have discussed and analyzed the relationship between criminal and educational outcomes of a particular individual. This chapter investigates how these two outcomes are related from an intergenerational perspective. More specifically, we analyze the effect of parents' criminal involvement on the educational attainment of children. For this purpose, data are used from the nationally representative 'Netherlands Kinship Panel Study' (NKPS), which were collected between 2002 and 2004 through self-reported questionnaires among 8,155 Dutch residents. These data include information on parents' criminal involvement and on the educational attainments of parents and their children. Criminal involvement is measured by asking respondents if they or their family members (i.e. spouse) have ever been convicted in a criminal court or have ever been in contact with the police as a consequence of delinquent behavior, other than for traffic offences (Dykstra et al., 2005; Dykstra and De Valk, 2007). Furthermore, reported criminal involvement corresponds to information on a criminal record.

\footnotetext{
${ }^{33}$ This chapter is based on Rud, I., Van Klaveren, C., Groot, W. and Maassen van den Brink, H. (2014). The externalities of crime: The effect of criminal involvement of parents on the educational attainment of their children, Economics of Education Review, 38, 89-103.
} 
The adopted estimation strategy is a multinomial logit model in combination with a statistical matching model that uses Mahalanobis distances. We use a multinomial logit model because observed educational attainment categories are not naturally ordered. The statistical matching approach is applied in order to compare children whose parents were criminally involved to children whose parents have no criminal involvement, but otherwise have similar observable background characteristics. This is important because parents who have no criminal past can be different in their characteristics from parents who have been criminally involved, and these differences may bias the estimated impact. In the matching analysis, we enforce that the parents' education levels are identical for the paired children, since parental education affects the educational choices of their children.

Our findings suggest that having criminally involved parents leads to lower educational attainment of their children. In particular, the effect of criminal involvement of parents on the probability of finishing primary education as the highest educational level attained for their children is estimated to be in the range of seven to nine percentage points. The effect of having criminally involved parents on the probability of attaining higher education is in the range of two to six percentage points. The lower bounds of these effects are estimated by addressing the effect of unobservable heterogeneity.

The contributions of this chapter to the empirical literature are threefold. First of all, we examine whether educational attainment of children is influenced by criminal involvement of their parents. The intergenerational literature on crime and education focuses mainly on the intergenerational transmission of either criminal behavior or educational attainment from parents to children. The effects that can exist between parents' criminal behavior and educational outcomes of children are generally ignored.

The second contribution is that information from a nationally representative survey is used, whereas previous studies primarily employed small samples of imprisoned parents with limited information on the background characteristics of these parents and their children (see, e.g., the review by Murray, Farrington and 
5. The relationship between criminal involvement of parents and educational attainment of their children

Sekol, 2012). Exceptions are the studies by Foster and Hagan (2007, 2009), Haskins (2011) and Habecker (2013) who control for a wide range of important covariates using rich survey data. We acknowledge that a disadvantage of using survey data is that respondents can underreport their (or their family members') criminal involvement (see Thornberry and Krohn, 2000) and address the potential impact of measurement error in the robustness section.

Finally, we provide estimation results for the Netherlands, whereas previous evidence is mainly focused on the United States. The patterns of criminal involvement and criminal justice in the Netherlands are comparable to many other Western European countries, but they are different from the United States (see, e.g., ICPS, 2012; Tak, 2003; Dünkel et al., 2011).

This chapter proceeds as follows. Section 5.2 shortly reviews the empirical literature on intergenerational effect of crime and education. Section 5.3 discusses the data and descriptive statistics. Section 5.4 explains the estimation strategy and reports the empirical results. In Section 5.5, robustness analyzes are performed. In this section, we examine how unobservable heterogeneity affects our estimates by using techniques proposed by Altonji et al. $(2005,2008)$ and perform other sensitivity checks. Moreover, this section examines how the estimation results depend on the definition of the outcome measure, and discusses the role of measurement error. Section 5.6 concludes.

\subsection{Literature}

Previous research on education and crime has generally suggested that there is a negative relationship between criminal behavior and educational attainment (e.g. Lochner and Moretti, 2004; Machin et al., 2011; Groot and Maassen van den Brink, 2010; Hjalmarsson, Holmlund and Lindquist, 2011). Moreover, these studies imply that children of criminally involved parents tend to have relatively low educated parents. 
A considerable amount of studies have examined intergenerational transmission of criminal behavior and education from parents to children. The empirical findings of these studies support a causal relationship between parents' and children's education (De Haan and Plug, 2009; Ermisch and Pronzato, 2010; Holmlund et al., 2011) and that parents' criminal behavior can be passed to their children (Farrington et al., 2009; Van de Rakt et al., 2010; Hjalmarsson and Lindquist, 2011, 2012). Meghir et al. (2012) suggest that an increase in parental education can reduce the probability of criminal behavior of children. Another set of studies explores the relationship between criminal involvement and labor market outcomes across different generations. For instance, Mesters (2014) analyses to what extent the effect of the unemployment rate on the probability of criminal involvement has changed throughout the last century for families of disadvantaged youths.

There are few studies that have examined how criminal involvement of parents can influence the educational outcomes of their children using information on imprisoned parents (see, e.g., the review by Murray et al., 2012 and references therein). Some of these studies conclude that parental incarceration is associated with lower educational outcomes of children (e.g. Stanton, 1980; Trice and Brewster, 2004; Habecker, 2013), while other studies find no relationship (e.g. Murray, Loeber and Pardini, 2012). Typical control groups that are used for identification purposes are children who are separated from their parents for other reasons than imprisonment (such as parental death, divorce, being on probation) or best friends of children whose parents are imprisoned. Although many of these studies discuss the generally low educational attainment of prisoners, they do not control for the education of imprisoned parents, such that the estimation results may represent the fact that criminally involved parents have a relatively low education level. Foster and Hagan (2007, 2009), Haskins (2011) and Habecker (2013) are rare exceptions. Foster and Hagan (2007, 2009) analyze the effect of fathers' imprisonment on the educational attainment of children, using the Add Health study data, a large-scale survey among U.S. adolescents which reports on demographic characteristics of them and their parents. These studies include father's education and a number of 
5. The relationship between criminal involvement of parents and educational attainment of their children

socio-economic characteristics as control variables. The results suggest a strong negative effect (the estimates range from -0.18 to -0.72 , depending on the estimation method used) of the father's incarceration on the educational attainment of their children. Using the same data and controlling for parental education in the OLS and logistic regression models, Habecker (2013) finds that parental incarceration lowers the odds of a child completing high school by 50 percent and lowers educational attainment of children by 0.33 of a standard deviation. Haskins (2011) combines OLS estimation and propensity score matching and controls for parental education in order to examine the effect of parental imprisonment on school readiness of 5-year-old children. The study exploits the Fragile Families and Child Wellbeing Study and finds that children whose parents were in prison have lower levels of non-cognitive skills that are vital for entry into formal schooling, while the effect on cognitive readiness is not statistically significant.

Other studies show that criminal involvement of parents has a negative influence on family stability and financial circumstances, and, as a result, on the general well-being of children (Roguski and Chauvel, 2009; Travis and Waul, 2003). Children whose parents are criminally involved are more likely to come into contact with the criminal justice system and tend to have emotional difficulties later in life (Geller, Garfinkel, Cooper and Mincy, 2009; Van de Rakt et al., 2010; Wilbur et al., 2007). Additionally, these children are more frequently stigmatized by their peers at school (Nesmith and Ruhland, 2008) and experience school-related problems (Hungerford, 1993; Peniston, 2006). It follows that children with criminally involved parents live in a socio-economic environment that is more unstable, and this may negatively affect both children's cognitive and non-cognitive skills development. Cunha and Heckman (2007) develop a theoretical model for the Technology of Skill Formation to explain how skills of children develop through different stages of life. From the perspective of this theory, parents who were criminally involved invest differently in their children's skills than parents who were not criminally involved. These differences in investments can greatly influence differences in skill formation in the long run, since acquired skills and investments in skills are complementary 


\section{Chapter 5}

over time. Therefore, the implications for children's educational outcomes can be substantial.

\subsection{Data and descriptive statistics}

In this chapter we use data from the Netherlands' Kinship Panel Study (NKPS), a nationally representative survey held from 2002 to 2004 among 8,155 Dutch residents aged between 18 and 79 (Dykstra et al., 2005). The NKPS data were collected through self-reported questionnaires. These data contain information on the past criminal involvement of parents and on the educational attainment and other demographic characteristics of parents and their children. Respondents report on their family members, in particular their spouses and children aged 15 and older. ${ }^{34}$ The age of children varies from 15 to 65 years. Approximately 70 percent of children are above 25 years old. Households are not considered in the analysis if respondents had no children and if there was no information on the educational and/or criminal involvement variables. ${ }^{35}$

We recode the data such that the observation unit is the child for whom there is information available on background characteristics of them and their parents. The resulting number of child-parent observations is 5,822. Criminal involvement of parents is measured by asking respondents (parents) if they or their family members (i.e. spouse) have ever been convicted in a criminal court or have ever been in contact with the police for delinquent behavior, other than for traffic offences (Dykstra et al., 2005; Dykstra and Valk, 2007). Individuals who commit minor offences in the Netherlands, such as traffic offences, are imposed to an administrative fine and do not receive a criminal record (Tak, 2003). Hence, criminal

\footnotetext{
${ }^{34}$ In case there are more than two children, respondents reported on two children of their choice (aged 15 and older).

${ }^{35}$ There are around 10 percent of respondents who refused to answer crime related questions. The probability of answering these questions is positively related to education levels, which means that excluding these observations might lead to a slightly less representative sample.
} 
5. The relationship between criminal involvement of parents and educational attainment of their children

involvement of parents reported in the survey is very likely to correspond to criminal offenses for which parents received a criminal record. Based on this information, a dummy variable is generated that takes a value of 1 if at least one parent in the household has ever been arrested and/or convicted, and 0 otherwise. The data show that 242 children had either one or two criminally involved parents, 97 of whom were convicted. ${ }^{36}$ The frequency and duration of this criminal involvement is, however, unknown. Furthermore, it may be the case that parents underreport their criminal involvement. The data suggest that four percent of the parents have been criminally involved in the past $(242 / 5822)$. The registration data on criminal involvement of Dutch residents over the life course are not publicly available. Nevertheless, it is known from administrative data that on a yearly basis around seven percent of individuals in the Netherlands are involved in criminal behavior and around one percent are arrested (CBS, 2014).

Table 5.1 shows descriptive statistics for various demographic characteristics. Columns 2 and 3 show the means and standard deviations for children whose parents have no criminal record $(N=5,580)$, while Columns 4 and 5 show the means and standard deviations for children whose parents have a criminal record $(N=242)$. The education categories presented in the table represent highest achieved education levels. These education categories refer to completed educational spells, which are used in the empirical analysis in Section 5.4.

The table shows that parents with a criminal record are, on average, younger, less often house owners, and that the size of the household is larger. Furthermore, children with parents who committed a criminal offense were born more often outside of the Netherlands and also their parents were born more often in a foreign country ( $2^{\text {nd }}$ generation immigrants). The majority of parents who were born outside of the Netherlands come from Morocco, Turkey, Suriname and the Netherlands Antilles. Parents with a criminal record are more likely to have only completed primary education compared to parents with no criminal record.

\footnotetext{
${ }^{36}$ Only in four cases both parents had a criminal record.
} 
Chapter 5

In general, descriptive statistics in Table 5.1 indicate that the individual and family characteristics of children with parents who have a criminal record differ substantially from children whose parents have no criminal record. In the empirical analysis, we take these differences into account.

Table 5-1: Descriptive statistics of households with parents who have no criminal record and households with parents who have a criminal record ${ }^{1}$

\begin{tabular}{|c|c|c|c|c|c|c|}
\hline & \multicolumn{2}{|c|}{$\begin{array}{c}\text { Parents with } \\
\text { no criminal record }\end{array}$} & \multicolumn{2}{|c|}{$\begin{array}{l}\text { Parents with } \\
\text { a criminal record }\end{array}$} & \multicolumn{2}{|c|}{ Mean differences } \\
\hline & Mean & Std. Dev. & Mean & Std. Dev. & $\Delta$ & Std. Err. \\
\hline Crime mother & & & 0.322 & 0.468 & & \\
\hline Age & 59.142 & 10.139 & 55.467 & 9.583 & $3.675^{* * *}$ & 0.663 \\
\hline $2^{\text {nd }}$ gen. immigrants ${ }^{2}$ & 0.087 & 0.282 & 0.161 & 0.368 & $-0.074 * * *$ & 0.019 \\
\hline Born NL & 0.991 & 0.092 & 0.971 & 0.168 & $0.020 * * *$ & 0.006 \\
\hline Single-parent & 0.160 & 0.248 & 0.163 & 0.260 & -0.003 & 0.016 \\
\hline Household size & 2.319 & 1.211 & 2.711 & 1.437 & $-0.391 * * *$ & 0.080 \\
\hline No. of children & 2.709 & 1.167 & 2.661 & 1.333 & 0.047 & 0.077 \\
\hline Ever house owner & 0.730 & 0.444 & 0.640 & 0.481 & $0.090 * * *$ & 0.029 \\
\hline Randstad area ${ }^{3}$ & 0.398 & 0.490 & 0.409 & 0.493 & -0.011 & 0.032 \\
\hline \multicolumn{7}{|l|}{ Child } \\
\hline Women & 0.502 & 0.500 & 0.450 & 0.499 & $0.052 *$ & 0.033 \\
\hline Age child & 31.920 & 10.279 & 28.318 & 9.577 & $3.602 * * *$ & 0.673 \\
\hline Urbanized area & 0.631 & 0.483 & 0.628 & 0.484 & 0.003 & 0.032 \\
\hline \multicolumn{7}{|l|}{ Parents' Education } \\
\hline (1) Primary & 0.129 & 0.335 & 0.231 & 0.423 & $-0.102 * * *$ & 0.022 \\
\hline (2) Lower Secondary & 0.356 & 0.479 & 0.318 & 0.467 & 0.038 & 0.031 \\
\hline (3) Gener. Secondary & 0.068 & 0.251 & 0.033 & 0.179 & $0.035 * *$ & 0.016 \\
\hline (4) Intermid. Vocat. & 0.179 & 0.384 & 0.182 & 0.386 & -0.003 & 0.025 \\
\hline (5) Higher & 0.268 & 0.443 & 0.236 & 0.425 & 0.033 & 0.029 \\
\hline \multicolumn{7}{|l|}{ Children's Education } \\
\hline (1) Primary & 0.114 & 0.318 & 0.215 & 0.412 & $-0.101 * * *$ & 0.021 \\
\hline (2) Lower Secondary & 0.226 & 0.418 & 0.289 & 0.454 & $-0.063 * *$ & 0.028 \\
\hline (3) Gener. Secondary & 0.151 & 0.359 & 0.140 & 0.348 & 0.012 & 0.024 \\
\hline (4) Intermid. Vocat. & 0.214 & 0.410 & 0.219 & 0.414 & -0.005 & 0.027 \\
\hline (5) Higher & 0.295 & 0.456 & 0.136 & 0.344 & $0.159 * * *$ & 0.030 \\
\hline No. obs. & 5.580 & & 242 & & & \\
\hline
\end{tabular}

Note: ${ }^{1}$ In this table only households with children are considered, therefore the descriptive statistics are somewhat different than in the original dataset. ${ }^{2}$ See definition by Keij (2000).

${ }^{3}$ Randstad is the congested metropolitan area bounded by the four largest Dutch cities: Amsterdam, Rotterdam, The Hague, and Utrecht. ${ }^{*} \rho \leq 0.1$. ${ }^{* *} \rho \leq 0.05$. ${ }^{* * * *} \rho \leq 0.01$. 
5. The relationship between criminal involvement of parents and educational attainment of their children

\subsection{Estimation strategy and empirical findings}

\subsubsection{Model description}

Educational attainment of children is measured on a five-point scale. The categories are not naturally ordered because it is not straightforward whether general secondary education is ranked higher than intermediate vocational education. Moreover, the education categories differ in the number of educational years that are needed to achieve a diploma and differ in terms of educational content.

Educational outcomes depend on earlier educational outcomes, in the sense that children are allowed to follow a higher educational track only if they completed a lower educational track. We analyze the individual probability to choose a certain level of education by using a Multinomial Logit Model (MNL) as this model better fits our data. We, therefore, estimate the effect of parents' criminal involvement on children's educational attainment by means of random utility model:

$$
U_{i j}=\alpha_{j}^{\prime} X_{i}+\beta_{j}^{\prime} D_{i}+\varepsilon_{i j}
$$

where $U_{i j}$ indicates the utility that child $i$ derives from attaining education level $j$, and where $j$ represent the 5 possible education levels (i.e. $j=1, \ldots, 5) . \alpha_{j}$ and $\beta_{j}$ are vectors of coefficients for all educational outcomes. $D$ is a dummy variable indicating criminal involvement of parents, and $X$ represents the vector of background characteristics presented in Table 5.1. The error terms $\varepsilon_{i 1}, \ldots, \varepsilon_{i 5}$ are assumed to be independently and identically distributed across the various educational alternatives $j$ and individuals $i$. The probability for individual $i$ to obtain educational level $j$ (i.e. $E_{j}$ ) is then

$$
\operatorname{Prob}\left(E_{j}\right)=P_{i j}=\frac{\exp \left(\alpha^{\prime} X_{i}+\beta_{j}^{\prime} D_{i}\right)}{\sum_{k=1}^{4} \exp \left(\alpha^{\prime} X_{i}+\beta_{k}^{\prime} D_{i}\right)}
$$




\section{Chapter 5}

The nonlinear nature of the multinomial logit analysis causes that the estimated parameters represent log odds ratios. These ratios cannot be straightforwardly interpreted. Therefore, we calculate marginal effects which represent the probability changes in educational attainment that are associated with the criminal involvement status of the parents. More precisely, they are calculated by averaging the individual marginal effects (Greene, 2000). The marginal effect of $D$ on the probability of choosing education level $j$ is given by

$$
\frac{\partial P_{i j}}{\partial D_{i}}=P_{i j}\left[\beta_{j}-\sum_{k=1}^{4} P_{i k} \beta_{k}\right] .
$$

\subsubsection{Results from the MNL model}

Attaining high education is the base-category in the empirical analysis. The multinomial logit results are presented in Table 5.2. Column 2 shows the estimated log odds ratios, Column RRR shows the relative risk ratios and Column ME shows the calculated marginal effects. The standard errors are presented in parentheses.

The estimated coefficients of $D_{i}$ for completing primary education, lower secondary education and intermediate vocational education are all positive and statistically significant. The coefficient for general secondary education is positive but not statistically significant. This suggests that children whose parents with a criminal record are more likely to finish lower levels of education compared to higher education.

Another way of interpreting the regression results is in terms of relative risk, which refers to the probability of choosing one educational category over the probability of choosing the reference category. The relative risk ratios show that having parents with a criminal record influences the chance of completing primary education, lower secondary education or intermediate vocational education 
5. The relationship between criminal involvement of parents and educational attainment of their children

compared to higher educational by $2.11,1.61$ and 1.62 , respectively. ${ }^{37}$ The marginal effects suggest that the probability of completing primary education as the highest educational level increases by 2.9 percentage points and that the probability of having higher education as the highest educational level decreases by 7.7 percentage points if at least one of the parents was criminally involved.

Table 5-2: Multinomial logit estimates in the full sample

\begin{tabular}{|c|c|c|c|c|c|c|}
\hline Children's education & Coef. & St. Err. & RRR & St. Err. & $\mathrm{ME}$ & St. Err. \\
\hline \multicolumn{7}{|l|}{ (1) Primary } \\
\hline D & $0.747 * *$ & (0.319) & $2.110 * *$ & $(0.672)$ & $0.029 *$ & $(0.017)$ \\
\hline \multicolumn{7}{|l|}{ (2) Lower Second. } \\
\hline D & $0.474 *$ & $(0.278)$ & $1.606^{*}$ & $(0.446)$ & 0.019 & $(0.030)$ \\
\hline \multicolumn{7}{|l|}{ (3) Gener. Second. } \\
\hline D & 0.337 & $(0.276)$ & 1.401 & $(0.386)$ & -0.002 & $(0.025)$ \\
\hline \multicolumn{7}{|l|}{ (4) Intermed. Voc. } \\
\hline D & $0.480 *$ & $(0.256)$ & $1.618^{*}$ & $(0.414)$ & 0.030 & $(0.032)$ \\
\hline \multicolumn{7}{|l|}{ (5) Higher (Ref.) } \\
\hline D & - & & - & & $-0.077^{* *}$ & $(0.038)$ \\
\hline Control variables & Yes & & & & & \\
\hline Pseudo R-squared & 0.153 & & & & & \\
\hline $\mathrm{N}$ & 5.822 & & & & & \\
\hline \multicolumn{7}{|c|}{$\begin{array}{l}\text { Note: The included control variables are: educational attainment of parents, age of } \\
\text { parents, gender of parents, } 1^{\text {st }} \text { generation immigration (dummy), ethnic origin (dummy), } \\
\text { single-parent household (dummy), household size, number of children, ever household } \\
\text { owner (dummy), living in the Randstad area (dummy), age of a child, gender of a child, } \\
\text { whether a child is living in urbanized residence area (dummy). Standard errors are }\end{array}$} \\
\hline
\end{tabular}

The results in Table 5.2 may, however, simply reflect that children whose parents were criminally involved are more likely to be 'lower ability' children from disadvantaged families/neighborhoods who, on average, follow lower educational tracks compared to children whose parents have no criminal involvement in the past. The estimation results, therefore, may simply be the result of comparing children whose parents have a criminal record to non-comparable children whose

37 The mean statistics for educational attainment of children in the control group are presented in Table 5.1 


\section{Chapter 5}

parents have no criminal record. As a consequence, the effect of criminal involvement of parents might be estimated with bias.

\subsubsection{Matching analysis}

To have more certainty that we compare children whose parents have a criminal record to comparable children whose parents have no criminal record, we adopt a matching technique. In particular, we apply a nearest neighbor matching approach (Rubin, 1973), and minimize the Mahalanobis distance between neighbors. Each child whose parents have a criminal record is paired with the best look-a-like child whose parents have no criminal record conditionally on a vector of background characteristics, $X$. The matching variables represent all characteristics included in the multinomial logit model, and they are presented in the form of binary indicators (e.g. gender, nationality) and a continuous variable (i.e. age).

Let $N_{1}$ and $N_{0}$ denote the number of children whose parents have, respectively, a criminal record and no criminal record. The matching approach then gives weights to the $k^{\text {th }}$ observation that could serve as a potential match for student $i$ in $N_{1}$. This weight function is denoted by $w(i, k)$ with $\sum_{j} w(i, k)=1$. The matching estimator for the average treatment effect on the treated is

$$
\Delta=\frac{1}{N_{1}} \sum_{i \in\{D=1\}}\left[U_{1, i j}-\sum_{k} w(i, k) * U_{0, i j}\right]
$$

where $0<w(i, h)<1,\{D=1\}$ is the set of children whose parents were criminally involved and $k$ represents a child from the set $N_{0}$. The weights are obtained by minimizing the Mahalanobis distances of the observed child characteristics:

$$
w(i, k)=1 \text { if } k=\arg \min _{h=1, \ldots, N_{1}}\left(x_{i}-x_{k}\right)^{\prime} \Sigma^{-1}\left(x_{i}-x_{k}\right)
$$


5. The relationship between criminal involvement of parents and educational attainment of their children where $\Sigma^{-1}$ represents the within-sample covariance matrix, and where $w(i, k)=1$ if a match is possible. We note that alternative matching approaches, such as kernel or propensity score matching, are not necessarily inferior to Mahalanobis matching (see Cameron and Trivedi, 2005; Rubin, 2006). Mahalanobis distance was chosen because it does not rely on any functional form or distribution. A functional form assumption may impose a specification bias on the estimated effect of parents' criminal involvement on children's educational outcomes (Yatchew, 1998). To validate the robustness of the Mahalanobis estimator, we also applied propensity score matching and kernel matching. The results generated by these matching estimators are comparable to the Mahalanobis matching results.

Educational attainment can be affected by both nature (e.g. inherited individual's ability) and nurture (e.g. family environment, parenting style) (Bjorklund, Jantti and Solon, 2007; Sacerdote, 2007). To control for individual's ability many studies use IQ score as a proxy (e.g., Altonji and Dunn 1996; Plug and Vijverberg, 2003; Galloway and Pudney, 2011). We, however, do not have this measure in our data. A rapidly growing body of evidence on the intergenerational transmission of education shows that children's education can be both indirectly and directly affected by the educational attainment of parents. Carneiro and Heckman (2003) find that a higher education level of parents leads to higher investments in children. Holmlund et al. (2011), and references therein, sum up the evidence on the causal effects of parents' schooling on child's schooling. They conclude that the causal effects of parents' schooling are relatively small and they represent a large part of the parental nurture effect. Therefore, we establish an exact match on parental education by dividing the children into five different subgroups according to their parents' education level. ${ }^{38}$ By matching on the educational attainment of parents, we can partly control for inherited ability differences.

Parental income is an important driver of the educational attainment of children (e.g. Chevalier, Harmon, O’Sullivan and Walker, 2010; Grimm, 2011),

\footnotetext{
${ }^{38}$ We emphasize that 96 percent of parents finished their schooling and were not in any educational program at the time the questionnaire was taken.
} 
however, because it can be endogenously driven by past criminal involvement, controlling for parental income can lead to biased estimates. For example, if parents' criminal involvement has a negative effect on educational attainment of children because it leads to a negative income shock, we would be controlling for part of the true treatment effect of criminal involvement of parents to education attainment of children. Therefore, we do not include income as a control in the analysis.

Exact matching on parental education level yields five subgroups. For each subgroup we perform one-to-one nearest neighbor matching with replacement on a broad range of demographic variables, including parents' gender, parents' age, ethnic origin, nationality, single-parent household, household size, number of children, whether someone was ever a house owner, whether someone lives in the Randstad metropolitan area, child's gender, age of the child, and urbanization level of the area where the child lives.

Table 5.3 shows the descriptive statistics for children whose parents have a criminal record (treatment group) and for the matched children whose parents have no criminal record (control group). The last two columns of the table indicate that the difference between means of the two groups is not statistically significant. The parental education levels are identical for both groups due to the exact matching on parental education level.

The average educational attainment of children in the control and intervention group is shown in Table 5.4. The table indicates that children whose parents have a criminal record more often completed primary education as the highest level of education attained and less often finished a higher education level. 
5. The relationship between criminal involvement of parents and educational attainment of their children

Table 5-3: Descriptive statistics for the matched sample

\begin{tabular}{|c|c|c|c|c|c|c|}
\hline \multirow[b]{2}{*}{ Parents/household } & \multicolumn{2}{|c|}{$\begin{array}{l}\text { Parents with } \\
\text { no criminal record }\end{array}$} & \multicolumn{2}{|c|}{$\begin{array}{l}\text { Parents with } \\
\text { a criminal record }\end{array}$} & \multicolumn{2}{|c|}{$\begin{array}{c}\text { Mean } \\
\text { differences }\end{array}$} \\
\hline & Mean & Std. Dev. & Mean & Std. Dev. & $\Delta$ & St. Err. \\
\hline Age & 56.310 & 9.689 & 55.467 & 9.072 & 0.843 & 0.853 \\
\hline $1^{\text {st }}$ gen. immigr. & 0.161 & 0.368 & 0.161 & 0.368 & & \\
\hline Dutch & 0.971 & 0.168 & 0.971 & 0.168 & 0 & 0 \\
\hline Women & 0.372 & 0.484 & 0.322 & 0.468 & 0.050 & 0.043 \\
\hline Single-parent & 0.145 & 0.253 & 0.163 & 0.260 & -0.019 & 0.023 \\
\hline Household size & 2.607 & 1.338 & 2.711 & 1.437 & -0.103 & 0.126 \\
\hline Household size & 2.607 & 1.338 & 2.711 & 1.437 & -0.103 & 0.126 \\
\hline No. of children & 2.679 & 1.264 & 2.661 & 1.333 & 0.017 & 0.118 \\
\hline Ever house owner & 0.649 & 0.478 & 0.640 & 0.481 & 0.008 & 0.044 \\
\hline Randstad area & 0.380 & 0.486 & 0.409 & 0.493 & -0.029 & 0.045 \\
\hline \multicolumn{7}{|l|}{ Parents' education } \\
\hline (1) Primary & 0.231 & 0.423 & 0.231 & 0.423 & 0 & 0 \\
\hline (2) Lower Second. & 0.318 & 0.467 & 0.318 & 0.318 & 0 & 0 \\
\hline (3) Gener. Second. & 0.033 & 0.179 & 0.033 & 0.179 & 0 & 0 \\
\hline (4) Interm. Vocat. & 0.182 & 0.386 & 0.182 & 0.386 & 0 & 0 \\
\hline (5) Higher & 0.236 & 0.425 & 0.236 & 0.425 & 0 & 0 \\
\hline \multicolumn{7}{|l|}{ Child: } \\
\hline Women & 0.471 & 0.500 & 0.450 & 0.499 & 0.021 & 0.045 \\
\hline Age & 29.211 & 9.677 & 28.318 & 9.577 & 0.893 & 0.875 \\
\hline Urbanized area & 0.632 & 0.483 & 0.628 & 0.484 & 0.004 & 0.044 \\
\hline No. obs. & 242 & & 242 & & & \\
\hline
\end{tabular}

Table 5-4: Educational outcomes of children in the matched sample

\begin{tabular}{lllllll}
\hline & \multicolumn{3}{c}{$\begin{array}{c}\text { Parents with } \\
\text { no criminal record }\end{array}$} & \multicolumn{2}{c}{$\begin{array}{c}\text { Parents with } \\
\text { a criminal record }\end{array}$} & \multicolumn{2}{c}{ Mean differences } \\
Children's education & Mean & Std. Dev. & Mean & Std. Dev. & $\Delta$ & St. Err. \\
\cline { 2 - 7 } (1) Primary & 0.132 & 0.339 & 0.215 & 0.412 & $-0.083^{* * *}$ & 0.034 \\
(2) Lower Second. & 0.293 & 0.456 & 0.289 & 0.454 & 0.004 & 0.041 \\
(3) Gen. Second. & 0.136 & 0.344 & 0.140 & 0.348 & -0.004 & 0.031 \\
(4) Interm. Vocat. & 0.223 & 0.417 & 0.219 & 0.414 & 0.004 & 0.038 \\
(5) Higher & 0.215 & 0.412 & 0.136 & 0.344 & $0.079 * *$ & 0.034 \\
No. obs. & 242 & & 242 & & & \\
\hline
\end{tabular}

Note: $\quad " \rho \leq 0.1 .{ }^{* *} \rho \leq 0.05$. ${ }^{* * * *} \rho \leq 0.01$. 
To increase the efficiency of the matching estimates, we analyze the matched sample by controlling for different background characteristics (Rubin, 1973, 1979; Rubin and Thomas, 2000). The estimation results of the multinomial logit model are shown in Table 5.5. From the results in the second column, the estimated $D$ parameter for primary education is positive and statistically significantly, indicating that having parents with a criminal record increases the probability of completing primary education relatively to completing higher education. The estimates for criminal involvement of parents for lower secondary, general secondary and intermediate vocational education are positive but not statistically significant. The relative risk ratio of primary education compared to higher education attainment is 3.57 for children with criminally involved parents. ${ }^{39}$ The marginal effects indicate that the probability of finishing primary education as the highest education level increases by 7.9 percentage points and that the probability of finishing higher education decreases by 6.1 percentage points if at least one of the parents had a criminal record.

We mentioned above that the results in Table 5.2 may be driven by differences in background characteristics between children whose parents have a criminal record and children whose parents have no criminal record. In the matching analysis, we compare children with criminally involved parents to comparable children whose parents have no criminal past. The magnitude of the effects in Table 5.5 is different compared to those in Table 5.2: the magnitude of the effect for primary education increase considerably, while the magnitude of the effect for higher education slightly decreases.

\footnotetext{
${ }^{39}$ The mean educational attainment of the children is reported in Table 5.4
} 
5. The relationship between criminal involvement of parents and educational attainment of their children

Table 5-5: Multinomial logit estimates in the matched sample

\begin{tabular}{lllllll}
\hline Children's education & Coef. & St. Err. & RRR & St. Err. & ME & St. Err. \\
\cline { 2 - 7 } $\begin{array}{l}\text { (1) Primary } \\
D\end{array}$ & $1.272^{* * *}$ & $(0.433)$ & $3.569 * * *$ & $(1.545)$ & $0.079^{* *}$ & $(0.032)$ \\
$\begin{array}{l}(2) \text { Lower Second. } \\
D\end{array}$ & 0.547 & $(0.389)$ & 1.728 & $(0.640)$ & -0.012 & $(0.047)$ \\
$\begin{array}{l}(3) \text { Gener. Second. } \\
D\end{array}$ & 0.500 & $(0.383)$ & 1.648 & $(0.632)$ & -0.007 & $(0.031)$ \\
$\begin{array}{l}(4) \text { Interm. Vocat. } \\
D\end{array}$ & 0.540 & $(0.365)$ & 1.716 & $(0.627)$ & 0.001 & $(0.040)$ \\
$\begin{array}{l}(5) \text { Higher E. (Ref.) } \\
D\end{array}$ & & & & & & \\
Control variables & Yes & & & & $-0.061^{*}$ & $(0.033)$ \\
$\begin{array}{l}\text { Pseudo R-squared } \\
\text { No. obs. }\end{array}$ & 0.235 & & & & & \\
\hline
\end{tabular}

Note: The control variables include educational attainment of parents, age of parents, gender of parents, $1^{\text {st }}$ generation immigration (dummy), ethnic origin (dummy), singleparent household (dummy), household size, number of children, ever household owner (dummy), living in the Randstad area (dummy), age of a child, gender of a child, whether a child is living in urbanized residence area (dummy). Standard errors are clustered the family level and presented in parentheses. $\quad " \rho \leq 0.1 . \quad \rho \leq 0.05 . \quad \rho \leq 0.01$.

\subsection{Robustness analyses}

\subsubsection{How sensitive are the estimates to selection on unobservables?}

In this section, we examine if the estimated effect of having parents with a criminal record is not simply the result of unobserved factors. We start with estimating how much of the association is accounted for by observable heterogeneity. First, we estimate a bivariate probit model with no controls included to estimate the effect of criminal involvement of parents on the 'extreme' categories of educational attainment of their children (i.e. primary education and higher education) for the full sample. The results are presented in Column 2 of Table 5.6. Marginal effects are presented in brackets.

The estimated marginal effect without controls is 8.2 percentage points and highly statistically significantly. When we add the full set of controls, the marginal effect reduces to 3.2 percentage points, while the pseudo- $R^{2}$ rises substantially from 0.005 to 0.28 . For the higher education category we observe a similar pattern: 


\section{Chapter 5}

the marginal effect reduces from -19 to -8 percentage points and the pseudo$R^{2}$ changes from 0.005 to 0.16 . Thus, even when we control for a large set of covariates, criminal involvement of parents appears to be a powerful predictor of children's educational attainment. The effect of parents' criminal involvement on primary education and higher education attainment of children remains relatively large and statistically significant. A similar exercise is performed for the matched sample and the results are shown in the third column of Table 5.6. As already mentioned above, the matched sample has a treated and a control group with similar distributions of observable characteristics. Therefore, applying the matching procedure, we already take into account the (observable) differences between children whose parents have a criminal record and children whose parents have no criminal record. The estimated marginal effect for primary education is 8.3 percentage points without the inclusion of control variables and nine percentage points when the control variables are included. These marginal effects are larger compared to the full-sample results with controls, which might be explained by the sample composition and also differences in the assumptions (i.e. including covariates as controls vs matching on covariates).

For the higher education category, the estimated marginal effect for the matched sample without control variables is -7.8 percentage points and it reduces to -6.2 percentage points when the control variables are included. The pseudo- $R^{2}$ rises from 0.012 to 0.250 due to the inclusion of the covariates. Assuming that there is a certain amount of unobserved heterogeneity, we can refer to these estimates as upper bound estimates (in absolute terms). 
5. The relationship between criminal involvement of parents and educational attainment of their children

Table 5-6: Estimates for primary education and higher education in a probit model

\begin{tabular}{lll}
\hline & Full Sample & Matched S \\
\cline { 2 - 3 } Primary education & & \\
No controls & $\left(0.415^{* * *}\right.$ & $0.326^{* *}$ \\
& {$[0.082]$} & $(0.136)$ \\
& 0.005 & {$[0.083]$} \\
Pseudo- $R^{2}$ & $0.223^{*}$ & 0.013 \\
Controls & $(0.129)$ & $0.501^{* * *}$ \\
& {$[0.032]$} & $(0.169)$ \\
& 0.275 & {$[0.090]$} \\
Pseudo- $R^{2}$ & & 0.276 \\
Higher education & $-0.558^{* * *}$ & \\
No controls & $(0.102)$ & $-0.307^{* *}$ \\
& {$[-0.190]$} & $(0.135)$ \\
& 0.005 & {$[-0.078]$} \\
Pseudo- $R^{2}$ & $-0.282^{* *}$ & 0.012 \\
Controls & $(0.125)$ & $-0.321^{*}$ \\
& {$[-0.080]$} & $(0.170)$ \\
& 0.163 & {$[-0.062]$} \\
Pseudo- $R^{2}$ & 5.822 & 0.250 \\
No. obs. & & 484 \\
\hline
\end{tabular}

Note: The control variables include educational attainment of parents, age of parents, gender of parents, $1^{\text {st }}$ generation immigration (dummy), ethnic origin (dummy), singleparent household (dummy), household size, number of children, ever household owner (dummy), living in the Randstad area (dummy), age of a child, gender of a child, whether a child is living in urbanized residence area (dummy). Standard errors are clustered at the family level. Standard errors are in parentheses and the marginal effects are in brackets. * $\rho \leq 0.1 . \quad \rho \leq 0.05 . \quad \rho \leq 0.01$.

Further, we would like to test whether the estimated effect cannot be explained entirely by selection on unobservables. Following Altonji et al. (2005), we estimate a bivariate probit model and impose constraints on the correlation between unobserved factors that influence criminal involvement of parents and the educational attainment of children. The following bivariate probit model is considered:

$$
\begin{gathered}
D_{i}=1\left(X_{i}^{\prime} \lambda+u_{i}>0\right), \\
Y_{i}=1\left(X_{i}^{\prime} \gamma+\alpha_{i} D_{i}+\varepsilon_{i}>0\right), \\
{\left[\begin{array}{l}
u \\
\varepsilon
\end{array}\right] \sim N\left(\left[\begin{array}{l}
0 \\
0
\end{array}\right]\left[\begin{array}{ll}
1 & \rho \\
\rho & 1
\end{array}\right]\right),}
\end{gathered}
$$




\section{Chapter 5}

where the parameter $\rho$ represents the correlation between the error terms $\varepsilon_{i}$ and $u_{i}$. The correlation between the error term captures how unobserved factors affect outcome $Y_{i}$ and the probability of having criminal parents $D_{i}$. Altonji et al. (2005, 2008) assign different values for $\rho$, and estimate the bivariate probit model conditionally on these $\rho$-values to analyze if the parameter of interest changes statistically significantly. We also perform similar approach and let $\rho$ vary between 0 and 0.25 (with 0.05 intervals) for primary education and let $\rho$ vary from 0 to -0.25 (with 0.05 intervals) for higher education. The range of $\rho$ commonly used in the literature varies from 0 to 0.5 or to -0.5 (Altonji et al., 2005; Hjalmarsson, 2008; Ward and Williams, 2014). The negative $\rho$-values for higher education indicate that the correlation between criminal involvement of parents and higher education is negative.

The results for the full sample are shown in Table 5.7, in Panel A. The values presented between brackets are the estimated marginal effects. When $\rho=0$, then it implies that all selection comes from observables, and the estimation results are then similar to those presented in Table 5.6. If we increase $\rho$ to $(-) 0.05$, then this is sufficient to make the coefficients of interest for the full sample statistically insignificant. Increasing $\rho$ to 0.25 in the full sample shifts the coefficient for primary education to a negative and statistically significant value and the coefficients for higher education to a positive and statistically significant value. 
5. The relationship between criminal involvement of parents and educational attainment of their children

Table 5-7: Estimation results of bivariate probit models for different $\rho$-values

\begin{tabular}{llllllll}
\hline Full sample & & \multicolumn{7}{c}{ Panel $A$} \\
\hline \multirow{4}{*}{ Primary } & $\rho=0.00$ & $\rho=0.05$ & $\rho=0.10$ & $\rho=0.15$ & $\rho=0.20$ & $\rho=0.25$ & $\rho=0.12$ \\
education & $0.223^{*}$ & 0.120 & 0.018 & -0.083 & -0.183 & $-0.282^{* *}$ & -0.002 \\
& $(0.129)$ & $(0.128)$ & $(0.127)$ & $(0.127)$ & $(0.126)$ & $(0.124)$ & $(0.127)$ \\
& {$[0.032]$} & {$[0.017]$} & {$[0.003]$} & {$[-0.012]$} & {$[-0.026]$} & {$[-0.040]$} & {$[-0.003]$} \\
& $\rho=0.00$ & $\rho=-0.05$ & $\rho=-0.10$ & $\rho=-0.15$ & $\rho=-0.20$ & $\rho=-0.25$ & $\rho=-0.05$ \\
Higher & $-0.282^{* *}$ & -0.172 & -0.060 & -0.053 & 0.168 & $0.284 * *$ & -0.172 \\
education & $(0.125)$ & $(0.124)$ & $(0.123)$ & $(0.122)$ & $(0.121)$ & $(0.120)$ & $(0.124)$ \\
& {$[-0.080]$} & {$[-0.049]$} & {$[-0.017]$} & {$[0.015]$} & {$[0.049]$} & {$[0.081]$} & {$[-0.049]$} \\
\hline Matched & & & \multicolumn{3}{c}{ Panel $B$} \\
\hline \multirow{4}{*}{ Primary } & $\rho=0.00$ & $\rho=0.05$ & $\rho=0.10$ & $\rho=0.15$ & $\rho=0.20$ & $\rho=0.25$ & $\rho=0.07$ \\
education & $0.501^{* * *}$ & $0.420^{* * *}$ & $0.339 * *$ & 0.257 & 0.174 & 0.090 & $0.389 * *$ \\
& $(0.169)$ & $(0.169)$ & $(0.169)$ & $(0.168)$ & $(0.167)$ & $(0.166)$ & $(0.169)$ \\
& {$[0.089]$} & {$[0.075]$} & {$[0.061]$} & {$[0.046]$} & {$[0.031]$} & {$[0.016]$} & {$[0.069]$} \\
Higher & $\rho=0.00$ & $\rho=-0.05$ & $\rho=-0.10$ & $\rho=-0.15$ & $\rho=-0.20$ & $\rho=-0.25$ & $\rho=-0.12$ \\
education & $-0.327^{*}$ & -0.247 & -0.166 & -0.084 & -0.002 & 0.080 & -0.133 \\
& $(0.178)$ & $(0.178)$ & $(0.178)$ & $(0.177)$ & $(0.176)$ & $(0.174)$ & $(0.177)$ \\
& {$[-0.059]$} & {$[-0.044]$} & $(-0.030)$ & {$[-0.015]$} & {$[-0.001]$} & {$[0.015]$} & {$[-0.024]$} \\
\hline
\end{tabular}

Note: $\rho=\hat{\rho}$ denotes to: selection on unobservables=selection on observables. Standard errors are clustered at the family level. Standard errors are in parentheses and the marginal effects are in brackets. ${ }^{*} \rho \leq 0.1 .{ }^{* *} \rho \leq 0.05$. ${ }^{* * * * *} \rho \leq 0.01$.

The results for the matched sample are presented in Panel B of Table 5.7. The effect for primary education remains positive and highly statistically significantly even when we increase $\rho$ to 0.10 . Therefore, this sensitivity analysis indicates that the statistically significant and positive effect is robust even in the presence of a substantial amount of selection on unobservables. The estimate for higher education in the matched sample is similar to those in the full sample: when $\rho$ is increased to 0.05 then the statistical significance disappears. The sensitivity analysis presented in Table 5.7, therefore, suggests that the results for primary education in the matched sample are more robust than those for higher education.

The sensitivity analysis performed above does not provide information on what values of $\rho$ are plausible. To address this issue, we again following Altonji et al. $(2005,2008)$ and impose that the effects of selection on unobservables is as large as the effects of selection on observables. As is described in Altonji et al. $(2005,2008)$, the estimates obtained in this analysis can be viewed as lower bound estimates (in 
absolute terms) of the treatment effect. We maximize the likelihood of the bivariate probit imposing $\rho=\operatorname{Cov}\left(X \beta, X^{\gamma}\right) / \operatorname{Var}\left(X^{\prime} \gamma\right)$ and obtain a point estimate of the criminal involvement effect. In the last column of Panel A and Panel B in Table 5.7, we present these estimation results while assuming that the effect of selection on unobservables is equal to the effect of selection on observables. The estimates for primary education and higher education in the full sample are not anymore statistically significant, even though the estimate for higher education is rather sizable (-4.9 p.p.). For the matched sample, the estimated marginal effect for primary education is 6.9 percentage points and it is statistically significant at the five percent level. The estimate for higher education is statistically insignificant, even though it has the expected negative sign and remains rather large in magnitude. Hence, under the assumption that selection on observables is as large as selection on unobservable, we find that our results appear to be rather robust.

Finally, we follow a different approach in Altonji et al. (2005) to examine in an alternative manner if the estimated effects can be entirely explained by selection on unobservables. We consider

$$
\frac{E(\varepsilon \mid D=1)-E(\varepsilon \mid D=0)}{\operatorname{var}(\varepsilon)}=\lambda \frac{E\left(X_{i}^{\prime} \hat{\beta} \mid D=1\right)-E\left(X_{i}^{\prime} \hat{\beta} \mid D=0\right)}{\operatorname{var}\left(X_{i}^{\prime} \hat{\beta}\right)}
$$

The equation shows that the selection on unobserved factors is $\lambda$ times as strong as the selection on observed characteristics, after adjustment for variance. The selection on observables is equal to the selection on unobservables if $\lambda=1$. Given the specification in equation (5-8), we can compute how large $\lambda$ should be such that the estimated effect is entirely explained by selection on unobservables. Under the hypothesis that the estimate obtained in the probit is entirely explained by selection on unobservables: 
5. The relationship between criminal involvement of parents and educational attainment of their children

$$
\lambda=\hat{\alpha}\left(\frac{\operatorname{Var}(D)}{\operatorname{Var}(\tilde{D})} \frac{\left[E\left(X_{i}^{\prime} \hat{\beta} \mid D=1\right)-E\left(X_{i}^{\prime} \hat{\beta} \mid D=0\right)\right]}{\operatorname{Var}\left(X_{i}^{\prime} \hat{\beta}\right)}\right)^{-1},
$$

where $\widetilde{D}$ represents the residuals from a regression of $D$ on $X$ (see Altonji et al., 2005; Dujardin and Goffette-Nagot, 2010). Assuming that having criminal parents has no effect on educational attainment, such that $\hat{\alpha}=0$, we can estimate $\beta$, and thus $E\left(X_{i}^{\prime} \hat{\beta} \mid D\right)$.

The estimation results of this method are presented in Table 5.8. For primary education for the full sample, the estimate of $\left(E\left(X_{i}^{\prime} \hat{\beta} \mid D=1\right)-E\left(X_{i}^{\prime} \hat{\beta} \mid D=0\right)\right) / \operatorname{Var}\left(X_{i}^{\prime} \hat{\beta}\right)$ is 0.09 . By multiplying this value by $\operatorname{Var}(D) / \operatorname{Var}(\hat{D})$, which equals 1.036 , we obtain the absolute value of the bias, which is 0.09 . If we calculate the absolute bias relative to the estimated effect of having criminal parents $(\hat{\alpha}=0.22)$ we find a value of 2.41 , which indicates that the estimated effect of having parents with a criminal record can only be entirely driven by unobserved factors if there is 2.41 as much selection on unobservables than that there is selection on observables. For the matched sample, this value equals 2.80 , indicating that it is unlikely that the estimated effects for primary education are solely driven by selection on unobservables.

For higher education, we find for the full (matched) sample that the estimated effect of having parents with a criminal record can only be entirely driven by unobserved factors if there is $3.10(2.70)$ as much selection on unobservables as there is selection on observables. Therefore, the results in Table 5.8 indicate that the estimated effects can only be driven by selection on unobserved factors if there is roughly three times as much selection on unobservables as selection on observables, which seems unlikely.

Finally, it is important to recognize that the different sensitivity analyses are complements rather than substitutes. If we assume that the matching results provide us with estimates that are less biased, we conclude that the sensitivity analyses generally suggest that the results for primary education are robust and that 
Chapter 5

a substantial amount of selection on unobservables, relative to the selection on observables, is needed to explain the entire estimated effect. The results for higher education seem less robust in terms of statistical significance, even though the effect sizes are quite large. Similar to primary education the results suggest that a substantial amount of selection on unobservables relative to the selection on observables is needed to explain the entire estimated effect.

Table 5-8: The relative amount of selection on unobservables required to explain the probit estimate

Primary education

$\hat{\alpha}$

$\frac{\hat{E}\left(X_{i}^{\prime} \hat{\beta} \mid D_{i}=1\right)-\hat{E}\left(X_{i}^{\prime} \hat{\beta} \mid D_{i}=1\right)}{\hat{\operatorname{Var}}\left(X_{i}^{\prime} \hat{\beta}\right)}$

$0.223^{*}$

$0.501 * * *$

0.090

0.174

$\widehat{\operatorname{Var}}\left(D_{i}\right) / \widehat{\operatorname{Var}}\left(\tilde{D}_{i}\right)$

1.036

1.023

Bias (absolute value)

0.093

0.179

$\hat{\alpha} /$ Bias (absolute value)

2.405

2.801

Higher education

$\frac{\hat{E}\left(X_{i}^{\prime} \hat{\beta} \mid D_{i}=1\right)-\hat{E}\left(X_{i}^{\prime} \hat{\beta} \mid D_{i}=1\right)}{\hat{\operatorname{Var}}\left(X_{i}^{\prime} \hat{\beta}\right)}$

$\widehat{\operatorname{Var}}\left(D_{i}\right) / \widehat{\operatorname{Var}}\left(\tilde{D}_{i}\right)$

$-0.282^{* *}$

$-0.327^{*}$

$-0.088$

$-0.118$

Bias (absolute value)

1.036

1.023

$\hat{\alpha} /$ Bias (absolute value)

0.091

0.121

Note: $\beta$ is estimated by the OLS model and the estimated effect presented as an absolute

value. $\quad \rho \leq 0.1$. $\rho \leq 0.05$. $\rho \leq 0.01$.

\subsubsection{How do the empirical findings depend on the definition of the outcome measure?}

In the empirical analysis, we have used educational spells that are finished, even though some children were still acquiring education at the time the survey was held. To check if the estimated effect of having criminally involved parents change if we take into account these unfinished spells, we re-estimate the model and consider a restricted children's sample who are older than 25 , as individuals in this age are 
5. The relationship between criminal involvement of parents and educational attainment of their children

usually finished with their formal education (OECD, 2014). In the matched sample, around 57 percent of observations are older than 25 . The estimation results are presented in Table 5.9.

The results show that the estimated marginal effects of having criminally involved parents for this restricted sample change. More specifically, the results show a 6 percentage point and 10 percentage point increase in finishing primary education and lower secondary education, respectively, and a 15 percentage points decrease in completing higher education. We therefore conclude that the bias of considering unfinished education spells reduces the general estimates, but only at the top of the educational attainment distribution. ${ }^{40}$

Table 5-9: Multinomial logit results for the restricted sample of children older than 25

\begin{tabular}{lllllll}
\hline Children's education & Coef. & St. Err. & RRR & St. Err. & ME & St. Err. \\
\cline { 2 - 7 } $\begin{array}{l}\text { (1) Primary } \\
D\end{array}$ & $2.133^{* * *}$ & $(0.742)$ & $8.436^{* * *}$ & $(6.256)$ & $0.056^{*}$ & $(0.032)$ \\
$\begin{array}{l}(2) \text { Lower Second. } \\
D\end{array}$ & $1.349^{* *}$ & $(0.513)$ & $3.855^{* * *}$ & $(1.979)$ & $0.101^{*}$ & $(0.058)$ \\
$\begin{array}{l}(3) \text { Gener. Second. } \\
D\end{array}$ & 0.748 & $(0.539)$ & 2.113 & $(1.139)$ & -0.006 & $(0.029)$ \\
$\begin{array}{l}(4) \text { Interm. Vocat. } \\
D\end{array}$ & 0.897 & $(0.454)$ & $2.453^{* *}$ & $(1.114)$ & -0.002 & $(0.060)$ \\
$\begin{array}{l}(5) \text { Higher (Ref.) } \\
D\end{array}$ & & & & & & \\
Control variables & Yes & & & & $-0.150^{* * *}$ & $(0.051)$ \\
$\begin{array}{l}\text { Pseudo R-squared } \\
\text { No. obs. }\end{array}$ & 0.264 & & & & & \\
\hline
\end{tabular}

Note: Standard errors are clustered at the family level and presented in parentheses. The included control variables are educational attainment of parents, age of parents, gender. " $\rho \leq 0.1 . \quad{ }^{* * *} \rho \leq 0.05 . \quad \rho \leq 0.01$.

\footnotetext{
${ }^{40}$ We also reestimate the model using years of schooling and by using an education variable for which we assume that all children who are still in education will finish this education level successfully. The estimation results of these robustness analyses are very similar to the results shown in Table 5.5 and 5.9.
} 
Table 5-10: Multinomial logit estimates in the matched sample

\begin{tabular}{lllll}
\hline $\begin{array}{l}\text { Children's education } \\
\text { (1) Primary }\end{array}$ & Coef. & St. Err. & ME & St. Err. \\
$D$ & & & & \\
Mother*D & $1.278^{* *}$ & $(0.573)$ & $0.125^{* * *}$ & $(0.044)$ \\
$\begin{array}{l}\text { (2) Lower Second. } \\
D\end{array}$ & 0.550 & $(0.854)$ & -0.098 & $(0.060)$ \\
$\begin{array}{l}\text { Mother*D } \\
\text { (3) Gener. Second. }\end{array}$ & -0.019 & $(0.481)$ & -0.064 & $(0.058)$ \\
$D$ & $1.848^{* *}$ & $(0.815)$ & 0.143 & $(0.091)$ \\
Mother*D & 0.203 & $(0.460)$ & -0.006 & $(0.037)$ \\
$\begin{array}{l}\text { (4) Interm. Vocat. } \\
D\end{array}$ & 1.083 & $(0.831)$ & -0.004 & $(0.064)$ \\
$\begin{array}{l}\text { Mother*D } \\
\text { (5) Higher (Ref.) }\end{array}$ & -0.048 & $(0.451)$ & -0.042 & $(0.048)$ \\
$D$ & $1.871^{* *}$ & $(0.815)$ & 0.116 & $(0.082)$ \\
$\begin{array}{l}\text { Mother*D } \\
\text { Control variables }\end{array}$ & & & & \\
Pseudo R-squared & 0.242 & & -0.013 & $(0.040)$ \\
No. obs. & & & $-0.158^{* *}$ & $(0.070)$ \\
\hline
\end{tabular}

Note: The included variables are educational attainment of parents, age of parents, gender of parents, $1^{\text {st }}$ generation immigration (dummy), ethnic origin (dummy), single-parent household (dummy), household size, number of children, ever household owner (dummy), living in the Randstad area (dummy), age of a child, gender of a child, whether a child is living in urbanized residence area (dummy). Standard errors are clustered at the family level and presented in parentheses. ${ }^{*} \rho \leq 0.1$. ${ }^{* *} \rho \leq 0.05$. ${ }^{* * * *} \rho \leq 0.01$.

\subsubsection{Does it matter if mothers or fathers are criminally involved?}

The effect of parental criminal involvement on children's educational attainment may depend on the gender of the parent who has a criminal record. Therefore, we interact the criminal involvement variable with a parental gender variable (where having a criminally involved father is the baseline). The results of this analysis are presented in Table 5.10 .

It appears that children at the bottom of the educational attainment distribution are more affected if fathers are criminally involved, while children at the top of the educational attainment distribution are more affected if the mothers are criminally involved. More specifically, the effect of crime on education is only statistically significant for primary education when the father is criminally involved 
5. The relationship between criminal involvement of parents and educational attainment of their children

and only statistically significant for high education when the mother is criminally involved.

Table 5-11: Multinomial logit estimates in the matched sample of children whose parents were convicted

Children's education

Coef.

RRR

ME

(1) Primary

$D$

$1.740^{* *}$

$5.697^{* *}$

$0.128^{* *}$

(0.870)

(4.955)

(0.032)

(2) Lower Second.

\section{D}

$$
0.450
$$

1.568

$-0.032$

(0.703)

(0.071)

(3) Gener. Second.

$$
D
$$

$$
0.002
$$

$-0.050$

(0.673)

(0.674)

(4) Interm. Vocat.

$D$

(5) Higher (Ref.)

D

(0.698)

(1.111)
0.002

(0.057)

$-0.047$

(0.050)

Control variables Yes

Pseudo R-squared $\quad 0.329$

N 194

Note: Standard errors are clustered at the family level and presented in parentheses. The included control variables are educational attainment of parents, age of parents, gender of parents, $1^{\text {st }}$ generation immigration (dummy), ethnic origin (dummy), single-parent household (dummy), household size, number of children, ever household owner (dummy), living in the Randstad area (dummy), age of a child, gender of a child, whether a child is living in urbanized residence area (dummy). ${ }^{*} \rho \leq 0.1 .{ }^{* *} \rho \leq 0.05 . \quad \rho \leq 0.01$.

\subsubsection{Does it matter if one of the parents was convicted?}

Since being convicted is different than being arrested, we examine the effect of having parents with past criminal convictions on the educational attainment of their children. For this purpose, we consider a treatment group that includes children whose parents were convicted, and we match it to a comparable group of children whose parents have no criminal record. 
There were 97 families with convicted parents and it follows that the sample size of the matched sample is $194 .^{41}$ The estimation results are shown in Table 5.11. The results suggest that having convicted parents increases the probability of finishing primary education at the highest level of education by 13 percentage points, which is statistically significantly higher than the effect found for criminal behavior in general. The estimates for the other educational categories are, however, not statistically significant. ${ }^{42}$

\subsubsection{Measurement error}

The social desirability literature suggests that people tend to underreport undesirable behavior and overreport desirable behavior (e.g. Phillips and Clancy, 1972; Kalton and Schuman, 1982). Criminal behavior is socially not accepted and it is very unlikely that adults over-report criminal behavior, unless they are diagnosed with an antisocial personality disorder (Nieves, Draine and Solomon, 2008) or provide information on victimization events (see Levine, 1976). Hence, we conclude that respondents generally do not overreport their criminal behavior, and we focus in this section on the problem of underreporting criminal involvement.

To understand how misreporting of treatment status can affect the estimated treatment effect, we refer to studies on measurement error in binary treatment variables (Aigner, 1973; Bollinger, 1996; Lewbel, 2007). These studies show that failure to account for misclassification generally results in attenuation bias in the estimated treatment effect.

Let $\lambda_{0}(x)$ denote the probability of having no criminal record given that the respondents report having no criminal record $(D=0)$, and $\lambda_{1}(x)$ indicate the probability of having a criminal record, given that respondents report having a criminal record $(D=1)$. $D^{*}$ represents the unobserved true criminal status, $Y$ denotes the educational outcome variable, and $\mathrm{X}$ represents a covariate vector. Below, we

\footnotetext{
${ }^{41}$ The matching was done conditionally on the conviction status of parents.

${ }^{42}$ Part of this can be driven by smaller sample size and reduced statistical power.
} 
5. The relationship between criminal involvement of parents and educational attainment of their children

define the bounds of the true effect when a binary dependent variable, criminal involvement of parents, is subject to misclassification and certain identifying assumptions hold. The first assumption is about non-differential measurement error (see, e.g., Lewbel, 2007; Battistin and Sianesi, 2011), which states that $E\left(Y \mid X, D^{*}, D\right)=E\left(Y \mid X, D^{*}\right)$ and imposes that $Y$ is mean independent of $D-D^{*}$, conditional on $X$ and $D^{*}$. We note that the assumption that underreporting criminal behavior is independent of background characteristics is a non-testable and strong assumption. One can argue that educational level and misreporting can correlate with each other, while the outcome (educational attainment of children) relates to the education of the parents as well. If there is a positive correlation between misreporting and parental education, the estimates can be biased upwards (in absolute terms). However, the literature suggests that higher rates of underreporting of socially undesirable behavior are more frequently found among lower educated individuals (e.g. Parry, Balter and Cisin, 1970; Wagenknecht, Burke, Perkins, Haley and Friedman, 1992; Fendrich and Vaughn, 1994). Parents with higher levels of education can misreport their behavior to avoid embarrassment (Tourangeau and Yan, 2007). There is only a small share of criminals among individuals with higher levels of education, in particular white-collar criminals (see, e.g., Lochner, 2004). Therefore, we expect that a correlation between underreporting of criminal involvement and parental education is negative and this would lead to attenuation bias.

The second assumption is that the sum of misclassification probabilities is less than 1 . This assumption is intuitive, as it implies that on average, observations of $D$ are more accurate than pure guesses (see, e.g., Bollinger, 1996; Lewbel, 2007; Battistin and Sianesi, 2011). As we pointed out above, it is unlikely that individuals over-report their criminal behavior, and therefore the probability of honestly reporting criminal involvement equals 1 (i.e. $\lambda_{1}(x)=1$ ), while the probability of honestly reported non-criminal involvement is positive and $0 \geq \lambda_{0}(x)>0$. 
Chapter 5

Under these identifying assumptions, the true ATE can be expressed as follows (Battistin and Sianesi, 2011):

$$
\Delta^{*}(x)=\frac{\Delta(x)}{\lambda_{0}(x)+\lambda_{1}(x)-1}
$$

We allow $\lambda_{0}(x)$ to range between 0.6 and 1 with an interval of 0.1 , and hence we assume that the total probability of underreporting is not larger than 0.4. Table 5.12 shows how the estimated ATE is bounded under the identifying assumptions and while holding $\lambda_{1}(x)$ constant.

The estimated effects when there is no underreporting behavior (i.e. when $\left.\lambda_{0}(x)=1\right)$, are taken from Tables 5.2 and 5.4. The absolute values of these estimated effects are lower bound estimates. Table 5.12 shows that conditionally on the observed covariates $X$, the magnitude of the estimated ATE is rising if the total probability of honestly reported non-criminal involvement lowers. This holds for the full sample, as well as for the matched sample. The results indicate that the estimates are not far removed from the estimated coefficients when $\lambda_{0}(x)=1$ even if we allow for a considerable amount of underreporting behavior.

Table 5-12: Sensitivity of the outcome to underreporting of criminal involvement

\begin{tabular}{lllll}
\hline & Full sample & \multicolumn{3}{c}{ Matched sample } \\
& Primary E. & Primary E. & Primary E. & Higher E. \\
\hline$\lambda_{0}(x)=1$ & 0.029 & -0.077 & 0.083 & -0.079 \\
$\lambda_{0}(x) \geq 0.9$ & 0.032 & -0.086 & 0.092 & -0.088 \\
$\lambda_{0}(x) \geq 0.8$ & 0.036 & -0.096 & 0.104 & -0.099 \\
$\lambda_{0}(x) \geq 0.7$ & 0.041 & -0.110 & 0.119 & -0.113 \\
$\lambda_{0}(x) \geq 0.6$ & 0.048 & -0.128 & 0.138 & -0.132 \\
\hline
\end{tabular}


5. The relationship between criminal involvement of parents and educational attainment of their children

\subsection{Conclusion}

It is widely recognized that crime involves different types of social costs. These are related to security measures, the criminal justice system, property loss, health services and victimization. It also entails intangible costs such as anxiety, inconvenience or suffering of close family members of the criminal person. Children are in particular affected by the criminal involvement of their parents as the social environment in the family becomes more unstable, which can result in emotional difficulties and transmitted criminal behavior (e.g. Geller et al., 2009; Wilbur et al., 2007; Van de Rakt et al., 2010). It follows that criminal behavior can have substantial long-term social costs also because it can affect the children of criminal parents negatively.

Despite a growing body of research on intergenerational transmission (e.g. educational attainment, socio-economic status, criminal behavior), not much attention has been paid to the effect of parents' criminal behavior on their children's educational outcomes. Existing studies do not fully control for parental education or other important household characteristics, such that the estimation results may partly represent the fact that criminally involved parents have lower education or different socio-economic backgrounds than parents with no criminal involvement. In this chapter we examine the effects of criminal involvement of parents on the educational attainment of their children, and considers the fact that parents with criminal involvement may be a selective group by adopting a statistical matching approach. For this purpose, Dutch survey data of the general population are used, rather than on an incarcerated population, which is common in other existing studies.

The empirical findings suggest that having parents with criminal involvement increases the probability of completing lower education levels relatively to completing higher education, also when we adopt a matching approach to control for socio-economic background characteristics and parental education. Following Altonji et al. $(2005 ; 2008)$, we performed various robustness analyses to examine the 
possible effects of selection on unobservables. Based on these sensitivity analyses, we conclude that a substantial amount of selection on unobservables, relative to the selection on observables, is needed to explain the entire estimated effect (around three times as much). The obtained results for primary education appear to be very robust, and even though the results for higher education are less robust in terms of statistical significance, the effect sizes remain quite sizable. We conclude that having criminally involved parents leads to: (1) an increase in the probability of finishing primary education as the highest educational level attained (in the range of 7 to 9 percentage points), and (2) a decrease in the probability of attaining higher education (in the range of 2 to 6 percentage points).

More robustness analyses are performed to examine (1) if the estimation results depend on the definition of the educational attainment variable; (2) the effect of criminal involvement of mothers relative to fathers; (3) the effect of convicted parents; and (4) how misclassified treatment status can bias the estimated effect of parents' criminal involvement. The robustness analyses indicate that the empirical findings do not depend on the specific definition of the educational attainment variable. An interesting parental gender-related result is that children at the bottom of the educational attainment distribution are more affected if fathers are criminally involved, while children at the top of the educational attainment distribution are more affected by if the mothers are criminally involved. We also find that the negative effect of having criminal parents on only completing primary education is more pronounced if parents were convicted. Finally, underreporting of criminal involvement can lead to attenuation bias in the estimated effect on educational attainment of children. We show that results are not strongly affected even when we assume rather strong levels of underreporting.

We conclude that growing up in households with criminal parents lowers educational attainment substantially can be seen as a negative investment in the skill acquisition process, in the context of Cunha and Heckman (2007)'s theory on the Technology of Skill Formation. Our research underlines the importance of designing policies that aim to increase education levels of children whose parents were 
5. The relationship between criminal involvement of parents and educational attainment of their children

criminally involved, and that can provide these children with a stimulating developmental environment. It also underlines that crime prevention or reduction may externally increase the educational attainment of future generations. 



\section{General conclusions}

In this chapter, the main findings of this dissertation are discussed. Conclusions are drawn from the existing body of empirical evidence on the relationship between youth crime and education as well as new evidence that we have produced by exploiting multiple data sources from the Netherlands. These data are analyzed by using a combination of different econometric techniques and (quasi-) experimental settings, including matching, a randomized control trial and fixed effects analyses. Table 6.1 presents the main findings per corresponding chapter. Below we elaborate on each of these findings and describe potential policy implications. Furthermore, we discuss limitations and provide suggestions for future research. 
Chapter 6

Table 6-1: The main findings of the dissertation per chapter

\begin{tabular}{lll}
\hline Chapter & Subject of interest & Main findings \\
\hline Ch. 2 & $\begin{array}{l}\text { The relationship between youth } \\
\text { crime and education }\end{array}$ & $\begin{array}{l}\text { a) Early interventions for children with a low } \\
\text { socio-economic status often yield positive } \\
\text { effects with respect to education and criminal } \\
\text { behavior outcomes in adolescence. } \\
\text { b) Empirical evidence shows that education has } \\
\text { a negative causal effect on criminal behavior of } \\
\text { young people. }\end{array}$ \\
Ch. 3 & $\begin{array}{ll}\text { What explains the relationship } \\
\text { between criminal involvement } \\
\text { in adolescence and early school } \\
\text { leaving? }\end{array}$ & $\begin{array}{l}\text { c) There is a strong association between early } \\
\text { criminal involvement and educational } \\
\text { outcomes. A large share of this association is } \\
\text { driven by family-specific and individual-specific } \\
\text { characteristics. }\end{array}$ \\
Ch.4 & $\begin{array}{l}\text { The effect of a restorative } \\
\text { juvenile justice program on } \\
\text { educational outcomes of } \\
\text { juvenile offenders }\end{array}$ & $\begin{array}{l}\text { d) The restorative juvenile justice program Halt } \\
\text { has positive effects on the educational } \\
\text { outcomes of juvenile offenders. }\end{array}$ \\
$\begin{array}{ll}\text { The relationship between } \\
\text { parents' criminal involvement } \\
\text { and children's educational } \\
\text { attainment }\end{array}$ & $\begin{array}{l}\text { e) Criminal involvement of parents negatively } \\
\text { affects the educational attainment of their } \\
\text { children. }\end{array}$ \\
\end{tabular}




\subsection{Key conclusions}

\section{a) Early interventions for children with a low socio-economic status often yield positive effects with respect to education and criminal behavior outcomes in adolescence.}

The relationship between education and youth crime is a complex and integrated process, that reflects cognitive and socio-emotional development of young people from early childhood onwards. Young people who were born and grew up in a socioeconomically disadvantaged environment are more likely to have low educational outcomes and become involved in criminal behavior. During the last decades, a number of early interventions have been implemented to help such individuals in their development and to improve their lifetime perspectives. Analysis of such interventions provides insights into how both criminal behavior and educational outcomes are shaped, and what link between the formation of these outcomes exists.

The results of our review (Chapter 2) suggest that investing in socioeconomically disadvantaged children in the early stages of their life-cycle can enhance educational performance and simultaneously reduce criminal behavior in adolescence and young adulthood. At the same time, interventions conducted for older children and adolescents tend to affect educational outcomes positively, while the effect on criminal behavior is ambiguous. We further note that the effect of childhood and adolescent interventions on education and criminal behavior outcomes tends to be heterogeneous across different demographic groups, for example with respect to gender and ethnicity.

Early interventions provide different types of investments (e.g. economic, social, behavioral, educational) that serve to equalize opportunities of socioeconomically disadvantaged children who do not receive (sufficiently) such investments. It is possible that the effects on crime and education operate by improving the same (set of) skill(s), or that there are separate pathways that lead to 
Chapter 6

an effect on each outcome. Early childhood interventions that target non-cognitive skills appear to be very promising with respect to improving educational and criminal behavior outcomes (Chapter 2).

\section{b) Empirical evidence shows that education has a negative causal effect on criminal behavior of young people.}

Evidence from the reviewed empirical studies that examine the relationship between education and youth crime shows that there is a negative causal effect of educational attainment on criminal behavior of young people (Chapter 2). This evidence is consistent with extensive evidence on the effect of educational attainment on adult crime (see reviews by Lochner, 2010; Hjalmarsson and Lochner, 2012). Studies from the U.S. and from non-U.S. countries suggests that despite differences in the system of education, the system of justice as well as the rates of youth crime and early school leaving, the estimated effect of educational attainment on criminal behavior of young people is of comparable magnitude. Furthermore, we document evidence suggesting that being in school reduces the likelihood of criminal behavior among young people, while not attending school increases their chances of committing crime. Both these effects are especially large for property crime. Presence at school, however, increases incidents of violent youth crime. This can be due to the high concentration of social interactions among peers. Finally, we conclude that not attending post-compulsory education, especially high-quality education, increases chances of criminal involvement among young people with low socio-economic status.

The effect of education on youth crime can have different pathways. Higher educational attainment appears to favorably influence emotional development, patience, risk aversion, and other skills that are negatively related to criminal behavior of young people. The opportunity costs of participating in criminal activities for higher educated people are also higher, which can deter young people from committing criminal activities. Finally, acquiring educational credentials, such as a 
diploma and an academic degree, can be an underlying mechanism behind the negative effect of education on youth crime: graduation from school can guarantee young people a particular social status (vs. stigma) which, in turn, provides more opportunities for legal activities (vs. illegal activities).

c) There is a strong association between early criminal involvement and educational outcomes. A large share of this association is driven by family-specific and individual-specific characteristics.

Evidence from empirical studies based on data from Anglo-Saxon countries (see Chapter 2) and from our study that exploits data from the Netherlands (see Chapter 3) shows that there is a strong correlation between early criminal involvement and educational outcomes. The results of our empirical analysis show that accounting for different confounding factors reduces the magnitude of the relationship between early criminal involvement and early school leaving substantially, although it remains statistically significant even in the most complete specification. In particular, observable and unobservable heterogeneity that we control for explain around three quarters of the unconditional correlation between criminal involvement and early school leaving. The remaining unexplained part either reflects individual-specific factors that are not captured by twin fixed effects, such as behavior and motivation, or a true treatment effect from the criminal activity, that may operate through the impact of time spent on crime, stigma or shocks. However, a true treatment effect from criminal involvement on early school leaving, if it exists, is likely to be small.

At the same time, more serious criminal involvement among adolescents has a stronger link to educational outcome. The results from our empirical analysis suggest that the estimated difference between overall and severe crime is not driven by selection. Therefore, the relationship between severe criminal involvement and early school leaving may represent a true causal effect. In particular, juvenile incarceration appears to have a negative causal effect on school graduation (Aizer 
Chapter 6

and Doyle, 2013). The underlying pathways of severe crime, and in particular incarceration, on educational outcomes can operate through accumulation of 'criminal capital' and an interruption of the educational process due to criminal involvement.

d) The restorative juvenile justice program Halt has positive effects on the educational outcomes of juvenile offenders.

Restorative juvenile justice generally aims to prevent reoffending among delinquent youth and it is often targeted at changing the behavior and attitudes of juvenile offenders. The educational components of restorative justice programs can be different, including victim-offender reconciliation, social training cources, youth conferencing, and cognitive behavioral therapy sessions. In the Netherlands, restorative justice for juveniles is represented by bureau Halt. Juvenile firstoffenders who are sent to bureau Halt by the police have to conduct different assignments, including learning tasks and community work services.

The results of our evaluation of the restorative justice program Halt on educational outcomes of young people show that participation in the program reduces the chance of leaving school early and increases educational attainment among juvenile offenders. We also find that this effect is smaller for boys, adolescents with Dutch origin, and juveniles in single-parent households. The Halt program is statistically significantly less effective for group offenders with regards to after-program years of education. The fact that the program is less effective for those adolescents who are surrounded by other delinquent offenders possibly points to the presence of negative peer effects.

We conclude that interventions for juvenile offenders, such as Halt, should be evaluated not only with regards to recidivism but also with regards to educational performance and perhaps also other societal outcomes, such as civil participation and other forms of risky behavior. The costs per one prevented early school leaver 
equal to $€ 8,352$, which are similar to the costs of one year of education. It is known from the literature that the returns to a year of schooling at the margin of dropout is higher than the average returns to a year of schooling (Harmon, Oosterbeek and Walker, 2003). Given that Halt participants leave school with at least a level 2 of post-secondary vocational education, the investment in the Halt program appears to be worthwhile even in the absence of any effects on recidivism. Moreover, spill-over effects of restorative justice programs for juveniles can be substantial, because higher educational attainment can, in turn, reduce criminal behavior in the long run.

Programs similar to the Halt intervention exist also in many countries around the world. The effect of restorative juvenile justice programs can differ from the effect that we have found for the Netherlands. On the other hand, there is evidence that the magnitude of the effect of education on youth crime is comparable across different developed countries, despite differences in the system of juvenile justice and the system of education, as well as differences in the rates of early school leaving and youth crime.

\section{e) Criminal involvement of parents negatively affects the educational attainment of their children.}

The results of our empirical analysis show that criminal involvement of parents has a negative effect on the educational attainment of their children (see Chapter 5). More specifically, having criminally involved parents leads to an increase in the probability of finishing primary education as the highest educational level attained, and a decrease in the probability of attaining higher education. The matching approach ensures that these effects are not driven by differences in the educational attainment of parents or other observable factors. Moreover, a method that addresses the potential effect of unobservables strongly suggests that a substantial part of this relationship is causal. 
Additionally, the results show that children at the bottom of the educational attainment distribution are affected more if fathers are criminally involved, while children at the top of the educational attainment distribution are affected more if their mothers are criminally involved. Furthermore, the negative effect of having criminal parents is more pronounced if parents were convicted rather than only arrested. This is also in line with evidence on the individual level: more serious criminal involvement has a substantially stronger negative link to educational attainment than less serious criminal behavior (see Chapter 4).

The mechanisms behind the negative effect of criminal involvement of parents on education of their children are not clear. It is possible that they operate through lower investment into skill development of children due to parents' interactions with criminal justice or because criminally involved parents are less inclined to motivate and invest time and effort in the education of their children.

\subsection{Policy implications and valorization of the research findings}

The findings on the relationship between youth crime and education presented in this dissertation can be interesting for policy makers. The findings, in general, suggest that education and criminal behavior of young people should be treated as linked processes. Below, we identify and discuss our main policy implications and valorization of our research findings.

\section{1) Reduction of youth crime can be achieved through effective policies that improve the educational outcomes of young people}

The literature that shows a negative effect of educational attainment and school attendance on criminal behavior of young people suggests that prevention of low educational outcomes among young people can decrease youth crime (Chapter 2). 
Therefore, policy makers may consider investing in education as a tool to prevent and reduce criminal behavior among young people. Evidence on the programs that simultaneously affect educational outcomes and criminal behavior of young people suggests that integrated interventions can address both low educational attainment and criminal involvement of young people in a more effective and efficient way than separate interventions for youth crime and education. The benefits of such programs can be long-lasting considering that there is also a causal link between education and criminal involvement of adults.

\section{2) Evidence on common factors that underlie early criminal involvement and educational outcomes suggests that there is a need to establish interventions that simultaneously address the causes of youth crime and lower educational outcomes.}

The factors that underlie criminal behavior and the factors that underlie poor educational outcomes strongly overlap. This implies that addressing them has the potential to simultaneously affect both criminal behavior and educational performance. We find that school environment characteristics play a relatively small role in the relationship between education and youth crime compared to the role of family-specific characteristics (Chapter 3). The findings from Chapter 5 on the negative role of criminal involvement of parents for the educational attainment of their children further highlight the importance of the family environment in shaping the educational careers of children, and likely in determining criminal behavior outcomes as well, given the empirical evidence on the intergenerational transmission of criminal participation (Chapter 5). Together this suggests that improving the family environment, especially in the early years, or compensating for such adverse environment through other investments (financial, but also in the form of time and effort) presents a promising pathway towards improved long-run outcomes in education and reduced participation in crime. 
Chapter 6

3) Intervention programs for socio-economically disadvantaged and at-risk adolescents should be evaluated with respect to their effects on a complete system of life-time outcomes.

The positive effects of Halt on early school leaving and years of education (Chapter 4) suggest that intervention programs aimed at reducing the criminal involvement of juveniles can have positive spill-over effects on other important outcomes, in particular education. Therefore, conclusions on program effectiveness should not be based only on the effects of the program for one single dimension (i.e. recidivism). This conclusion is in line with previous evidence on other programs, for example the Perry Preschool Program. The Perry Preschool Program did not improve the IQ's of children as it was intended to do, but still achieved large long-run improvements, in terms of educational attainment, employment, and reduced criminal behavior, through changes in non-cognitive skills. Multiple previous studies have shown that successful intervention programs can affect both criminal behavior and education outcomes of young people. Therefore, educational benefits should not be ignored when criminal intervention programs are evaluated, and vice versa. It is also important to analyze the effectiveness of intervention programs with respect to other lifetime outcomes.

\section{4) Policies that aim to provide better educational opportunities for children of criminally involved parents are needed.}

Evidence from our empirical study (Chapter 5) shows that children with criminally involved parents are identified as a group with a higher risk of having poor educational outcomes. The poor educational outcomes of these children go beyond the fact that they grow up in an environment with less educated parents, who also have lower income and live in poorer neighborhoods. Having criminally involved parents provides an isolated extra risk in relation to low educational performance. 
This underlines an extra need for designing policies that aim to increase the level of education of children whose parents were criminally involved, for example, by providing these children with a more stimulating development. It also underlines how improvements in one outcome can accumulate gains over time, not only for one specific person but also from one generation to the next.

\subsection{Limitations and suggestions for further research}

The findings of this dissertation provide a comprehensive picture of the relationship between both education and youth crime, and on the role of 'third variables' that relate to both outcomes. The general shortage of experimental settings and exogenous variations with respect to criminal activity and educational attainment makes it challenging to identify the true causal effects between education and youth crime. In this dissertation, we have addressed the problem of endogeneity and reverse causality by using different econometric techniques and relying on a randomized control trial. We acknowledge that these methods and the data we have used have some limitations.

In Chapter 3, we have addressed unobservable heterogeneity by using sibling and twin fixed effects estimates. Unfortunately, the data do not allow us to identifying identical twins which would have allowed us to control for a larger share of unobserved heterogeneity. In Chapter 4, we use experimental data and we are able to find treatment effects of the restorative justice program Halt versus a control group that has not received any punishment. The settings of the Halt experiment do not allow us to examine the effect of the restorative justice program Halt versus traditional juvenile justice (i.e. prosecution by the public prosecutor, detention). In Chapter 5, in addition to the matching approach, we have used a method that addresses the potential effect of unobservable heterogeneity in the relationship between criminally involved parents and the education of their children, which produces an estimated effect that lies in the particular range. This method however 
Chapter 6

does not allow us to provide an exact point estimate of the causal effect. Future studies can contribute to this research by overcoming these limitations.

Future research can also further investigate the mechanisms that are behind the relationship between youth crime and education. Assessing the heterogeneity in the relationship between youth crime and education by type of criminal behavior can be another direction for future research. Furthermore, additional evidence is needed on what specific components of intervention programs are the most effective in improving education and criminal behavior outcomes, for example by providing experimental variation in program components. Addressing all these issues can provide more precise policy recommendations with respect to what types of investments in children and adolescents should be made in order to prevent them from obtaining low educational outcomes and becoming involved in criminal behavior. 


\section{References}

Aigner, D. J. (1973). Regression with a binary independent variable subject to errors of observation. Journal of Econometrics, 1, 49-59.

Aizer, A. (2004). Home alone: supervision after school and child behaviour. Journal of Public Economics of Education Review, 88, 1835-1848.

Aizer, A. and Doyle, J. J. (2013). Juvenile incarceration, human capital and future crime: Evidence from randomly-assigned judges (Working Paper No. 19102). Retrieved from http://www.nber.org/papers/w19102.

Altonji, J. G. and Dunn, T. A. (1996). The effects of family characteristics on the return to schooling. Review of Economics and Statistics, 78, 692-704.

Altonji, J. G., Elder, T. E. and Taber, C. R. (2005). Selection on observed and unobserved variables: Assessing the effectiveness of catholic schools. Journal of Political Economy, 113, 151-184.

Altonji, J. G., Elder, T. E. and Taber, C. R. (2008). Using selection on observed variables to assess bias from unobservables with evaluating Swan-Ganz Catheterization. American Economic Review: Papers and Proceedings, 98, 345-350.

Anderson, D. (1999). The aggregate burden of crime. Journal of Law and Economics, 42, 611642.

Anderson, M. (2014). In school and out of trouble? The minimum dropout age and juvenile crime. Review of Economics and Statistics, 96, 318 - 331.

Angrist, J. and Pischke, J. (2009). Instrumental variable in action: Sometimes you get what you need (Chapter 4) in Mostly harmless econometrics: An empiricist's companion. Princeton, NJ: Princeton University Press.

Aoki, Y. (2014). Does schooling reduce juvenile delinquency? Evidence from a natural experiment in Japan. Paper presented at the meeting of the European Association of Labour Economists. Retrieved from http://www.eale.nl/Conference2014/Program/papers/Parallel\%20E/E01.1\%20Aoki. pdf

Apel, R. and Sweeten, G. (2010). The impact of incarceration on employment during the transition to adulthood. Social Problems, 57, 448-479.

Ashworth, A., Hardman, J., Hartfree, Y., Maguire, S., Middleton, S., Smith, D., et al. (2002). Education Maintenance Allowance: the first two years. A quantitative evaluation. Research Report, 352. Retrieved from http://webarchive.nationalarchives.gov.uk/20130401151715/https:/www.education .gov.uk/publications/eOrderingDownload/RB352.pdf

Ashworth, A., Hardman, J., Liu, W. C., Maguire, S., Middleton, S., Dearden, L., et al. (2001). Education Maintenance Allowance: the first year. A quantitative evaluation 
(Research Repor No. 257). Retrieved from

http://discovery.ucl.ac.uk/18495/1/18495.pdf

Åslund, O., Grönqvist, H., Hall, C. and Vlachos, J. (2014). Education policy and criminal behavior: Insights from an expansion of upper secondary school. Paper presented at the Labour Seminars Amsterdam. Retrieved from http://www.tinbergen.nl/seminar/title-announced-90/

Bandura, A. (1969). Social-learning theory of identificatory processes. In D. A. Goslin (Ed.), Handbook of socialization theory and research (pp. 213-262). Chicago: Rand McNally.

Barnett, W. S., Jung, K., Yarosz, D. J., Thomas, J., Hornbeck, A., Stechuk, R., et al. (2008). Educational effects of the Tools of the Mind curriculum: A randomized trial. Early Childhood Research Quarterly, 23, 299-313.

Battistin, E. and Sianesi, B. (2011). Misclassified treatment status and treatment effects: An application to returns to education in the UK. Review of Economics and Statistics, 93, 495-509.

Bazemore G. and Schiff, M. F. (1996). Community justice/restorative justice: Prospects for a new social ecology for community corrections. International Journal of Comparative and Applied Criminal Justice, 20, 311-335.

Becker, G. S. (1968). Crime and punishment: An economic approach. Journal of Political Economy, 76, 169-217.

Behncke, S. (2009). How Do Shocks to Non-Cognitive Skills Affect Test Scores? (IZA WP No. 4222). Retrieved from http://www.econstor.eu/bitstream/10419/35539/1/605486832.pdf

Behrman, J. R. and Taubman, P. (1976). Intergenerational transmission of income and wealth. American Economic Review, 66, 436-440. Retrieved from http://www.jstor.org/discover/10.2307/1817257?uid=3738736anduid=2anduid=4an dsid $=21105441698563$

Behrman, J. R., Hrubec, Z., Taubman, P. and Wales, T.J. (1980). Socioeconomic Success: A Study of the Effects of Genetic Endowments, Family Environment, and Schooling. North-Holland Publishing Group, Amsterdam.

Belfield, C. R. and Levin, H. M. (2009). High school dropouts and the economic losses from juvenile crime in California (California Dropout Research Project Report No. 16). Retrieved from http://www.hewlett.org/uploads/High_School_Dropouts_and_The_Economic_Losse s.pdf

Bjorklund, A., Jantti, M. and Solon, G. (2007). Nature and nurture in the intergenerational transmission of socio-economic status: Evidence from Swedish children and their biological and rearing parents. The B.E. Journal of Economic Analysis and Policy, 7, 123.

Blau, D. and Currie, J. (2006). Preschool, daycare, and afterschool care: Who's minding the kids? In E. Hanushek and F. Welch (Eds.), Handbook of the Economics of Education (Vol. 2, pp. 1163-1278). Amsterdam: North-Holland.

Bloom, D., Gardenhire-Crooks, A. and Mandsager, C. L. (2009). Reengaging high school dropouts: Early results of the National Guard Youth Challenge Program Evaluation (MDRC Report). Retrieved from http://www.mdrc.org/sites/default/files/full_491.pdf

Bogin, B. (1999). Evolutionary perspective on human growth. Annual Review of Anthropology, 28, 109-153. 
Boisjoli, R., Vitaro, F., Lacourse, E., Barker, E. D. and Tremblay, R. E. (2007). Impact and clinical significance of a preventive intervention for disruptive boys: 15 year followup British Journal of Psychiatry, 191, 415 - 419.

Bollinger, C. R. (1996). Bounding mean regressions when a binary regressor is mismeasured. Journal of Econometrics, 73, 387-399.

Borkenau, P., Riemann, R., Angleitner, A., \& Spinath, F. M. (2002). Similarity of childhood experiences and personality resemblance in monozygotic and dizygotic twins: a test of the equal environments assumption. Personality and Individual differences, 33(2), 261-269.

Bosick, S. J. (2009). Operationalizing crime over the life course. Crime and Delinquency, 55, $472-496$.

Bouchard, T., Lykken, D., McGue, N., Segal, N. and Tellegen, A. (1990). Sources of human psychological difference: The Minnesota study of twins reared apart. Science, 12, 223-228.

Bradshaw, W. and Roseborough, D. (2005). Restorative justice dialogue: The impact of mediation and conferencing on juvenile recidivism. Retrieved from http://connection.ebscohost.com/c/articles/20929919/restorative-justice-dialogueimpact-mediation-conferencing-juvenile-recidivism

Braithwaite, J. (1989). Crime, Shame, and Reintegration. Cambridge: Cambridge University Press.

Briscoe, S. and Donnell, N. (2003). Problematic licensed premises for assault in inner Sydney, Newcastle and Wollongong. Australian and New Zealand Journal of Criminology, 36, $18-33$.

Brugård, K. H. and Falch, T. (2012). Student performance and imprisonment (Working Paper No. 9/2012). Retrieved from http://www.ntnu.edu/documents/140152/38224165/9_studentperformance_KHB_ TF.pdf/f481cadc-047e-4b9f-afed-6092db870e47

Calvó-Armengol, A. and Zenou, Y. (2004). Social networks and crime decisions: The role of social structure in facilitating delinquent behavior, International Economic Review, 45, 935-954.

Calvó-Armengol, A., Patacchini, E. and Zenou, Y. (2009). Peer effects and social networks in education. The Review of Economic Studies, 76, 1239-1267.

Cameron, A. C. and Trivedi, P. K. (2005). Microeconometrics: Methods and applications. New York, NY: Cambridge University Press.

Campbell, F. A., Ramey, C. T., Pungello, E. P., Miller-Johnson, S. and Sparling, J. J. (2002). Early childhood education: Young adult outcomes as a function of differing treatment. Applied Developmental Science, 6, 42-57.

Carneiro, P. and Heckman, J. J. (2003). Human capital policies. In J. Heckman and A. Krueger (Eds.), Inequality in America: What role for human capital policies (pp. 74-130). Cambridge: MIT Press.

Carreira Da Cruz, M. (2010). A potential use of crime statistics - measuring costs effectiveness of restorative justice programmes: a cross eye on the British and Canadian debate (Effectius Newsletter No. 10). Retrieved from http://effectius.com/yahoo_site_admin/assets/docs/A_potential_use_of_crime_sta tistics_-

_measuring_cost_effectiveness_of_restorative_justice_programmes_a_cross_eye_ on_the_British_and_Canadian_debate_MACDC_Newsletter10.33394302.pdf

Chevalier, A., Harmon, C., O'Sullivan, V. and Walker, I. (2010). The impact of income and education on the schooling on their children (University College Dublin, Geary 
Institute Discussion Paper Series, WP 10 32). Retrieved from:

http://www.ucd.ie/geary/static/publications/workingpapers/gearywp201032.pdf

Clarke, S. H. and Campbell, F. A. (1998). Can intervention early prevent crime later? The Abecedarian project compared with other programs. Early Childhood Research Quarterly, 13, 319 - 343.

Cloward, R. and Ohlin, L. (1960). Delinquency and Opportunity. New York: Free Press.

Cohen, A. (1955). Delinquent boys. New York: Free Press.

Cook, P. J. and Kang, S. (2013). Birthday, schooling, and crime: New evidence on the dropoutcrime nexus (Working Paper No. 18791). Retrieved from http://www.nber.org/papers/w18791.pdf

Cullen, J. B., Jacob, B. and Levitt, S. D. (2006). The effect of school choice on participants: Evidence from randomized lotteries. Econometrica, 74, 1191-1230.

Cunha and Heckman, J. (2010). Investing in our young people (Working Paper No. 5050). Retrieved from http://ftp.iza.org/dp5050.pdf

Cunha and Heckman, J. J. (2007). The Technology of Skill Formation. American Economic Review, 97, 31-47.

Cunha, F., Heckman, J. J., Lochner, L. J. and Masterov, D. V. (2006). Interpreting the evidence on life cycle skill formation. In E. A. Hanushek and F. Welch (Eds.), Handbook of the Economics of Education (Vol. 1, pp. 697-812). Amsterdam: North-Holland.

Currie, J. (2001). Early childhood education programs. Journal of Economic Perspectives, 15, 213-238.

Dandurand, Y. and Griffiths, C. (2006). Handbook on restorative justice programmes. Criminal Justice Handbook Series. United Nations Office on Drugs and Crime. Retrieved from http://www.unodc.org/pdf/criminal_justice/06-56290_Ebook.pdf

De Haan, M. and Plug, E. J. S. (2009). Estimating intergenerational schooling mobility on censored samples: Consequences and remedies. Journal of Applied Econometrics, 26, 151-166.

Deković, M., Asscher, J. J., Slagt, M. I. and Boendermaker, L. (2012). Prevention programmes in early and middle childhood and their effect on adult crime. In R. Loeber, M. Hoeve, N. W. Slot and P. van der Laan (Eds.), Persisters and desisters in crime from adolescence into adulthood. Explanation, prevention and punishment (pp. 239 - 262). Surrey, UK: Ashgate.

Deming, D. (2009). Early childhood intervention and life-cycle skill development: Evidence from Head Start. American Economic Journal, 1, 111-134.

Deming, D. (2011). Better schools, less crime? The Quarterly Journal of Economics, 126, 2063 $-2115$.

Doyle, O., Harmon, C., Heckman, J. and Tremblay, R. (2009). Investing in early human development: Timing and economic efficiency. Economics and Human Biology, 7, 16.

Dujardin, C. and Goffette-Nagot, F. (2010). Neighborhood effects on unemployment?: A test a' la Altonji. Regional Science and Urban Economics, 40, 380-396.

Dünkel, F., Grzywa, J., Horsfield, P. and Pruin, I. (Eds.) (2011). Juvenile justice systems in Europe: current situation and reform developments. Mönchengladbach: Forum Verlag Godesberg.

Durlak, J. A., Weissberg, R. P., Dymnicki, A. B., Taylor, R. D. and Schellinger, K. B. (2011). The impact of enhancing students' social and emotional learning: A meta-analysis of school-based universal interventions. Child Development, 82, 405-432.

Dykstra, P. A. and De Valk, H. (2007). Criminelen in de familie: Verband tussen crimineel gedrag en bevolkingskenmerken onderzocht. Demos: Bulletin Over Bevolking en 
Samenleving, 23, 6-8. Retrieved from

http://www.nidi.nl/shared/content/demos/2007/demos-23-01-dykstra.pdf

Dykstra, P. A., Kalmijn, M., Knijn, T. C. M., Komter, A. E., Liefbroer, A. C. and Mulder, C. H. (2005). Codebook of the Netherlands Kinship Panel Study: A multi-Actor, multimethod panel study on solidarity in family relationships, Wave 1. The Hague: Netherlands Interdisciplinary Demographic Institute.

Eckenrode, J., Campa, M., Luckey, D. W., Henderson, C. R., Cole, R., Kitzman, H., et al. (2010). Long-term effects of prenatal and infancy nurse home visitation on the life course of youths: 19-year follow-up of a randomized trial. Journal of the American Medical Association, 164, 9-15.

Elliott, D. S. (1966). Delinquency, school attendance and dropout. Social Problems, 13, 307314.

Ellis, L., Beaver, K. M. and Wright, J. (2009). Handbook of Crime Correlate. Academic Press.

Enzmann, D., Marshall, I. H., Killias, M., Junger-Tas, J., Steketee, M. and Gruszczynska, B. (2010). Self-reported youth delinquency in Europe and beyond: First results of the second international self-report delinquency study in the context of police and victimization data. European Journal of Criminology, 7, 159 - 183.

Ermish, J. and Pronzato, C. (2010). Causal effect of parents' education on children's education (ISER Working Paper Series No. 2010-16). Retrieved from: http://www.childcentre.unito.it/papers/child05_2010.pdf

European Commission (2011). Overview and examples of costs of early school leaving in Europe. Retrieved from http://ec.europa.eu/education/policy/strategicframework/doc/europe-esl-costs_en.pdf

European Commission. (2014). Europe 2020 indicators. Retrieved from http://epp.eurostat.ec.europa.eu/portal/page/portal/europe_2020_indicators/head line_indicators/data

Fagan, J. and Pabon, E. (1990). Contributions of delinquency and substance abuse to school dropout among inner-city youths. Youth and Society, 21, 306-354.

Falk, G. J. (1952). The influence of the seasons on the crimes. The Journal of Criminal Law, Criminology, and Police Science, 43, 199 - 213. Retrieved from http://scholarlycommons.law.northwestern.edu/cgi/viewcontent.cgi?article=4004a ndcontext=jclc

Farrington, D. P. (1986). Age and crime. In M. Tonry and N. Morris (Eds.), Crime and justice: An annual review of research (Vol. 7, pp. 189-250). Chicago: University of Chicago Press.

Farrington, D. P. (2001). Predicting persistent young offenders. In G. L. McDowell and J. S. Smith (Eds.), Juvenile delinquency in the US and the UK. London: Macmillan Press Limited.

Farrington, D. P., Coid, J. W. and Murray, J. (2009). Family factors in the intergenerational transmission of offending. Criminal Behaviour and Mental Health, 19, 109-124.

Feinstein, L. and Sabates, R. (2005). Education and youth crime: Effects of introducing the Educational Maintenance Allowance programme (Research Report, No. 14). Retrieved from http://www.learningbenefits.net/

Fendrich, M. and Vaughn, C. M. (1994). Diminished lifetime substance use over time: An inquiry into differential underreporting. Public Opinion Quarterly, 58, 96-123.

Ferwerda, H. B., van Leiden, I. M. G. G., Arts, N. A. M. and Hauber, A. R. (2006). Halt: Het alternatief? De effecten van Halt beschreven (WODC and Beke Report No. 244). Retrieved from http://www.wodc.nl/onderzoeksdatabase/praktijk-en-effectenhaltafdoening.aspx 
Foster, H. and Hagan, J. (2007). Incarceration and intergenerational social exclusion. Social Problems, 54(4), 399-433.

Foster, H. and Hagan, J. (2009). The mass incarceration of parents in America: Issues of race/ethnicity, collateral damage to children, and prisoner reentry. Annals of the American Academy of Political and Social Science, 623, 179-194.

Galloway, T. A. and Pudney, S. (2011). Initiation into crime: An analysis of Norwegian register data on five birth cohorts. (ISER Working Paper Series No. 2011-11). Retrieved from: http://www.ssb.no/a/publikasjoner/pdf/DP/dp655.pdf.

Garces, E., Thomas, D. and Currie, J. (2002). Longer-term effects of Head Start. American Economic Review, 92, 999-1012.

Gaviria, A. and Raphael, S. (2001). School-Based Peer Effects and Juvenile Behavior, Review of Economics and Statistics, 83, 257-268.

Geller, A., Garfinkel, I., Cooper, C. E. and Mincy, R. B. (2009). Parental incarceration and child well-being: Implications for urban families. Social Science Quarterly, 90, 1186-1202.

Goldschmidt, P. and Huang, D. (2007). The long-term effects of after-school programming on educational adjustment and juvenile crime: A study of the LA's BEST after-school program. Retrieved from http://www.lasbest.org/imo/media/doc/LASBEST_DOJ_Final\%20Report.pdf

Goldstein , A. P. and Glick, B. (1999). Aggression reduction strategies: Effective and ineffective. School Psychology Quarterly, 14, 41-57.

Goldstein, A. P. and Glick, B. (1994). Aggression replacement training: Curriculum and evaluation. Simulation and Gaming, 25, 9-26.

Gottfredson, D. C. and Soulè, D. A. (2005). The timing of property crime, violent crime, and substance use among juveniles. Journal of Research in Crime and Delinquency, 42, $110-120$.

Greene, W. H. (2000). Econometric analysis (4th ed.). New Jersey: Prentice Hall.

Greenwood, P. W. (1995). Juvenile crime and juvenile justice. In J. Q. Wilson and J. Petersilia (Eds.), Crime (pp. 91-117). San Francisco: Institute for Contemporary Studies.

Greenwood, P. and Turner, S. (2011). Juvenile crime and juvenile justice. In I.Q. Wilson and J. Petersilia (eds), Crime and Public Policy. New York: Oxford University Press (pp. 88129).

Grimm, M. (2011). Does household income matter for children's schooling? Evidence for rural Sub-Saharan Africa. Economics of Education Review, 30, 740-754.

Grogger, J. (1995). The effect of arrests on the employment and earnings of young men. Quarterly Journal of Economics, 110, 51-72.

Grogger, J. (1998). Market Wages and Youth Crime. Journal of Labor Economics, 16, 756-91.

Groot, W. and Maassen van den Brink, H. (2010). The effects of education on crime. Applied Economics, 42, 279-289.

Grossman, J. and Tierney, J. (1998). Does mentoring work? An impact study of the Big Brothers Big Sisters Program. Evaluation Review, 22, 403-426.

Habecker, P. (2013). Sings of Fathers (and Mothers): Impact of parental incarceration upon educational outcomes. Sociology Thesis, Dissertation and Student Research. University of Nebraska - Lincoln. Retrieved from:

http://digitalcommons.unl.edu/cgi/viewcontent.cgi?article=1025andcontext=sociolo gydiss.

Harlow, C. W. (2003). Education and correctional populations (Bureau of Justice Statistics Special Report No. 195670). Retrieved from http://www.bjs.gov/content/pub/pdf/ecp.pdf 
Harmon, C., Oosterbeek, H. and Walker, I. (2003). The returns to education: Microeconomics. Journal of economic surveys, 17(2), 115-156.

Haskins, A. R. (2011). Unintended consequences of mass imprisonment: Effects of paternal incarceration on child school readiness. Working Paper No. WP 11-18FF. Princeton, NJ: Center for Research on Child Wellbeing. Retrieved from: http://crcw.princeton.edu/workingpapers/WP11-18-FF.pdf.

Hawkins, J. D., Guo, J., Hill, K. G., Battin-Pearson, S. and Abbott, R. D. (2001). Long-term effects of the Seattle Social Development intervention on school bonding trajectories. Applied Developmental Science, 5, 225 - 236.

Hawkins, J. D., Kosterman, R., Catalano, R. F., Hill, K. G. and Abbott, R. D. (2005). Promoting positive adult functioning through social development intervention in childhood. Archives of Pediatrics and Adolescent Medicine, 159, 25-31.

Hayes, H. (2005). Assessing reoffending in restorative justice conferences. Australian and New Zealand Journal of Criminology, 38, 77-101.

Heaver, C., Maguire, M., Middleton, S., Maguire, S., Youngs, R., Dobson, B., et al. (2002). Evaluation of Education Maintenance Allowance pilots: Leeds and London first year evidence. Retrieved from http://dera.ioe.ac.uk/4689/1/RR353.pdf

Heckman, J. J., Humphries, J. E. and Kautz, T. (2012). The economic and social benefits of GED certification. In J. J. Heckman, J. E. Humphries and T. Kautz (Eds.), The GED and the role of character in American life: University of Chicago Press.

Heckman, J. J., Moon, S. H., Pinto, R., Savelyev, P. A. and Yavitz, A. Q. (2010). Analyzing social experiments as implemented: A reexamination of the evidence from the HighScope Perry Preschool Program. Quantitative Economics, 1, 1-46.

Heckman, J. J., Stixrud, J. and Urzua, S. (2006). The effects of cognitive and noncognitive abilities on labor market outcomes and social behavior. Journal of Labor Economics, 24, 411-482.

Heckman, J., Pinto, R. and Savelyev, P. (2013). Understanding the mechanisms through which an influential early childhood program boosted adult outcomes. The American Economic Review, 103, 2052 - 2086.

Heller, S. B., Pollack, H. A., Ander, R. and Ludwig, J. (2013). Preventing youth violence and dropout: A randomized field experiment (Working Paper No. 19014). Retrieved from http://www.nber.org/papers/w19014

Hjalmarsson, R. (2008). Criminal justice involvement and high school completion. Journal of Urban Economics, 63, 613 - 630.

Hjalmarsson, R. and Lindquist, M. (2012). Like godfather, like son: Exploring the intergenerational nature of crime. Journal of Human Resources, 47, 550-582.

Hjalmarsson, R. and Lindquist, M. J. (2011). The origins of intergenerational association in crime: Lessons from Swedish Adoption Data. Labour Economics, 20, 68-81.

Hjalmarsson, R. and Lochner, L. (2012). The impact of education on crime: International Evidence (Research Report). Retrieved from http://www.economics.handels.gu.se/digitalAssets/1439/1439011_4955_research_lochner.pdf

Hjalmarsson, R., Holmlund, H. and Lindquist, M. J. (2011). The effect of education on criminal convictions and incarceration: Causal evidence from microdata (Centre for Economic Policy Research, Discussion Paper No. 8646). Retrieved from: http://ssrn.com/abstract=1964136.

Holmlund, H., Lindahl, M. and Plug, E. J. S. (2011). The causal effect of parents' schooling on children's schooling: A comparison of estimation methods. Journal of Economic Literature, 49, 615-651. 
Huang, D., Kim, K. S., Marshall, A. and Perez, P. (Eds.). (2005). Keeping kids in school: An LA's BEST example - a study examining the long-term impact of LA's BEST on students' dropout rates. Los Angeles: UCLA: National Center for Research on Evaluation, Standards, and Student Testing (CRESST).

Hungerford, G. P.(1993). The children of inmate mothers: An exploratory study of children, caretakers, and inmate mothers in Ohio. Ph.D. dissertation Columbus, OH: School of Social Work, Ohio State University. Retrieved from:

https://www.ncjrs.gov/App/Publications/abstract.aspx?ID=147221.

ICPS (2012). Entire world - Prison Population Rates per 100,000 of the national population. International Centre for Prison Studies. Retrieved from http://www.prisonstudies.org/info/worldbrief/wpb_stats.php?area=allandcategory= wb_poprate.

Jacob, B. and Lefgren, L. (2003). Are idle hands the devil's workshop? Incapacitation, concentration, and juvenile crime. American Economic Review, 93, 1560 - 1577.

Jarjoura, G. R. (1993). Does dropping out of school enhance delinquent involvement? Results from a large-scale national probability sample. Criminology, 31, 149 - 172.

Jarjoura, G. R. (1996). The conditional effect of social class on the dropout-delinquency relationship. Journal of Research in Crime and Delinquency, 33, 232 - 255.

Junger-Tas, J. and Block, R. L. (Eds.). (1988). Juvenile delinquency in the Netherlands. Kugler Publications

Junger-Tas, J., Marshall, I. H., Enzmann, D., Killias, M., Stekete, M. and Gruszczynska, B. (2010). Juvenile delinquency in Europe and beyond: Results of the second International Self-Report Delinquency Study. Dordrecht, Netherlands: Springer.

Kahan, D. (1996). What do alternative sanctions mean? The University of Chicago Law Review, 63, 591-653. Retrieved from http://digitalcommons.law.yale.edu/fss_papers/114/

Kalton, G. and Schuman, H. (1982). The effect of the question on survey responses: A review. Journal of the Royal Statistical Society, 145, 42-57.

Kautz, T., Heckman, J. J., Diris, R., Ter Weel, B. and Borghans, L. (2014). Fostering and measuring skills: Improving cognitive and non-cognitive skills to promote lifetime success (OECD Education Working Papers, No. 110), Retrieved from http://www.oecd-ilibrary.org/education/fostering-and-measuringskills_5jxsr7vr78f7-en

Keij, I. (2000). Standaarddefinitie allochtonen. Hoe doet het CBS dat nou? Index, 10, 24-25.

Keith, L. G., Papiernik, E., Keith, D. M. and Luke, B. (eds.) (1995). Multiple pregnancy: Epidemiology, gestation, and perinatal outcome. New York: Parthenon.

Kirk, D. S. and Sampson, R. J. (2013). Juvenile arrest and collateral educational damage in the transition to adulthood. Sociology of Education, 86, 36-62.

Kleibergen, F. and Paap, R. (2006) Generalized reduced rank tests using the singular value decomposition. Journal of Econometrics, 127, 97-126.

Kohler, H.-P., Behrman, J. R. and Schnittker, J. (2010). Social science methods for twins data: Integrating causality, endowments and heritability (PSC Working Paper No. 21). Retrieved from http://repository.upenn.edu/psc_working_papers/21/

KPMG (2011). Halt Nederland. Onderzoek kostprijsvergelijking. Vergelijking van de kosten van een Halt-afdoening en de behandeling via de justitiele lijn.

Krohn, M. D., Thornberry, T. P., Collins-Hall, L. and Lizotte, A. J. (1995). School dropout, delinquent behavior, and drug use: An examination of the causes and consequences of dropping out of school. In H. B. Kaplan (Ed.), Drugs, Crime, and Other Deviant Adaptations: Longitudinal Studies (pp. 163 - 183). New York: Plenum Press. 
Kurtz, L. R. (2008). Encyclopedia of violence, peace, and conflict (Second Ed.). Elsevier Inc.

Lally, J. R., Manggione, P. L. and Honig, A. S. (1988). Syracuse University Family Development Research Program: Long-range impact of an early intervention with low-income children and their families. In D. R. Powell (Ed.), Parent Education as Early Childhood Intervention: Emerging Directions in Theory, Research, and Practice (pp. 79-104). Norwood, NJ: Ablex Publishing Company.

Landers $\varnothing$, R., Nielsen, H. S. and Simonsen, M. (2013). School starting age and crime (IZA Discussion Paper No. 7228). Retrieved from http://ftp.iza.org/dp7228.pdf

Lee, V. E. and Burkam, D. T. (2003). Dropping out of high school: The role of school organization and structure. American Educational Research Journal, 40, 353-393.

Leve, L. and Chamberlain, P. (2005). Association with delinquent peers: Intervention effects for youth in the juvenile justice system. Journal of Abnormal Child Psychology, 33, 339-347.

Levine, J. P. (1976). The potential for crime overreporting in criminal victimization surveys. Criminology, 14, 307-330.

Levitt, S. D. and Lochner, L. (2001). The determinants of juvenile crime. In J. Gruber (Ed.), Risky behaviour among youths: An economic analysis (pp. 327 - 373). Chicago: University of Chicago Press.

Lewbel, A. (2007). Estimation of average treatment effects with misclassification. Econometrica, 75, 537-551.

Lochner, L. (2004). Education, work, and crime: Theory and evidence. International Economic Review, 45, 811-843.

Lochner, L. (2010). Education Policy and Crime (Working Paper No. 15894). Retrieved from http://www.nber.org/papers/w15894.pdf

Lochner, L. (2011). Non-production benefits of education: Crime, health, and good citizenship (NBER Working Paper No. 16722). Retrieved from http://www.nber.org/papers/w16722

Lochner, L. and Moretti, E. (2004). The effect of education on crime: Evidence from prison inmates, arrests, and self-reports. American Economic Review, 94, 155-189.

Loeber, R., Hoeve, M., Slot, N. W. and Van der Laan, P. H. (2013). Persisters and desisters in crime from adolescence into adulthood: Explanation, prevention and punishment. Ashgate Publishing, Ltd.

Luallen, J. (2006). School's out... forever: A study of juvenile crime, at-risk youths and teacher strikes. Journal of Urban Economics, 59, 75-103.

Machin, S., Marie, O. and Vujić, S. (2011). The crime reducing effect of education. The Economic Journal, 121, 463 - 484.

Machin, S., Marie, O. and Vujić, S. (2012). Youth crime and education expansion. German Economic Review, 13, 336 - 384.

Mascherini, M., Salvatore, L., Meierkord, A. and Jungblut, J. (2012). NEETs Young people not in employment, education or training: Characteristics, costs and policy responses in Europe. European Foundation for the Improvement of Living and Working conditions. Retrieved from

http://eurofound.europa.eu/sites/default/files/ef_publication/field_ef_document/e f1254en.pdf

Marie, O., Traag, T. and Van der Velden, R. (2015). Education and Crime: Individual Measures of the Causal Relationship. Unpublished manuscript.

McCollister, K., French, M. and Fang, H. (2010). The cost of crime to society: new crimespecific estimates for policy and program evaluation. Drug and Alcohol Dependency, 108, 98-109. 
McCord, J., Widom, C. S. and Crowell, N. A. (2001). Juvenile crime, juvenile justice. Panel on juvenile crime: Prevention, treatment, and control. Washington, DC: National Academy Press.

McCormick, M. C., Brooks-Gunn, J., Buka, S. L., Goldman, J., Yu, J., Salganik, M., et al. (2006). Early intervention in low birth weight premature infants: Results at 18 years of age for the infant health and development program. Pediatrics, 117, 771-780.

McGuire, S. and Segal, N. (2013). Peer Network Overlap in Twin, Sibling, and Friend Dyads. Child Development, 84, 500-511.

Meghir, C., Palme, M. and Schnabel, M. (2012). The effect of education policy on crime: An intergenerational perspective (Working Paper No. 18145). Retrieved from http://www.nber.org/papers/w18145

Mesters, G., Bijleveld, C. and Huschek, D. (2013). The Effect of Unemployment on Crime in High Risk Families in the Netherlands between 1920 and 2005. Retrieved from http://geertmesters.nl/wp-content/uploads/2014/07/UnemploymentCrime.pdf

Merlo, A. and Wolpin, K. (2009). The transition from school to jail: Youth crime and high school completion among Black males (Penn Institute for Economic Research Working Paper No. 09-002). Retrieved from https://ideas.repec.org/p/pen/papers/09-002.html

Merton, R. K. (1957). Social Theory and Social Structure. New York: Free Press.

Miers, D., Maguire, M, Goldie, Sh., Sharpe, K., Hale, Ch., Netten, A. et al. (2001). An exploratory evaluation of restorative justice schemes. Home Office Research, Development and Statistics Directorate, U.K. Retrieved from http://www.ibarji.org/docs/miers.pdf

Millenky, M., Bloom, D., Muller-Ravet, S. and Broadus, J. (2011). Staying on course: Threeyear results of the National Guard ChalleNGe Evaluation. Retrieved from http://www.mdrc.org/sites/default/files/full_510.pdf

Miller, P.W., Mulvey, C. and Martin, N. (1995) What do twin studies reveal about the economic returns to education? A comparison of Australian and U.S. findings. American Economic Review, 85, 586-599.

Ministry of Education, Culture and Science (2012). The approach to early school leaving. Retrived from http://www.aanvalopschooluitval.nl/userfiles/file/2014/VSVBoekje_UK_2014.pdf

Ministry of Justice. (2014). Youth Justice Statistics 2012/13 England and Wales (Youth Justice Board / Ministry of Justice Statistics bulletin). Retrieved from https://www.gov.uk/government/uploads/system/uploads/attachment_data/file/2 78549/youth-justice-stats-2013.pdf

Morgan, M. and Kett, M. (2003). The Prison Adult Literacy survey. Results and implications. Retrieved from http://www.epea.org/uploads/media/Adult_Literacy_Survey.pdf

Morris, N. and Tonry, M. (1990). Between prison and probation. Oxford University Press.

Mulder, E., Brand, E., Bullens, R. and Van Marle, H. (2011). Risk factors of overall recidivism and severity of recidivism in serious juvenile offenders. International Journal of Offender Therapy and Comparative Criminology, 55(1), 118-135.

Muncie, J. and Goldson, B. (2006). Youth crime and justice: Critical issues (Eds.). London: Sage.

Murray J., Loeber, R. and Pardini, D. (2012). Parental involvement in the criminal justice system and the development of youth theft, marijuana use, depression, and poor academic performance. Criminology, 50, 255-302. 
Murray, J., Farrington, D. P., and Sekol, I. (2012). Children's antisocial behavior, mental health, drug use, and educational performance after parental incarceration: A systematic review and meta-analysis. Psychological Bulletin, 138, 175-210.

Nesmith, A. and Ruhland, E. (2008). Children of incarcerated parents: Challenges and resiliency, in their own words. Children and Youth Services Review, 30, 1119-1130.

Newman, S. A., Fox, J. A., Flynn, E. A. and Christeson, W. (2000). America's afterschool choice: The primetime for juvenile crime, or youth enrichment and achievement. Washington, DC: Fight Crime: Invest in Kids.

Nieves, K. E., Draine, J. N. and Solomon, P. L. (2000) The validity of self-reported criminal arrest history among clients of a psychiatric probation and parole service. Journal of Offender Rehabilitation, 30, 133-151.

OECD (2014). Education at a Glance 2014: OECD Indicators. OECD Publishing. Retrieved from http://www.oecd.org/edu/Education-at-a-Glance-2014.pdf

OECD (2013). OECD Skills Outlook 2013: First Results from the Survey of Adult Skills, OECD Publishing. http://dx.doi.org/10.1787/9789264204256-en

OJJDP (2006). Juvenile Offenders and Victims: 2006 National Report. Retrieved from http://www.ojjdp.gov/ojstatbb/nr2006/downloads/chapter3.pdf

OJJDP(2013). OJJDP Statistical Briefing Book. Retrieved from http://www.ojjdp.gov/ojstatbb/structure_process/qa04102.asp?qaDate=2012

Olds, D., Sadler, L. and Kitzman, H. (2007). Programs for parents of infants and toddlers: Recent evidence from randomized trials. Journal of Child Psychology and Psychiatry, $48,355-391$.

Oreopoulos, P. (2007). Do dropouts drop out too soon? Wealth, health and happiness from compulsory schooling. Journal of Public Economics, 91, 2213-2229.

Parry, H., J., Balter, M., B. and Cisin, I. H. (1971). Primary levels of underreporting psychotropic drug use. Public Opinion Quarterly, 34, 582-592.

Paus, T. (2005). Mapping brain maturation and cognitive development during adolescence. Trends in Cognitive Sciences, 9, 60-68.

Peniston, D. A. (2006). The effects of parental incarceration on children: An examination of delinquency and criminality, school performance and alcohol and drug usage. University of Texas at Arlington, Arlington.

Pettit, B. and Western, B. (2004). Mass imprisonment and the life course: Race and class inequality in U.S. incarceration. American Sociological Review, 69, 151-169.

Phillips, D. L. and Clancy, K. J. (1972). Some effects of "social desirability" in survey studies, American Journal of Sociology, 77, 921-940.

Piquero, A. R., Farrington, D. P. and Blumstein, A. (2007). Key issues in criminal career research: New analyses of the Cambridge Study in Delinquent Development. Cambridge, UK: Cambridge University Press.

Plug, E. and Vijverberg, W. (2003). Schooling, family background, and adoption: Is it nature or is it nurture? Journal of Political Economy, 111, 611 - 641.

Prevoo, T. and Ter Weel, B. (2013). The importance of early conscientiousness for socioeconomic outcomes: Evidence from the British Cohort Study (CPB Discussion Paper No. 251). Retrieved from http://www.cpb.nl/en/publication/importance-early-conscientiousness-socioeconomic-outcomes-evidence-british-cohort-study

Psacharopoulos, G. (2007). The costs of school failure: A feasibility study. European Commission, European Expert Network on Economics of Education.

Reiss, A. (1988). Co-offending and criminal careers. In M. Torny and N. Morris (Eds.), Crime and justice: A review of research (Vol. 10, pp. 117-170). Chicago University Press. 
Reynolds, A. J., Temple, J. A., Robertson, D. L. and Mann, E. A. (2001). Long-term effects of an early childhood intervention on educational achievement and juvenile arrest- a 15 -year follow-up of low-income children in public schools. Journal of American Medical Association, 285, 2339-2346.

Reynolds, A., Mann, E., Miedel, W. and Smokowski, P. (1997). The state of early childhood intervention: Effectiveness, myths, and realities, new directions. Focus, 19, 5-11. Retrieved from http://www.irp.wisc.edu/publications/focus/pdfs/foc191.pdf

Riggs, N. R. and Greenberg, M. T. (2004). After-school youth development programs: A developmental-ecological model of current research. Clinical Child and Family Psychology Review, 7, 177 - 190.

Rodríguez-Planas, N. (2012a). Longer-term impacts of mentoring, educational services, and learning incentives: Evidence from a randomized trial in the United States. American Economic Journal: Applied Economics, 4, 121-139.

Rodríguez-Planas, N. (2012b). School and drugs: Closing the gap - evidence from a randomized trial in the US (IZA Discussion Paper No. 6770). Retrieved from http://papers.ssrn.com/sol3/papers.cfm?abstract_id $=2157912$

Roguski, M. and Chauvel, F. (2009). The effects of imprisonment on inmates' and their families' health and wellbeing. Wellington: Litmus Ltd.

Rosenbaum, P. R. (2002). Observational studies. New York: Springer.

Rubin, D. B. (1973). Matching to remove bias in observational studies. Biometrics, 29, 159184.

Rubin, D. B. (1979). Using multivariate matched sampling and regression adjustment to control bias in observational studies. Journal of the American Statistical Association, 74, 318-328.

Rubin, D. B. (2006). Matched sampling for causal effects. Cambridge: Cambridge University Press.

Rubin, D. B. and Thomas, N. (2000). Combining propensity score matching with additional adjustments for prognostic covariates. Journal of the American Statistical Association, 95, 573-585.

Sacerdote, B. (2007). How large are the effects from changes in family environment? A study of Korean American adoptees. Quarterly Journal of Economics, 122, 119-57.

Sacerdote, B. (2010). Nature and nurture effects on children's outcomes: What have we learned from studies of twins and adoptees. Handbook of social economics, 1, 1-30.

CBS (2014). Statistisch jaarboek 2014. Centraal Bureau voor de Statistiek. Retrieved from http://www.cbs.nl/nl-NL/menu/publicaties/boeken/statistischjaarboek/archief/2014/2014-statistisch-jaarboek-pub.htm

Schochet, P. Z., Burghardt, J. and McConnell, S. (2008). Does Job Corps work? Impact findings from the National Job Corps Study. American Economic Review, 98(5), 1864-1886.

Schweinhart, L. J. and Weikart, D. P. (1997). Lasting differences: The High/Scope Preschool Curriculum Comparison Study through age 23. Ypsilanti: High/Scope Press.

Schweinhart, L. J., Montie, J., Xiang, Z., Barnett, W. S., Belfield, C. R. and Nores, M. (2005). Lifetime effects: The High/Scope Perry Preschool Study through age 40. Ypsilanti, MI: High/Scope Press.

Scitovsky, T. (1999). Boredom: An overlooked disease? Challenges, 42, 5-15.

Sherman, L. W. and Strang, H. (2007). Restorative justice: The evidence. London: The Smith Institute. Retrieved from http://www.smith-

institute.org.uk/publications.html?search=restorative+andcategory_id=. 
Snyder, H. N. and Sickmund, M. (1999). Juvenile offenders and victims: 1999 national report. Retrieved from https://www.ncjrs.gov/html/ojjdp/nationalreport99/frontmatter.pdf.

Stanton, A. M. (1980). When mothers go to jail. Lexington, Mass.: Lexington Books.

Steinberg, L. (2005). A social neuroscience perspective on adolescent risk-taking. Developmental Review, 28, 78-106.

Stenberg, A. (2013). Interpreting estimates of heritability - A note on the twin decomposition. Economics and Human Biology, 11, 201-205.

Stillwell, R. and Sable, J. (2013). Public school graduates and dropouts from the common core of data: School year 2009-10. U.S. Department of Education. Washington, DC:

National Center for Education Statistics. Retrieved from

http://nces.ed.gov/pubs2013/2013309rev.pdf

Sweeten, G. (2006). Who will graduate? Disruption of high school education by arrest and court involvement. Justice Quarterly, 23, 462-481

Tak, P. (2003). The Dutch criminal justice system (WODC document No. 205). Retrieved from http://www.wodc.nl/images/ob205-full-text_tcm44-57899.pdf

Taylor-Butts, A. (2010). Where and when youth commit police-reported crimes, 2008. Retrieved from http://www.statcan.gc.ca/pub/85-002-x/2010002/article/11241eng.htm

Thornberry, T. and Krohn, M. (2000). The self-report method for measuring delinquency and crime. In: Duffee D., Crutchfield R. D. , Mastrofski S., Mazerolle L., McDowall D., Ostrom B., (Eds.), Innovations in Measurement and Analysis (33-83). National Institute of Justice; Washington.

Thornberry, T., Moore, M. and Christenson, R. L. (1985). The effect of dropping out of high school on subsequent criminal behavior. Criminology, 23, 3 - 18.

Tierney, J. P., Grossman, J. B. and Resch, N. L. (1995). Making a difference: An impact study of Big Brothers/Big Sisters. Philadelphia, PA: Public/Private Ventures.

Torrey, E., Bowler, A., Taylor, E. and Gottesman, I. (1994). Schizophrenia and manicdepressive disorder: The biological roots of mental illness as revealed by the landmark study of identical twins. Basic Books, New York.

Travis, J. and Waul, M. (Eds.). (2003). Prisoners once removed: The impact of incarceration and reentry on children, families and communities. Washington, D.C: Urban Institute Press.

Tremblay, R. E., Mâsse, B., Perron, D., LeBlanc, M., Schwartzman, A. E. and Ledingham, J. E. (1992). Early disruptive behavior, poor school achievement, delinquent behavior, and delinquent personality: Longitudinal analyses. Journal of Consulting and Clinical Psychology, 60, 64 - 72.

Trice, A. D. and Brewster, J. (2004). The effects of maternal incarceration on adolescent children. Journal of Police and Criminal Psychology, 19, 27-35.

Utting, D., Bright, J. and Henricson, C. (1993). Crime and the family. Improving child-rearing and preventing delinquency. London: Family Policy Studies Centre.

Van de Rakt, M., Ruiter, S., De Graaf, N.D. and Nieuwbeerta, P. (2010). When does the apple fall from the tree? Static versus dynamic theories predicting intergenerational transmission of convictions. Journal of Quantitative Criminology, 26, 371-389.

Van der Laan, A. and Blom, M. (2011). 'Jeugdcriminaliteit in de periode 1996-2010: ontwikkelingen in zelfgerapporteerde daders, door de politie aangehouden verdachten en strafrechtelijke daders op basis van de Monitor Jeugdcriminaliteit 2010'. Den Haag: Wetenschappelijk Onderzoek- en Documentatiecentrum (WODC). 
Retrieved from http://www.cbs.nl/NR/rdonlyres/0644989A-B7A6-44C8-89E4785ED1084E52/0/2011jeugdcrimwodccbspub.pdf

Van Elk, R., Van der Steeg, M. and Webbink, D. (2013). The effects of a special program for multi-problem school dropouts on educational enrolment, employment and criminal behaviour (CPB Discussion Paper No. 241). Retrieved from

http://www.cpb.nl/en/publication/de-effecten-van-de-wijkschool-rotterdam-oponderwijsdeelname-werk-en-criminaliteit

Wagenknecht, L. E., Burke, G. L., Perkins, L. L., Haley, N.J. and Friedman, G. D. (1992). Misclassification of smoking status in the CARDIA study: A comparison of self-report with serum cotinine levels. American Journal of Public Health, 82, 33-36.

Walker, S. P., Chang, S. M. a. V.-H. n. M. and Grantham-McGregor, S. (2011). Early childhood stimulation benefits adult competence and reduces violent behavior. American Academy of Pediatrics, 127, 849-857.

Walker, S. P., Chang, S. M., Powell, C. A. and Grantham-McGregor, S. M. (2005). Effects of early childhood psychosocial stimulation and nutritional supplementation on cognition and education in growth-stunted Jamaican children: prospective cohort study. Lancet, 366, 1804-1807.

Walker, S., Powell, C. and Grantham-McGregor, S. (1990). Dietary intakes and activity levels of stunted and non-stunted children in Kingston, Jamaica. part 1. dietary intakes. European Journal of Clinical Nutrition 44, 527-534.

Ward, S. and Williams, J. (2014). Does juvenile delinquency reduce educational attainment? (Working Paper). Retrieved from http://papers.ssrn.com/sol3/papers.cfm?abstract_id $=2469675$

Webbink, D., Koning, P., Vujic, S. and Martin, N. G. (2013). Why are criminals less educated than non-criminals? Evidence from a cohort of young Australian twins. The Journal of Law, Economics, and Organization 29, 115 - 144.

Wilbur, M. B., Marani, J. E., Appugliese, D., Woods, R., Siegel, J. A., Cabral, H. J., and Frank, D. A. (2007). Socioemotional effects of father's incarceration on low income, urban, school-aged children. Pediatrics, 120, e678-e685.

Wooldridge, J. (2009). Instrumental variables and two stage least squares (Chapter 15) in Introductory econometrics: $A$ modern approach ( $4^{\text {th }}$ edition). Mason, $\mathrm{OH}$ : SouthWestern Cengage Learning.

Yatchew, A. (1998). Nonparametric regression techniques in economics. Journal of Economic Literature, 36, 669-721. 


\section{Appendix}

Table A-1: Halt-worthy offenses related to law sections

\begin{tabular}{|c|c|c|}
\hline Section of the Law & Offense & Category \\
\hline 141(1) Criminal Law (CL) & Public violence possessions & Demolition \\
\hline $157 \mathrm{CL}$ & $\begin{array}{l}\text { Incendiaries with danger or } \\
\text { goods (not persons) }\end{array}$ & Public safety \\
\hline $310 \mathrm{CL}$ & (Shop)Theft + attempt to & Offense against property \\
\hline 311(1) (under 4th) CL & $\begin{array}{l}\text { (Shop)Theft in association with } \\
\text { one or more persons + attempt } \\
\text { to }\end{array}$ & Offense against property \\
\hline $321 \mathrm{CL}$ & Fraud + attempt to & Offense against property \\
\hline $350 \mathrm{CL}$ & Demolition & Demolition \\
\hline Graffiti & Demolition & \\
\hline $416 \mathrm{CL}$ & $\begin{array}{l}\text { Deliberately handling stolen } \\
\text { goods }\end{array}$ & Offense against property \\
\hline $417 \mathrm{CL}$ & Debt handling & Offense against property \\
\hline $326 \mathrm{CL}$ & Change of price tags (fraud) & Offense against property \\
\hline $424 \mathrm{CL}$ & $\begin{array}{l}\text { Reckless behavior with } \\
\text { danger/disadvantage goods }\end{array}$ & Reckless behavior \\
\hline $461 \mathrm{CL}$ & Trespassing & Other \\
\hline 1.2.2 Fireworks Decree & Illegal/defective firework & Firework offense \\
\hline 1.2.4 Fireworks Decree & $\begin{array}{l}\text { Possession of more than } 10 \mathrm{~kg} \text { of } \\
\text { firework in stock }\end{array}$ & Firework offense \\
\hline 2.3.6 Fireworks Decree & $\begin{array}{l}\text { Ignite fireworks outside } \\
\text { permitted period }\end{array}$ & Firework offense \\
\hline General Local Regulation & Firework & Firework offense \\
\hline Reckless behavior & Reckless behavior & \\
\hline $\begin{array}{l}72 \text { Regulation passenger } \\
\text { traffic }\end{array}$ & $\begin{array}{l}\text { Behavior that disturbs (or can } \\
\text { disturb) peace, safety and good } \\
\text { order }\end{array}$ & Public safety \\
\hline $\begin{array}{l}73 \text { Regulation passenger } \\
\text { traffic }\end{array}$ & $\begin{array}{l}\text { Ignore regulation with respect of } \\
\text { peace, safety and good order }\end{array}$ & Public safety \\
\hline
\end{tabular}


Table A-2: Assignment characteristics of juveniles in each Halt bureau

\begin{tabular}{|c|c|c|c|c|c|c|c|c|}
\hline & \multicolumn{2}{|c|}{ Amsterdam } & \multicolumn{2}{|l|}{ Breda } & \multicolumn{2}{|c|}{ Den Bosch } & \multicolumn{2}{|c|}{ The Hague } \\
\hline & $\mathrm{T}=82$ & $C=84$ & $T=10$ & $C=10$ & $\mathrm{~T}=45$ & $C=46$ & $T=70$ & $C=80$ \\
\hline Age & $\begin{array}{l}14.72 \\
(1.21)\end{array}$ & $\begin{array}{l}14.02^{* * *} \\
(1.54)\end{array}$ & $\begin{array}{l}14.20 \\
(1.62)\end{array}$ & $\begin{array}{l}15.30^{*} \\
(1.76)\end{array}$ & $\begin{array}{l}15.09 \\
(1.55)\end{array}$ & $\begin{array}{l}15.20 \\
(1.38)\end{array}$ & $\begin{array}{l}14.59 \\
(1.44)\end{array}$ & $\begin{array}{l}14.23^{*} \\
(1.55)\end{array}$ \\
\hline Women & $\begin{array}{l}0.35 \\
(0.48)\end{array}$ & $\begin{array}{l}0.35 \\
(0.48)\end{array}$ & $\begin{array}{l}0.50 \\
(0.53)\end{array}$ & $\begin{array}{l}0.40 \\
(0.52)\end{array}$ & $\begin{array}{l}0.27 \\
(0.45)\end{array}$ & $\begin{array}{l}0.33 \\
(0.47)\end{array}$ & $\begin{array}{l}0.27 \\
(0.45)\end{array}$ & $\begin{array}{l}0.26 \\
(0.44)\end{array}$ \\
\hline $\begin{array}{l}\text { Dutch } \\
\text { parents }\end{array}$ & $\begin{array}{l}0.39 \\
(0.48)\end{array}$ & $\begin{array}{l}0.32 \\
(0.47)\end{array}$ & $\begin{array}{l}0.60 \\
(0.52)\end{array}$ & $\begin{array}{l}0.67 \\
(0.50)\end{array}$ & $\begin{array}{l}0.86 \\
(0.35)\end{array}$ & $\begin{array}{l}0.80 \\
(0.40)\end{array}$ & $\begin{array}{l}0.57 \\
(0.50)\end{array}$ & $\begin{array}{l}0.49 \\
(0.50)\end{array}$ \\
\hline $\begin{array}{l}\text { Group } \\
\text { offense }\end{array}$ & $\begin{array}{l}0.73 \\
(0.45)\end{array}$ & $\begin{array}{l}0.67 \\
(0.47)\end{array}$ & $\begin{array}{l}0.60 \\
(0.52)\end{array}$ & $\begin{array}{l}0.50 \\
(0.53)\end{array}$ & $\begin{array}{l}0.80 \\
(0.41)\end{array}$ & $\begin{array}{l}0.60^{* *} \\
(0.50)\end{array}$ & $\begin{array}{l}0.83 \\
(0.38)\end{array}$ & $\begin{array}{l}0.75 \\
(0.43)\end{array}$ \\
\hline Demolition & $\begin{array}{l}0.18 \\
(0.39)\end{array}$ & $\begin{array}{l}0.18 \\
(0.39)\end{array}$ & $\begin{array}{l}0 \\
0\end{array}$ & $\begin{array}{l}0.20^{*} \\
(0.42)\end{array}$ & $\begin{array}{l}0.18 \\
(0.39)\end{array}$ & $\begin{array}{l}0.07^{*} \\
(0.25)\end{array}$ & $\begin{array}{l}0.09 \\
(0.28)\end{array}$ & $\begin{array}{l}0.09 \\
(0.28)\end{array}$ \\
\hline Graffiti & $\begin{array}{l}0.06 \\
(0.24)\end{array}$ & $\begin{array}{l}0.04 \\
(0.19)\end{array}$ & $\begin{array}{l}0 \\
0\end{array}$ & $\begin{array}{l}0 \\
0\end{array}$ & $\begin{array}{l}0 \\
0\end{array}$ & $\begin{array}{l}0.04 * \\
(0.21)\end{array}$ & $\begin{array}{l}0.04 \\
(0.20)\end{array}$ & $\begin{array}{l}0.05 \\
(0.22)\end{array}$ \\
\hline Shoplifting & $\begin{array}{l}0.37 \\
(0.48)\end{array}$ & $\begin{array}{l}0.46 \\
(0.50)\end{array}$ & $\begin{array}{l}0.60 \\
(0.52)\end{array}$ & $\begin{array}{l}0.60 \\
(0.52)\end{array}$ & $\begin{array}{l}0.18 \\
(0.39)\end{array}$ & $\begin{array}{l}0.26 \\
(0.44)\end{array}$ & $\begin{array}{l}0.37 \\
(0.49)\end{array}$ & $\begin{array}{l}0.33 \\
(0.47)\end{array}$ \\
\hline $\begin{array}{l}\text { Property } \\
\text { crime }\end{array}$ & $\begin{array}{l}0.16 \\
(0.37)\end{array}$ & $\begin{array}{l}0.17 \\
(0.37)\end{array}$ & $\begin{array}{l}0.20 \\
(0.42)\end{array}$ & $\begin{array}{l}0 \\
0\end{array}$ & $\begin{array}{l}0.04 \\
(0.21)\end{array}$ & $\begin{array}{l}0 \\
0\end{array}$ & $\begin{array}{l}0.23 \\
(0.42)\end{array}$ & $\begin{array}{l}0.18 \\
(0.38)\end{array}$ \\
\hline $\begin{array}{l}\text { Handling } \\
\text { stolen goods }\end{array}$ & $\begin{array}{l}0.04 \\
(0.19)\end{array}$ & $\begin{array}{l}0.02 \\
(0.15)\end{array}$ & $\begin{array}{l}0.20 \\
(0.42)\end{array}$ & $\begin{array}{l}0.20 \\
(0.42)\end{array}$ & $\begin{array}{l}0 \\
0\end{array}$ & $\begin{array}{l}0.07^{* *} \\
(0.25)\end{array}$ & $\begin{array}{l}0.01 \\
(0.12)\end{array}$ & $\begin{array}{l}0.03 \\
(0.16)\end{array}$ \\
\hline $\begin{array}{l}\text { Reckless } \\
\text { behavior }\end{array}$ & $\begin{array}{l}0.07 \\
(0.26)\end{array}$ & $\begin{array}{l}0.04 \\
(0.19)\end{array}$ & $\begin{array}{l}0.20 \\
(0.42)\end{array}$ & $\begin{array}{l}0.20 \\
(0.42)\end{array}$ & $\begin{array}{l}0.11 \\
(0.32)\end{array}$ & $\begin{array}{l}0.24 * \\
(0.43)\end{array}$ & $\begin{array}{l}0.17 \\
(0.38)\end{array}$ & $\begin{array}{l}0.15 \\
(0.36)\end{array}$ \\
\hline Joint Sign. Test & Prob $>F$ & $=0.1962$ & Prob $>F$ & $=0.0175$ & Prob $>F$ & $=0.2010$ & Prob $>F$ & 0.5556 \\
\hline
\end{tabular}


Table A-2: Assignment characteristics of juveniles in each Halt bureau (continued)

\begin{tabular}{|c|c|c|c|c|c|c|c|c|}
\hline & \multicolumn{2}{|c|}{ Enschede } & \multicolumn{2}{|c|}{ Friesland } & \multicolumn{2}{|c|}{ Gorinchem } & \multicolumn{2}{|c|}{ Groningen } \\
\hline & $\mathrm{T}=17$ & $C=17$ & $\mathrm{~T}=43$ & $C=43$ & $\mathrm{~T}=15$ & $C=15$ & $\mathrm{~T}=51$ & $C=53$ \\
\hline Age & $\begin{array}{l}14.47 \\
(1.12)\end{array}$ & $\begin{array}{l}14.12 \\
(1.27)\end{array}$ & $\begin{array}{l}14.30 \\
(1.48)\end{array}$ & $\begin{array}{l}14.65 \\
(1.52)\end{array}$ & $\begin{array}{l}13.80 \\
(1.47)\end{array}$ & $\begin{array}{l}14.47 \\
(1.55)\end{array}$ & $\begin{array}{l}14.78 \\
(1.50)\end{array}$ & $\begin{array}{l}14.55 \\
(1.47)\end{array}$ \\
\hline Women & $\begin{array}{l}0.12 \\
(0.33)\end{array}$ & $\begin{array}{l}0.24 \\
(0.44)\end{array}$ & $\begin{array}{l}0.26 \\
(0.44)\end{array}$ & $\begin{array}{l}0.42^{*} \\
(0.50)\end{array}$ & $\begin{array}{l}0.20 \\
(0.41)\end{array}$ & $\begin{array}{l}0.40 \\
(0.51)\end{array}$ & $\begin{array}{l}0.29 \\
(0.46)\end{array}$ & $\begin{array}{l}0.32 \\
(0.47)\end{array}$ \\
\hline $\begin{array}{l}\text { Dutch } \\
\text { Parents }\end{array}$ & $\begin{array}{l}0.71 \\
(0.47)\end{array}$ & $\begin{array}{l}0.71 \\
(0.47)\end{array}$ & $\begin{array}{l}0.86 \\
(0.35)\end{array}$ & $\begin{array}{l}0.81 \\
(0.39)\end{array}$ & $\begin{array}{l}0.67 \\
(0.49)\end{array}$ & $\begin{array}{l}0.87 \\
(0.35)\end{array}$ & $\begin{array}{l}0.88 \\
(0.33)\end{array}$ & $\begin{array}{l}0.83 \\
(0.38)\end{array}$ \\
\hline $\begin{array}{l}\text { Group } \\
\text { offense }\end{array}$ & $\begin{array}{l}0.65 \\
(0.49)\end{array}$ & $\begin{array}{l}0.47 \\
(0.51)\end{array}$ & $\begin{array}{l}0.79 \\
(0.41)\end{array}$ & $\begin{array}{l}0.74 \\
(0.45)\end{array}$ & $\begin{array}{l}0.73 \\
(0.46)\end{array}$ & $\begin{array}{l}0.79 \\
(0.43)\end{array}$ & $\begin{array}{l}0.76 \\
(0.43)\end{array}$ & $\begin{array}{l}0.75 \\
(0.43)\end{array}$ \\
\hline Demolition & $\begin{array}{l}0.18 \\
(0.39)\end{array}$ & $\begin{array}{l}0.24 \\
(0.44)\end{array}$ & $\begin{array}{l}0.28 \\
(0.45)\end{array}$ & $\begin{array}{l}0.21 \\
(0.41)\end{array}$ & $\begin{array}{l}0.33 \\
(0.49)\end{array}$ & $\begin{array}{l}0.27 \\
(0.46)\end{array}$ & $\begin{array}{l}0.22 \\
(0.42)\end{array}$ & $\begin{array}{l}0.17 \\
(0.38)\end{array}$ \\
\hline Graffiti & $\begin{array}{l}0 \\
0\end{array}$ & $\begin{array}{l}0 \\
0\end{array}$ & $\begin{array}{l}0.07 \\
(0.26)\end{array}$ & $\begin{array}{l}0 \\
0\end{array}$ & $\begin{array}{l}0.07 \\
(0.26)\end{array}$ & $\begin{array}{l}0 \\
0\end{array}$ & $\begin{array}{l}0 \\
0\end{array}$ & $\begin{array}{l}0.02 \\
(0.14)\end{array}$ \\
\hline Shoplifting & $\begin{array}{l}0.12 \\
(0.33)\end{array}$ & $\begin{array}{l}0.41^{* *} \\
(0.51)\end{array}$ & $\begin{array}{l}0.30 \\
(0.46)\end{array}$ & $\begin{array}{l}0.42 \\
(0.50)\end{array}$ & $\begin{array}{l}0.40 \\
(0.51)\end{array}$ & $\begin{array}{l}0.27 \\
(0.46)\end{array}$ & $\begin{array}{l}0.39 \\
(0.49)\end{array}$ & $\begin{array}{l}0.43 \\
(0.50)\end{array}$ \\
\hline $\begin{array}{l}\text { Property } \\
\text { crime }\end{array}$ & $\begin{array}{l}0.29 \\
(0.47)\end{array}$ & $\begin{array}{l}0.18 \\
(0.39)\end{array}$ & $\begin{array}{l}0.19 \\
(0.39)\end{array}$ & $\begin{array}{l}0.14 \\
(0.35)\end{array}$ & $\begin{array}{l}0 \\
0\end{array}$ & $\begin{array}{l}0.40^{* * *} \\
(0.51)\end{array}$ & $\begin{array}{l}0.20 \\
(0.40)\end{array}$ & $\begin{array}{l}0.11 \\
(0.32)\end{array}$ \\
\hline Handling & 0 & 0 & 0.02 & 0 & 0 & 0 & $\begin{array}{l}0.08 \\
(027)\end{array}$ & 0 \\
\hline stolen goods & 0 & 0 & (0.15) & 0 & 0 & 0 & $(0.27)$ & 0 \\
\hline $\begin{array}{l}\text { Reckless } \\
\text { behavior }\end{array}$ & $\begin{array}{l}0.18 \\
(0.39)\end{array}$ & $\begin{array}{l}0.06 \\
(0.24)\end{array}$ & $\begin{array}{l}0.07 \\
(0.26)\end{array}$ & $\begin{array}{l}0.09 \\
(0.29)\end{array}$ & $\begin{array}{l}0.13 \\
(0.35)\end{array}$ & $\begin{array}{l}0 \\
0\end{array}$ & $\begin{array}{l}0.06 \\
(0.24)\end{array}$ & $\begin{array}{l}0.06 \\
(0.23)\end{array}$ \\
\hline Joint Sign. Test & Prob $>F$ & $=0.6240$ & Prob $>F$ & 0.0392 & Prob $>F$ & $=0.1107$ & Prob $>F$ & 0.7952 \\
\hline
\end{tabular}


Table A-2: Assignment characteristics of juveniles in each Halt bureau (continued)

\begin{tabular}{|c|c|c|c|c|c|c|c|c|}
\hline & \multicolumn{2}{|l|}{ Leiden } & \multicolumn{2}{|c|}{ Maastricht } & \multicolumn{2}{|c|}{ Nijmegen } & \multicolumn{2}{|l|}{ Zwolle } \\
\hline & $T=58$ & $C=55$ & $T=13$ & $C=13$ & $T=34$ & $C=34$ & $\mathrm{~T}=27$ & $C=29$ \\
\hline Age & $\begin{array}{l}14.48 \\
(1.67)\end{array}$ & $\begin{array}{l}14.58 \\
(1.54)\end{array}$ & $\begin{array}{l}14.85 \\
(1.34)\end{array}$ & $\begin{array}{l}14.92 \\
(1.32)\end{array}$ & $\begin{array}{l}13.97 \\
(1.44)\end{array}$ & $\begin{array}{l}14.32 \\
(1.66)\end{array}$ & $\begin{array}{l}14.78 \\
(1.50)\end{array}$ & $\begin{array}{l}14.62 \\
(0.32)\end{array}$ \\
\hline Women & $\begin{array}{l}0.16 \\
(0.37)\end{array}$ & $\begin{array}{l}0.20 \\
(0.40)\end{array}$ & $\begin{array}{l}0.46 \\
(0.52)\end{array}$ & $\begin{array}{l}0.38 \\
(0.51)\end{array}$ & $\begin{array}{l}0.26 \\
(0.45)\end{array}$ & $\begin{array}{l}0.38 \\
(0.49)\end{array}$ & $\begin{array}{l}0.11 \\
(0.32)\end{array}$ & $\begin{array}{l}0.14 \\
(0.35)\end{array}$ \\
\hline $\begin{array}{l}\text { Dutch } \\
\text { parents }\end{array}$ & $\begin{array}{l}0.76 \\
(0.43)\end{array}$ & $\begin{array}{l}0.75 \\
(0.44)\end{array}$ & $\begin{array}{l}0.83 \\
(0.39)\end{array}$ & $\begin{array}{l}0.85 \\
(0.38)\end{array}$ & $\begin{array}{l}0.82 \\
(0.39)\end{array}$ & $\begin{array}{l}0.65^{*} \\
(0.49)\end{array}$ & $\begin{array}{l}0.96 \\
(0.19)\end{array}$ & $\begin{array}{l}0.83^{*} \\
(0.38)\end{array}$ \\
\hline $\begin{array}{l}\text { Group } \\
\text { offense }\end{array}$ & $\begin{array}{l}0.84 \\
(0.37)\end{array}$ & $\begin{array}{l}0.74^{*} \\
(0.44)\end{array}$ & $\begin{array}{l}0.75 \\
(0.45)\end{array}$ & $\begin{array}{l}0.38 * * \\
(0.51)\end{array}$ & $\begin{array}{l}0.85 \\
(0.36)\end{array}$ & $\begin{array}{l}0.75 \\
(0.44)\end{array}$ & $\begin{array}{l}0.78 \\
(0.42)\end{array}$ & $\begin{array}{l}0.90 \\
(0.31)\end{array}$ \\
\hline Demolition & $\begin{array}{l}0.19 \\
(0.40)\end{array}$ & $\begin{array}{l}0.20 \\
(0.40)\end{array}$ & $\begin{array}{l}0.08 \\
(0.28)\end{array}$ & $\begin{array}{l}0.08 \\
(0.28)\end{array}$ & $\begin{array}{l}0.35 \\
(0.49)\end{array}$ & $\begin{array}{l}0.15^{* *} \\
(0.36)\end{array}$ & $\begin{array}{l}0.26 \\
(0.45)\end{array}$ & $\begin{array}{l}0.31 \\
(0.47)\end{array}$ \\
\hline Graffiti & $\begin{array}{l}0.05 \\
(0.22)\end{array}$ & $\begin{array}{l}0.04 \\
(0.19)\end{array}$ & $\begin{array}{l}0 \\
0\end{array}$ & $\begin{array}{l}0 \\
0\end{array}$ & $\begin{array}{l}0 \\
0\end{array}$ & $\begin{array}{l}0 \\
0\end{array}$ & $\begin{array}{l}0 \\
0\end{array}$ & $\begin{array}{l}0 \\
0\end{array}$ \\
\hline Shoplifting & $\begin{array}{l}0.17 \\
(0.38)\end{array}$ & $\begin{array}{l}0.24 \\
(0.43)\end{array}$ & $\begin{array}{l}0.62 \\
(0.51)\end{array}$ & $\begin{array}{l}0.77 \\
(0.44)\end{array}$ & $\begin{array}{l}0.24 \\
(0.43)\end{array}$ & $\begin{array}{l}0.56^{* * *} \\
(0.50)\end{array}$ & $\begin{array}{l}0.30 \\
(0.47)\end{array}$ & $\begin{array}{l}0.17 \\
(0.38)\end{array}$ \\
\hline $\begin{array}{l}\text { Property } \\
\text { crime }\end{array}$ & $\begin{array}{l}0.12 \\
(0.33)\end{array}$ & $\begin{array}{l}0.15 \\
(0.35)\end{array}$ & $\begin{array}{l}0.08 \\
(0.28)\end{array}$ & $\begin{array}{l}0 \\
0\end{array}$ & $\begin{array}{l}0.09 \\
(0.29)\end{array}$ & $\begin{array}{l}0.03 \\
(0.17)\end{array}$ & $\begin{array}{l}0.19 \\
(0.40)\end{array}$ & $\begin{array}{l}0.34^{*} \\
(0.48)\end{array}$ \\
\hline $\begin{array}{l}\text { Handling } \\
\text { stolen goods }\end{array}$ & $\begin{array}{l}0 \\
0\end{array}$ & $\begin{array}{l}0.02 \\
(0.13)\end{array}$ & $\begin{array}{l}0.08 \\
(0.29)\end{array}$ & $\begin{array}{l}0.08 \\
(0.29)\end{array}$ & $\begin{array}{l}0.03 \\
(0.17)\end{array}$ & $\begin{array}{l}0.03 \\
(0.17)\end{array}$ & $\begin{array}{l}0 \\
0\end{array}$ & $\begin{array}{l}0 \\
0\end{array}$ \\
\hline $\begin{array}{l}\text { Reckless } \\
\text { behavior }\end{array}$ & $\begin{array}{l}0.21 \\
(0.41)\end{array}$ & $\begin{array}{l}0.31 \\
(0.47)\end{array}$ & $\begin{array}{l}0.08 \\
(0.28)\end{array}$ & $\begin{array}{l}0.08 \\
(0.28)\end{array}$ & $\begin{array}{l}0.12 \\
(0.33)\end{array}$ & $\begin{array}{l}0.24 \\
(0.43)\end{array}$ & $\begin{array}{l}0.22 \\
(0.42)\end{array}$ & $\begin{array}{l}0.17 \\
(0.38)\end{array}$ \\
\hline Joint Sign. Test & Prob $>F$ & 0.3783 & Prob $>F$ & $=0.3766$ & Prob $>F$ & $=0.2249$ & Prob $>F$ & 0.2637 \\
\hline
\end{tabular}


Table A-3: Age distribution for Participants in the Halt Experiment

\begin{tabular}{llll}
\hline Age & Frequency & Percent & Cumulative \% \\
\hline 11 & 6 & 0.64 & 0.64 \\
12 & 75 & 7.97 & 8.58 \\
13 & 182 & 19.28 & 27.86 \\
14 & 206 & 21.82 & 49.68 \\
15 & 223 & 23.62 & 73.31 \\
16 & 147 & 15.57 & 88.88 \\
17 & 92 & 9.75 & 98.62 \\
18 & 13 & 1.38 & 100.00 \\
\hline Observations & 944 & 100.00 & \\
\hline
\end{tabular}





\section{Summary}

This dissertation analyzes the relationship between youth crime and education. Criminal behavior and low educational attainment among young people are two social problems that have high private and public costs. The costs are especially large because low levels of education and criminal involvement in adolescence are connected to adverse life outcomes, including reduced chances of employment and lower predicted earnings, bad health and criminal involvement in adulthood. Youth crime and low educational outcomes appear to have common roots. For instance, adolescents from low socio-economic background are more likely to become criminally involved and dropout from compulsory school. Criminal behavior and education can also be dynamically integrated: criminally involved adolescents may leave compulsory school earlier, which in turn can reduce their chances at the labor market and also encourage them to come back to criminal activities. However, it is not fully clear how youth crime and education are specifically related and what are the mechanisms behind this relationship. Evidence on this relationship can provide a path to more effective and efficient interventions that address criminal involvement and educational outcomes in young age.

Previous research has mainly been focused on analyzing the effect of educational attainment on criminal involvement in adulthood. Youth crime, however, tends to differ from crime of adults by its nature and motives. Intellectual and socio-emotional development as well as peer interactions can drive adolescents into criminal activities, whereas criminal involvement of adults is more often based on rational economic choices. Moreover, for young people criminal involvement can 
precede educational attainment, which is generally not the case for adults. Hence, causality between youth crime and education may run in both directions: from education to youth crime and vice versa. Moreover, it is generally difficult to establish causal effects between crime and education because they both can be driven by similar observable and unobservable characteristics.

In this dissertation we provide evidence on the relationship between youth crime and education, based on a combination of findings from the literature and results of empirical analyses. We have exploited rich survey and registration data from the Netherlands and applied various econometric techniques to examine several aspects of this relationship. The chapters of this dissertation are summarized below.

Chapter 2 provides a systematic literature review on the relationship between youth crime and education. We first refer to evidence from interventions studies that aim to improve future perspectives of at-risk children and adolescents. These interventions, in general, serve to equalize opportunities of socioeconomically disadvantaged individuals who do not sufficiently receive investments (e.g. economic, social, behavioral and educational) in their cognitive and socioemotional development. We have considered early childhood interventions, early school-age interventions and interventions for adolescents. We refer only to those interventions that were evaluated with respect to their effectiveness on education and criminal involvement outcomes. From this literature, we conclude that especially early childhood and pre-school interventions targeted at children with low socioeconomic status tend to have a favorable effect on both future criminal behavior and educational outcomes. Early school and adolescent interventions have been shown to positively affect educational outcomes as well, while they appear to be less successful with respect to criminal behavior outcomes. More evidence regarding what exact components of these interventions are the most important for improving education and criminal behavior outcomes of at-risk individuals is needed. It is already known that certain non-cognitive skills affected by these interventions are responsible for a range of life outcomes, including criminal behavior and education. 
Studies that examine the effects between youth crime and education generally conclude that educational attainment is causally and negatively related to criminal behavior in adolescence and young adulthood. Furthermore, evidence shows that being in school reduces chances of criminal involvement, in particular property crime, while not attending school increases the probability of criminal involvement (again, with respect to property offences). Finally, it is shown that attending post-compulsory education, especially high-quality, has a negative effect on criminal behavior of adolescents with low socio-economic background. Different mechanisms can be behind the negative effect of education on youth crime, among them influence of education on socio-emotional skills of young people, high opportunity costs of participating in criminal activities for higher educated people, and the positive signal from acquiring educational credentials, such as a diploma and an academic degree, which can prevent adolescents from committing illegal activities.

Studies that examine the effect of crime on education show there is a strong correlation between early criminal involvement and educational outcomes. The relationship between more serious criminal behavior and education is likely to reflect a negative causal effect. This effect can result from accumulation of 'criminal capital', disruptions in the traditional educational (and learning) process due to interactions with criminal justice, stigma effects, and shocks to socio-emotional skills of young people.

Chapter 3 examines what factors can drive the relationship between criminal involvement in adolescence and early school leaving. We use administrative data from the Netherlands that contain information on criminal involvement, educational careers and on a wide range of socio-economic characteristics of students and their family. Criminal involvement is associated with a 10.7 percentage points higher probability of early school leaving. This chapter shows that the magnitude of this relationship decreases, while remaining statistically significant after we account for underlying factors by adding control variables and by using school, sibling and twin fixed effect estimators. Moving from an unconditional correlation model to the 
models with fixed-effects, allows us to analyze to what extent the relationship between criminal involvement and early school leaving is driven by school-, familyand individual-specific characteristics.

We conclude that observable and unobservable heterogeneity that we account for by using same-gender twin fixed effects explains around 72 percent of the unconditional correlation between criminal involvement and early school leaving. The remaining 28 percent is likely to reflect individual-specific factors, such as behavior and motivation, or the true treatment effect from the criminal activity (e.g. time spent on crime, interactions with criminal justice). It appears that a true treatment effect from criminal involvement on early school leaving, if it exists, is likely to be small. At the same time, the association between criminal involvement and early school leaving is stronger for serious crime. Moreover, the difference between overall and severe crime does not appear to be driven by selection. We conclude that even if criminal involvement does not causally affect educational involvement, our research suggests that factors that underlie criminal behavior and education are very similar and affecting them can simultaneously improve educational and criminal behavior outcomes. In this respect, family-specific factors appear to be especially important.

In Chapter 4 we examine the effects of a Dutch restorative justice program for adolescent offenders on early school leaving and years of education attained. Causal statistical estimates are presented using data from a randomized experiment, in which 944 adolescent offenders are randomly assigned to the experimental condition, and by linking these data to registration data that tracks the educational careers of all Dutch adolescents. We adopt an instrumental variable approach to address selective dropout of participants from the treatment group. We find that the program reduces early school leaving by six percentage points and that it increases years of education attained by 0.29 years. The positive effect of Halt tends to be smaller for boys, adolescents with Dutch origin and juveniles in single-parent households. Furthermore, we find that the Halt program is less effective for group offenders with regards to after-program years of education. We conclude that spill- 
over effects of restorative justice programs can be substantial, because such programs can positively affect educational outcomes of juvenile offenders and also because higher educational attainment can, in turn, reduce criminal behavior in the long run. The mechanisms that are behind the positive effect of Halt on educational attainment are difficult to identify because the components of the program are tailor-made for different types of juvenile offenders. This means that the program corresponds to the motives of criminal involvement and specific behavioral problems of the participants.

Chapter 5 examines the effect of parents' criminal involvement on the educational attainment of their children. The empirical literature on education and crime suggests that both criminal behavior and educational attainment are transferred from parents to children. However, the impact of criminal behavior of parents on educational outcomes of children is generally ignored, even though the entailed social costs can be substantial. We acknowledge that parents with a criminal past may be a selective group, especially with respect to their level of education. Therefore, we adopt a statistical matching approach (Mahalanobis matching) that establishes a sample of parents with comparable observable characteristics but with a difference in the treatment status. We apply a multinomial logit model that can simultaneously estimate the effect of criminal involvement of parents on the probabilities of obtaining any of the five categories of children's educational attainment. The results of our empirical analysis show that criminal involvement of parents is likely to have a negative effect on educational attainment of their children. More specifically, having criminally involved parents (1) increases the probability of finishing primary education (in the range between 7 to 9 percentage points), and (2) decreases the probability of attaining higher education (in the range between 2 to 6 percentage points). These results are robust to various specifications. The effect of unobservable heterogeneity is taken into account by using the techniques that assess how sensitive the results to selection on unobservables based on the identified selection on observable characteristics (Altonji et al., 2005). The heterogeneity analyses show that children at the bottom of the educational 
attainment distribution are more affected if fathers are criminally involved, while children at the top of the educational attainment distribution are more affected if the mothers are criminally involved. Furthermore, the negative effect of having criminal parents is more pronounced if parents were convicted rather than only arrested.

This dissertation documents that there is strong evidence on the causal negative effect of education on youth crime. Our empirical analysis provide suggestive evidence on the negative impact of early criminal involvement on educational outcomes. Combining our findings with findings from the literature, this dissertation further underlines the dynamic relationship between crime and education. Early criminal involvement, especially for serious crimes, can negatively affect educational outcomes, and also adult criminal behavior, while influenced by criminal behavior education, in turn, can have an impact on the propensity for adult crime. This dissertation shows that such spillovers can even persist into the next generation. We find that the impact of crime on education is not homogenous across all types of crime. In particular, results suggest that severe criminal involvement has a stronger negative effect on educational outcomes, while the intergenerational effect of crime of parents to education of children is also found to be stronger for more serious offenses. Further assessing such heterogeneity can be a direction for future research.

These findings imply that policy can benefit from considering low educational levels and criminal behavior among young people as interrelated problems. This evidence is important for providing pathways for integrated programs that can simultaneously address both problems in a more effective and efficient way than separate policy programs for criminal involvement and educational outcomes. Improving educational outcomes of young people can be a tool to prevent and reduce youth crime, whereas interventions targeted at criminal behavior can have positive spill-over effects with respect to educational attainment of individuals and also their children. The benefits of such policies can be long-lasting considering the dynamic link between education and criminal behavior. The evaluation of the 
restorative juvenile justice program from the Netherlands has shown that interventions aimed to reduce criminal behavior of juveniles can positively affect their education as well. Therefore, such interventions can be also constructed and evaluated with respect to education and other societal outcomes. Furthermore, this dissertation has confirmed that factors that underlie criminal behavior and the factors that underlie poor educational outcomes (e.g. family-specific characteristics, socio-economic environment) strongly overlap, and hence, policy-makers are advised to target these factors. 



\section{Samenvatting}

Deze thesis analyseert de relatie tussen jeugdcriminaliteit en onderwijs. Crimineel gedrag en lage opleidingsniveaus onder jongeren vormen twee belangrijke sociale problemen die hoge private en publieke kosten met zich meebrengen. Deze kosten zijn vooral hoog omdat jeugdcriminaliteit en slechte schoolprestaties sterk gerelateerd zijn aan diverse negatieve uitkomsten tijdens de rest van het leven, zoals een hoge werkloosheid, een laag loon, slechte gezondheid en crimineel gedrag tijdens volwassen levensjaren. Jeugdcriminaliteit en slechte schoolprestaties lijken een gedeelde oorsprong te hebben. Bijvoorbeeld, jongeren uit een laag sociaaleconomisch milieu hebben zowel een grotere kans op het vertonen van crimineel gedrag als op voortijdig schoolverlaten. Criminaliteit en onderwijs kunnen ook dynamisch op elkaar inwerken: jongeren die crimineel actief zijn kunnen besluiten om hun school niet af te maken, wat vervolgens hun kansen op de arbeidsmarkt verkleind, hetgeen weer een reden kan zijn om opnieuw te vervallen in crimineel gedrag etc. Het is echter nog steeds niet duidelijk hoe jeugdcriminaliteit en onderwijs exact aan elkaar gerelateerd zijn en wat de specifieke mechanismes zijn die achter deze relatie steken. Empirisch onderzoek over deze resultaten kan helpen om meer effectieve en efficiënte maatregelen te ontwikkelen die zowel criminaliteit als slechte schoolprestaties op een jonge leeftijd kunnen aanpakken.

Eerder onderzoek heeft zich vooral gericht op de relatie tussen opleidingsniveau en crimineel gedrag van volwassenen. Jeugdcriminaliteit verschilt echter sterk van volwassen criminaliteit als het gaat om de aard van de misdrijven en de motieven. De intellectuele en sociaal-emotionele ontwikkeling van jongeren 
alsmede interacties met vrienden en klasgenoten worden gezien als de belangrijkste voorspellers van crimineel gedrag van jongeren, terwijl bij volwassencriminaliteit economische motieven vaker een rol spelen. Daarnaast kan jeugdcriminaliteit plaatsvinden voordat het opleidingsniveau is bepaald, terwijl dit voor volwassencriminaliteit normaal gesproken niet zo is. De causaliteit tussen crimineel gedrag van jongeren en onderwijs kan dus in beide richtingen lopen: van onderwijs naar jeugdcriminaliteit en vice versa. Een ander conceptueel probleem is dat het vaak moeilijk is om causale effecten tussen criminaliteit en onderwijs goed te meten omdat ze gedreven kunnen worden door dezelfde observeerbare en nietobserveerbare kenmerken.

Deze dissertatie levert belangrijke inzichten in de relatie tussen jeugdcriminaliteit en onderwijs, gebaseerd op zowel bevindingen uit de literatuur als resultaten van empirische analyses. We gebruiken daarbij zeer uitgebreide Nederlandse data uit zowel administratieve bronnen als uit vragenlijsten en passen verschillende econometrische technieken toe om de verscheidene aspecten van deze relatie te onderzoeken. De hoofdstukken van deze dissertatie zijn hieronder samengevat.

Hoofdstuk twee presenteert een systematisch literatuuroverzicht van de relatie tussen jeugdcriminaliteit en onderwijsuitkomsten. We vatten eerst het bewijs samen dat geleverd is door interventieprogramma's die als doel hebben om de toekomstperspectieven van kinderen uit achtergestelde sociale milieus te verbeteren. Deze kinderen ervaren vaak een gebrek aan broodnodige investeringen (zowel financieel als in termen van aandacht en betrokkenheid) in hun vroege levensjaren, hetgeen deze programma's (deels) proberen te compenseren. We concluderen dat vooral programma's die al beginnen voordat kinderen naar school zijn en die gericht zijn op kinderen met een lage sociaaleconomische status erin slagen om zowel gunstige uitkomsten op het gebied van criminaliteit als op het gebied van onderwijs te realiseren. Interventies die gericht zijn op schoolgaande kinderen en adolescenten zijn vaak ook effectief als het gaat om schoolprestaties, maar hebben minder vaak een gunstig effect op criminaliteit. Er is nog steeds weinig 
bekend over hoe deze interventieprogramma's deze gunstige effecten precies bereiken. Recente studies geven aan dat verbeteringen in bepaalde non-cognitieve vaardigheden vooral verantwoordelijk lijken voor verbeteringen in langetermijnuitkomsten, maar er is meer bewijs nodig over welke vaardigheden dit exact zijn en hoe deze nu effectief verbeterd worden.

Studies die de relatie tussen jeugdcriminaliteit en onderwijsprestaties onderzoeken concluderen dat opleidingsniveau een negatief en causaal effect heeft op crimineel gedrag in de adolescente jaren. Daarnaast blijkt dat er een directe (negatieve) link is tussen de tijd die leerlingen op school zijn en het plegen van criminaliteit, met name als het gaat om diefstal. Ten slotte geven empirische studies aan dat het volgen van postsecundair onderwijs een sterke negatief effect heeft op criminele activiteiten van adolescenten uit een laag sociaaleconomisch milieu. Dit effect is sterker naarmate het gevolgde onderwijs van hoger niveau is. De literatuur noemt verschillende mogelijke mechanismes die achter deze effecten steken, zoals verbeterde non-cognitieve vaardigheden, hogere opportuniteitskosten van het participeren in criminele activiteiten en het positieve signaal van het verkrijgen van een diploma.

Er zijn ook een aantal studies die de omgekeerde relatie onderzoeken; wat is de invloed van jeugdcriminaliteit op onderwijsuitkomsten? Analyses laten zien dat er een sterke negatieve relatie is, en dat er voor de relatie tussen zware delicten en onderwijsprestaties zeer waarschijnlijk een causale component bestaat. Dit effect zou voort kunnen komen door de opbouw van 'crimineel kapitaal', verstoringen in het onderwijsproces vanwege juridische procedures, stigmatisatie, en mogelijke negatieve 'shocks' in de ontwikkeling van sociaal-emotionele vaardigheden van jongeren.

Hoofdstuk 3 analyseert welke factoren vooral verantwoordelijk zijn voor de relatie tussen crimineel gedrag en vervroegde schooluitval. We gebruiken Nederlandse administratieve data die informatie bevatten over gepleegde criminaliteit, onderwijscarrières en diverse sociaaleconomische kenmerken van studenten en de families waarin ze opgroeien. Studenten die crimineel gedrag 
vertonen hebben een kans op vervroegde schooluitval die 10.7 procentpunt hoger ligt dan die voor studenten die niet crimineel actief zijn. We controleren vervolgens voor verschillende mogelijke onderliggende aspecten door het opnemen van achtergrondvariabelen en door het controleren voor aspecten die worden gedeeld ('fixed effects') op het niveau van de school, op het niveau van de familie, en tussen tweelingen binnen de familie. Door te starten met een ruwe associatie en vervolgens in verschillende stappen voor steeds meer factoren te controleren kunnen we een beeld krijgen van in hoeverre de correlatie tussen jeugdcriminaliteit en schooluitval verklaard kan worden door school-specifieke, familie-specifieke en individuspecifieke kenmerken.

We concluderen dat het meest 'complete' model, het model dat controleert voor aspecten die gedeeld worden tussen tweelingen, 72 percent verklaart van het ruwe verschil in schooluitval tussen criminele en niet-criminele jongeren. De overgebleven 28 percent reflecteert ofwel individu-specifieke aspecten zoals gedrag en motivatie ofwel een echt causaal effect van het crimineel actief zijn (bijv. de tijd die besteed wordt aan criminele activiteiten en dus niet aan school of de gevolgen van interacties met juridische instanties). Het is echter waarschijnlijk dat, mocht er al een echt causaal effect zijn van jeugdcriminaliteit op schooluitval, dit effect relatief vrij klein is. Tegelijkertijd is er een veel sterkere relatie tussen het plegen van zwaardere delicten en schooluitval, en deze relatie blijkt veel minder gedreven te worden door de verschillende observeerbare en niet-observeerbare aspecten waar we voor kunnen controleren. We concluderen dat zelfs wanneer er geen causaal verband bestaat tussen jeugdcriminaliteit en schooluitval uit de resultaten duidelijk blijkt dat er een sterke overlap is tussen de aspecten die beide uitkomsten bepalen. Dit geeft ook aan dat verbeteringen in deze aspecten gelijktijdig kunnen leiden tot verbeteringen in onderwijsuitkomsten en afname van crimineel gedrag van jongeren. Uit de resultaten blijkt dat vooral familie-specifieke aspecten in deze belangrijke zijn.

Hoofdstuk 4 analyseert het effect van 'Halt', een Nederlandse alternatief strafprogramma voor jonge wetsovertreders. Halt is gericht op jongeren die voor de 
eerste keer zijn aangehouden voor het plegen van een crimineel delict, op voorwaarde dat het geen zwaar delict betreft. De analyse is gebaseerd op een gerandomiseerd experiment met controlegroep, waardoor het causale effect van Halt onderzocht kan worden. Het experiment verdeelt 944 jonge overtreders willekeurig over de programmagroep en de controlegroep. Deze jongeren zijn in administratieve data gekoppeld aan uitgebreide informatie over hun schoolcarrières. We gebruiken een 'intent-to-treat' analyse waarin daadwerkelijke participatie in Halt wordt geïnstrumenteerd met beoogde participatie om te corrigeren voor selectieve uitval. We vinden dat Halt leidt tot een afname in vroegtijdig schoolverlaten met 6 procentpunt en een toename van het aantal gevolgde jaren onderwijs met 0.29 jaar. De effecten zijn lager voor jongens, autochtonen en jongeren uit eenpersoonshuishoudens. Verder blijkt dat Halt duidelijk minder effectief is voor plegers van groepsdelicten. We concluderen dat programma's voor jonge delinquenten die alternatieve straffen toepassen sterke 'spillover' effecten kunnen hebben op het gebied van onderwijsprestaties. Aangezien een hoger opleidingsniveau weer gerelateerd is aan een lagere kans op crimineel gedrag in de volwassen jaren kunnen de opbrengsten van dit soort programma's op de lange termijn zeer hoog zijn. Het is moeilijk om de onderliggende factoren te identificeren die hebben geleid tot het positieve effect van Halt op onderwijs, omdat de inhoud van het programma voor elke jongere individueel is aangepast. Het is mogelijk dat Halt effectief is omdat het een soort van sociale controle levert en mogelijk ook schoolaspiraties en sociaal-emotionele vaardigheden verbeterd.

In hoofdstuk 5 wordt het effect van de criminele betrokkenheid van ouders op de schoolprestaties van hun kinderen geanalyseerd. De empirische literatuur geeft aan dat zowel de kans op crimineel gedrag als het behaalde onderwijsniveau deels wordt 'doorgegeven' van generatie op generatie. Er is echter zeer weinig bekend over een mogelijk effect van crimineel gedrag van ouders op het opleidingsniveau van hun kinderen, terwijl dit potentieel een zeer belangrijk aspect kan vormen van de totale publieke kosten van criminaliteit. De analyse erkent dat ouders met criminele betrokkenheid waarschijnlijk een zeer selectieve groep is. 
Daarom wordt er gebruik gemaakt van 'statistical matching' (Mahalanobis matching) om te controleren voor observeerbare verschillen tussen leerlingen met crimineel betrokken ouders en leerlingen zonder crimineel betrokken ouders. We gebruiken verder een multinomial logit model dat ons in staat stelt om gelijktijdig de impact te schatten van de criminele betrokkenheid van ouders op de kans om elk van de vijf gedefinieerde opleidingsniveaus te behalen. De resultaten geven aan dat de criminele betrokkenheid van de ouders de kans op het niet behalen van een middelbareschooldiploma verhoogt met 7 tot 9 procentpunt en de kans op het afronden van hoger onderwijs verlaagt met 2 tot 6 procentpunt. De resultaten houden rekening met de mogelijke invloed van niet-observeerbare heterogeniteit tussen jongeren met en zonder crimineel betrokken ouders door middel van een methode ontwikkelt door Altonji et al. (2005). Verdere analyse laat zien dat de effecten aan de onderkant van de distributie (i.e. geen middelbareschooldiploma) sterker zijn als vaders crimineel betrokken zijn geweest terwijl de effecten aan de bovenkant van de distributie (i.e. het behalen van een diploma voor hoger onderwijs) sterker zijn bij criminele betrokkenheid van de moeder. Daarnaast zijn de effecten ook sterker als de criminele betrokkenheid heeft geleid tot een veroordeling.

De bevindingen van deze dissertatie gecombineerd met eerdere bevindingen uit de literaturen geven aan dat er een sterke dynamische relatie is tussen crimineel gedrag en onderwijsuitkomsten. Vroege criminele betrokkenheid kan, vooral voor serieuze delicten, een negatief effect hebben op onderwijsprestaties en verhoogt de kans op toekomstig crimineel gedrag, terwijl een hoger opleidingsniveau op zijn beurt weer de kans op later crimineel gedrag verlaagt. Hoofdstuk 5 geeft aan dat dit soort van 'spillover effects' zelfs kunnen doorwerken tot in de volgende generatie. We vinden ook dat de impact van criminaliteit op onderwijsuitkomsten niet homogeen is over de verschillende soorten van criminaliteit. De resultaten suggereren dat zwaardere delicten een sterker negatief effect hebben op schooluitval, terwijl het intergenerationele effect van criminaliteit van ouders op het opleidingsniveau van hun kinderen sterker is wanneer het gaat om delicten die ook 
tot een veroordeling hebben geleid. Toekomstig onderzoek zou dieper kunnen ingaan op deze vorm van heterogeniteit.

De bevindingen van deze thesis impliceren dat het gunstig kan zijn als beleidsmakers lage opleidingsniveaus en jeugdcriminaliteit als geïntegreerde problemen benaderen. Op deze manier zou er een geïntegreerde aanpak ontwikkeld kunnen worden die gelijktijdig beide problemen op een effectieve en efficiënte manier adresseert. Het verbeteren van onderwijsuitkomsten van jongeren kan een middel zijn om jeugdcriminaliteit te voorkomen, terwijl interventieprogramma's die gericht zijn op het voorkomen van (verder) crimineel gedrag positieve spillovers kunnen hebben op onderwijsuitkomsten van individuen, en potentieel in de toekomst ook die van hun kinderen. De opbrengsten van zulk beleid kunnen op de lange termijn groot en continue zijn, vanwege de dynamische link tussen criminaliteit en onderwijs. De bevindingen van Hoofdstuk 4 laten zijn dat het ook in de evaluatie van programma's gericht op jonge delinquenten belangrijk is dat er ook wordt gekeken naar onderwijsuitkomsten en eventueel andere uitkomsten die belangrijk kunnen zijn vanuit maatschappelijk perspectief. Daarnaast heeft deze dissertatie duidelijk gemaakt dat er een sterke overlap is tussen factoren die gerelateerd zijn aan crimineel gedrag en factoren die gerelateerd zijn aan slechte onderwijsprestaties (bijvoorbeeld familiale omstandigheden). Beleid dat specifiek gericht is op het verbeteren van deze factoren kan dus potentieel zeer rendabel zijn. 



\section{Biography}

Iryna Rud was born in Kyiv, Ukraine, on October $24^{\text {th }}, 1985$. She obtained a BA degree in Sociology in 2007 (cum laude) and a Specialist's degree in Social Work in 2008 from the Faculty of Sociology at the National Technical University of Ukraine 'Kyiv Polytechnic Institute', followed by a MA degree in Analyzing Europe in 2009 from the Faculty of Arts and Social Sciences, Maastricht University, the Netherlands. In her master thesis, Iryna examined the impact of student mobility on labor market outcomes. In 2008, Iryna was a research scholar of the International Visegrad Fund program at the Corvinus University of Budapest, Hungary. In November 2009, Iryna joined the Top Institute for Evidence Based Education Research at Maastricht University as a research assistant, and from May 2010 until May 2014 she worked there as a Ph.D. candidate.

Iryna presented the results of her Ph.D. work at different international

conferences, including the International Workshop on Applied Economics of Education (2012), the European Economic Association Annual Congress (2012, 2013), the Society of Labor Economists Annual Meeting (2013) and the Scottish Economics Society Annual Conference (2014). She was also invited to participate as a young economist in the Lindau Nobel Laureate Meeting on Economic Sciences (2014).

Iryna currently works as a researcher at the CPB Netherlands Bureau for Economic Policy Analysis in The Hague. Her research interests include the economics of education, migration economics and the economics of crime. 



\section{Top Institute for Evidence Based Education Research (TIER)}

The Top Institute for Evidence Based Education Research (TIER) is an inter-university institute that conducts research to develop evidence based education. The institute has three partners: the University of Amsterdam, Maastricht University and the University of Groningen and is located in Amsterdam, Maastricht and Groningen.

TIER contributes to the improvement of the quality of education in the Netherlands by promoting an evidence based approach as a guiding principle in education policy and practice. It accomplishes this by developing (cost) effective education interventions that are grounded in sound scientific research. TIER research is funded by the Ministry of Education, Culture and Science and the participating universities through the NWO and complies with the quality standards and evaluation procedures used by NWO.

The following books recently appeared in the TIER Research Series:

I. C. Haelermans (2012), On the productivity and efficiency of education. The role of innovations in Dutch secondary education

II. L. van Welie (2013), They Will Get There! Studies on Educational Performance of Immigrant Youth in the Netherlands

III. S. Cabus (2013), An Economic Perspective on School Dropout Prevention using Microeconometric Techniques

IV. I. Cornelisz (2013), School Choice, Competition and Achievement: Dutch Compulsory Education

V. M. Heers (2014), The Effectiveness of Community School: Evidence from the Netherlands

VI. N. Ruijs (2014) Empirical Studies in the Economics of education

VII. D. Bartelet (2015), Basic Mathematics Skills Development in Children: An Evaluative Study on Cognitive and educational factors

VIII. I. Rud (2015), The Relationship between Youth Crime and Education 
